\title{
16 Schauplätze von „Glück“? Emotionspolitische Mobilisierung in Zürich und Berlin, 1933-1945
}

Wenn Glückswissen gesellschaftlichen Normen unterworfen und „gleichgeschaltet" wird, ist dies Ausdruck eines repressiven Machtmissbrauchs der Staatsgewalt, wie sie im Nationalsozialismus im Rahmen der NS-Arbeitspolitik „Kraft durch Freude“ praktiziert wurde. Die Ziele, nach denen ein Mensch seine Lebensführung ausrichtet, beeinflussen sein Glückswissen. In einem totalitären Regime sieht sich der Staat dazu befähigt, Glückswissen zur emotionspolitischen Selbstdarstellung und massenpsychologischen Mobilisierung $\mathrm{zu}$ instrumentalisieren.

In der Machtpolitik von „Idola Theatri““, einer wissenschaftlich gestützten Instrumentalisierungsstrategie zur Mobilisierung der Bevölkerung, sieht die vorliegende Untersuchung ein zentrales Merkmal einer Politik der ,Glückskulturen‘.

\section{1 „Idola Theatri“ - Oder: Von den Schauplätzen eines propagierten „Glücks“}

Dem englischen Wissenschaftsphilosophen, Juristen und Politiker Francis Bacon (1561-1626) zufolge seien „Idola Theatri“ aus „Fabeln“ der wissenschaftlichen Theorien („ex fabulis theoriarum“), ihren „,verkehrten Gesetzen der Beweisführung dem Verstand beigebracht und von ihm aufgenommen“ worden: ${ }^{2}$

„Es gibt [...] Idole [„Idola“], welche in den Geist der Menschen aus den verschiedenen dogmatischen Behauptungen philosophischer Lehrmeinungen wie auch aus den verkehrten Gesetzen der Beweisführungen eingedrungen sind; diese nenne ich die Idole des Theaters; denn so viele Philosophien angenommen oder erfunden worden sind, so viele Fabeln sind

1 „Idola Theatri, sive theoriarum, multa sunt, et multo plura esse possunt, et aliquando fortasse erunt; Die Idole des Theaters oder der Theorien sind zahlreich: sie können noch weit zahlreicher sein, sie werden es vielleicht auch einmal werden." Vgl. Bacon 1990, N.O.I. Aph. 61, 127.

2 „At Idola Theatri innata non sunt, nec occulto insinuata in intellectum; sed ex fabulis theoriarum et perversis legibus demonstrationum plane indita et recepta.; Die Idole des Theaters sind nicht angeboren, noch haben sie sich heimlich in den Geist eingeschlichen; sondern sie sind offensichtlich aus den Fabeln der Theorien und den verkehrten Gesetzen der Beweisführungen dem Verstand beigebracht und von ihm angenommen worden.“ Bacon 1990, N.O.I. Aph. 61, 125.

ว OpenAccess. () 2021 Isabelle Haffter, publiziert von De Gruyter. (cc) BY-NC-ND Dieses Werk ist lizenziert unter einer Creative Commons Namensnennung - Nicht kommerziell - Keine Bearbeitung 4.0 International Lizenz. https://doi.org/10.1515/9783110661439-016 
nach meiner Auffassung damit geschaffen und für wahr unterstellt worden, welche die Welt als unwirklich und erdichtet haben erscheinen lassen.“3

Mit seiner scharfen und zuweilen polemischen Kritik an den Wissenschaften glaubt Bacon, „die Welt als unwirklich und erdichtet [...]“ entlarvt zu haben. Bacon behauptet, dass die aus den Wissenschaftstheorien entwickelten „Fabeln“4 und die aus fiktiven Narrationen für die Schaubühne entwickelten Dramen („narrationes fictae ad scenam“) eine wissenshistorische Gemeinsamkeit besäßen: Beide übten eine massenpsychologische Wirkungsmacht auf ihr Publikum aus:

„Diese Dichtungen des Theaters haben mit den für die Bühne gestalteten Dichtungen gemein [Theatari fabulae etiam illud quod in theatro poetarum usu venit], daß Theaterstücke [narrationes fictae ad scenam] gegenüber den wahren Erzählungen der Geschichte [narrationibus ex historia veris] beliebter, gefälliger und ganz nach dem Geschmack des Publikums sind [concinniores sint et elegantiores, et quales quis magis vellet].“5

Sowohl die Wirkung zahlreicher wissenschaftlicher Vorstellungen (von Bacon als Trugbilder entlarvt) als auch die fiktiven Narrationen, welche für die Schaubühne verfasst wurden („narrationes fictae ad scenam“), seien „gefälliger“ und beim Publikum „beliebter“ als die „wahren Erzählungen der Geschichte“.

Was haben „Idola Theatri“ und die Analyse einer Politik der ,Glückskulturen“ gemein? Eine Politik der ,Glückskulturen` kann als eine auf unterschiedlichen Narrationen von wissenschaftlichen Theorien basierende Wissenspolitik begriffen werden. In einer wechselseitigen Wissenszirkulation kann eine Politik der ,Glückskulturen' ambivalent als wissenschaftlich begründete, moralisierende Lebensführung und/oder als politische Ideologie propagiert werden. Die Politik der ,Glückskulturen' basiert grundsätzlich auf einem arbeits- und massenpsychologischen Glückswissen.

Ein Beispiel: Theaterwissenschaftler wie Kindermann waren mit Blick auf die Schaubühne der Ansicht, dass sich in der theaterästhetischen Erfahrung ein einzigartiges Wirkungspotential eines gemeinschaftsstiftenden Theatererlebnisses entfalten könne, welches sich emotionspolitisch instrumentalisieren ließe. Der Theaterwissenschaftler bezeichnet die „gemeinschaftsbildende Kraft des Thea-

3 Bacon 1990, N.O.I. Aph. 44, 105.

4 In der deutschen Übersetzung wird das lateinische Wort „fabula“ als „Fabel“ übersetzt. Bedeutung nach Duden: „1. Lehrhafte, oft satirische Erzählung in Vers oder Prosa, in der Tiere nach menschlichen Verhaltensweisen handeln und in der eine allgemein anerkannte Wahrheit, eine praktische Lebensweisheit o. Ä. veranschaulicht wird, 2. erfundene, fantastische Geschichte, 3. einer Dichtung zugrunde liegende Handlung in ihren wesentlichen Zügen." vgl. Art. Fabel 2017. 5 Bacon 1990, N.O.I. Aph. 62, 129. 
ters“ in Form einer theaterästhetischen „Augenblickswirkung“ als das Alleinstellungsmerkmal unter den Künsten:

\begin{abstract}
„Keine andere Kunst kann sich ja, in solcher weithin nachhallenden Augenblickswirkung, mit der gemeinschaftsbildenden Kraft des Theaters messen. [...] Jedes Zuschauer-Ich, wie immer es aussehe, tritt in dieser festlichen Stunde des theatralischen Erlebnisses in den gemeinsamen Kreis und läßt die gleiche Verzauberung an sich geschehen, ja wirkt unwillkürlich selbst an ihr mit. Da prasselt es Beifall der Zustimmung nieder oder tiefe Ergriffenheit läßt ein heiliges Schweigen den Raum durchwallen [...]. Die Art der Verwandlung, ja Verzauberung aber hängt aufs innigste [...] zusammen nicht nur mit dem, was der Dichter zu sagen hatte, sondern auch wie die Theaterleute es in ihrem, einander ergänzenden, Gemeinschaftswerk darboten. So kommt es, daß das Theater auch die verschiedenartigsten Geister für das gleiche Ideal zu entflammen vermag. Das aber ist nicht zuletzt auch die Ursache dafür, daß das Theater im politischen und geschichtlichen Wachstumsprozeß der Nation zuzeiten eine erhebliche Rolle spielte und heute erfreulicherweise wieder spielt. Gemeinsam mit der Dichtung und den übrigen Künsten gehört ja gerade das volksbewußt geführte Theater zu den in vorderster Linie der Kulturpolitik mitkämpfenden Kräften im ständigen Ringen um die Bewahrung der rassischen und völkischen Art.“6
\end{abstract}

Dieses massenpsychologische Glückswissen der Theaterwissenschaft wussten die NS-Theaterpropagandisten für ihre Zwecke zu instrumentalisieren. Zur Erinnerung:

„Die Kunst ist eine Leidenschaft, die den ganzen Menschen erfordert und ausfüllt. Wer einmal von ihr ergriffen ist, kommt nicht mehr los davon. Es gibt kein größeres Glück unter den Menschen, als ihr dienen zu dürfen. Und ein Staatsmann kann sich nichts Höheres zur Ehre anrechnen, als ihr die Wege bereiten zu helfen. “"7

Eine Politik der ,Glückskulturen` ist kein singulär auftretendes Phänomen, das sich ausschließlich im Untersuchungszeitraum 1933 bis 1945 nachweisen ließe. Eine Wissensgeschichte über eine affirmative Gefühlspolitik, ein emotionspolitisches Zusammenspiel aus der machtvollen Trias von „Glück“, Wissen und Politik reicht bis in die Antike zurück. Nicht erst Goebbels, sondern bereits die griechischen Philosophen (wie gesehen in Aristoteles' philosophischem Werk „Politik“) bezogen in ihre Überlegungen über „Glück“ und Gesellschaft sowohl die volkserzieherischen Aufgaben der griechischen Polis als auch das massenpsychologische Machtinstrument der Gefühle mit ein.

6 Kindermann 1943a, $9 f$.

7 Goebbels 1991a, 219.

8 Kap. 7. 


\section{2 „Wissen ist Macht!“ Glückswissen auf der Schaubühne}

„Wissen ist Macht!“ Dieser vielzitierte Ausspruch geht auf Bacon zurück, der in den „Religious mediations“ (1598) den Gedanken „Knowledge is power“ postulierte. ${ }^{9}$ Die Entstehungszusammenhänge von Wissen beschrieb Bacon in Abhängigkeit zur empirischen Methodik der Wissenschaften als eine „Generalisierung von in Beobachtung und Experiment gesammelten Tatsachen.“10

„Macht ist Wissen - Wissen ist Macht“, so lautet 1872 die wissenshistorische Prämisse von Wilhelm Liebknecht (1826-1900), dem Mitbegründer der „Sozialdemokratischen Partei Deutschlands“ und Vater von Karl Liebknecht (1871-1919). In seiner „Festrede“ im Rahmen der Gründungsfeier des „Dresdener BildungsVereins“ bezog sich Liebknecht auf Bacons Wissenskritik. Im Vorwort zur Ausgabe „Wissen ist Macht - Macht ist Wissen“ von 1888 forderte Liebknecht das „arbeitende[...] Volk[...]“11 dazu auf, sich wissenschaftliches, „politische[s]“12 und „soziale[s] Wissen“13 anzueignen. Auf diese Weise sollten ,,jene falschen Staatsmänner“14 und jene Wissenschaftler*innen, die als „,Wissende[...]“ im Dienste der Gewalthaber“15 aufträten, davon abgehalten werden, weiterhin wie „Scharlatane“ „Lüge“ und „Dummheit“ zu verbreiteten. ${ }^{16}$ „Das Volk soll nichts wissen, weil es sonst nicht länger regierbar ist." ${ }^{17}$ Dieser macht- und erziehungspolitischen Doktrin, welche „die Verdummung und Verrohung der Massen“ herbeiführe, widersetzte sich Liebknecht vehement. ${ }^{18}$

Bacons Kritik an der vermeintlichen Objektivität der Wissenschaften lagen ähnliche Überlegungen zugrunde. Er entwarf eine Typologie von vier „Trugbildern“ („Idola“), welche die Erkenntnismöglichkeit über die Welt einschränken würden. ${ }^{19}$ Unter der Prämisse, die Welt sei eine Schaubühne geworden, verstand

9 Vgl. Henry 2002.

10 Vgl. Müller-Wille, Reinhardt und Sommer 2017, 4.

11 Liebknecht 1904, 10.

12 Ebd., 8.

13 Ebd., 8.

14 Ebd., 9.

15 Ebd., 8.

16 Vgl. ebd., 8.

17 Ebd., 9.

18 Vgl. ebd.

19 „Idola Specus“ (,Höhlen-Trugbilder'), „Idola Theatri“ (,Trugbilder des Theaters'), „Idola Fori“ (,Trugbilder des Marktplatzes`) und „Idola Tribus“ (,Trugbilder der Gattung'). Mehr zur IdolenLehre vgl. Kritik der Erkenntnisinstrumente. In: Krohn 2006, 100 - 115. Zur „Idola Theatri“ gemäß Stanford Encyclopedia of Philosophy: „According to the insight that the world is a stage, the Idols of the Theatre are prejudices stemming from received or traditional philosophical systems. These 
Bacon jene Idola, die aus der wissenshistorischen Kontinuität philosophischer Denksysteme entstanden seien und die Welt in eine Schaubühne verwandelt hätten. ${ }^{20}$ Zahlreiche, bislang nicht hinterfragte Lehrsätze würden das Verständnis über Mensch und Natur trüben. ${ }^{21}$ Auf welche Weise? Die tradierten Denkmuster hätten insofern etwas mit Theateraufführungen gemein, als sie auf der fiktionalen Erzählungslogik ihrer Verfasser`innen basierten. Ihre Erzählungen würden dem Geschmack des Publikums entsprechen und müssten zur Verifizierung zuerst einer wissenschaftlichen Überprüfung unterzogen werden. Folglich ist Bacon der Ansicht, dass man sich vom „scholastischen Buchwissen in Bibliotheken“ emanzipieren und „die Welt zu durchwandern und die Dinge selbst zu untersuchen" habe. ${ }^{22}$

Der Anlass für Liebknechts Wissenskritik war wiederum die trügerische Gefühlspolitik des Preußischen Staates ein Jahr nach dem Deutsch-Französischen Krieg: Dieser sähe in den „Arbeitern“ lediglich Soldaten, die sich im Krieg opfern sollten und dabei allein mit affirmativen „Hurrah-Kanaillen die Gegner der Volkfeinde niederbrüllen dürften “. ${ }^{23}$ In diesem Zusammenhang rief Liebknecht „zur Rettung unserer Kultur“ auf, indem er seinen Kritikerinnen folgende Argumente entgegenbrachte:

\begin{abstract}
„Aber, höre ich fragen: ist es denn auch wahr, daß ,Wissen Macht“ ist? Und wenn es wahr ist, sind wir dann nicht verloren in unserem Kampf gegen die Gewalthaber? Sind nicht die Wissenden auf ihrer Seite? Haben sie nicht die Wissenschaft wie die Kunst gekauft und in ihre Dienste gestellt? Und wie können wir hoffen, der Summe der Macht, die in diesem Wissen steckt, eine überlegene Macht gegenüberzustellen und so den Sieg zu erringen?

Nicht kleinlaut! Nicht so niedrig gedacht von der Wissenschaft und ihrer schönen Schwester, der Kunst! Kunst und Wissenschaft lassen sich nicht kaufen - [...] eine Kunst und eine Wissenschaft, die sich kaufen lassen, sind keine Kunst und keine Wissenschaft. Die ,Wissenden' im Dienste der Gewalthaber, sie haben auf Wissenschaft ebensowenig Anspruch, wie eine Dirne auf Tugend. “24
\end{abstract}

Liebknechts Polemik über das unmoralische Handeln jener Künstler^innen und Wissenschaftler^innen, die sich in seinen Augen wie „Prostituierte[...] des Geis-

systems resemble plays in so far as they render fictional worlds, which were never exposed to an experimental check or to a test by experience. The idols of the theatre thus have their origin in dogmatic philosophy or in wrong laws of demonstration." Vgl. Klein 2016.

20 Vgl. Bacon 1990, N.O.I Aph. 44, 105.

21 Vgl. Krohn 2006.

22 Vgl. Köchy 2017, 258.

23 Vgl. Liebknecht 1904, 9.

24 Ebd., $7 \mathrm{f}$. 
tes“25 in den „Dienst der Gewalthaber“ stellten und sich dafür bezahlen ließen, mag übertrieben klingen. Mit Blick auf die totalitäre Gefühlspolitik des NS-Regimes eröffnen Liebknechts Forderungen nach einer Demokratisierung von Wissen im Bereich der Politik, Wissenschaft und der Künste eine wissenspolitische Dimension. Liebknecht schließt sein Vorwort mit den Worten:

„Dieses Wissen dringt in immer weitere Kreise, und mit jedem Vordingen des Wissens wächst unsere Macht. Nicht in der Faust - im Hirn liegt die welterobernde Kraft. Die Faust ohne Hirn kann nur blind zerstören. [...] Am Tage, da das Wissen die Massen des arbeitenden Volkes erleuchtet, beherrscht, haben wir auch die Macht, und fällt krachend das Zwingsuri [ZwingUri] der Gewalthaber.“26

Liebknechts massenpsychologischem Appell, mit „Wissen“ statt mit „Fäusten“ die „Gewalthaber“ zu Fall zu bringen, liegt seine pazifistische Überzeugung zugrunde. „[D]as Wissen des arbeitenden Volkes“ bedeute „Macht“ und „welterobernde Kraft“. Wie einst die innerschweizerischen Freiheitskämpfer^innen die sagenumwobene habsburgische Burg zum Fall gebracht hätten, sollte das ,arbeitende Volk“ symbolisch die „Zwing-Uri“, die Macht des Kaiserreiches, zum Einsturz bringen und eine Demokratie errichten.

In Schillers Drama „Wilhelm Tell“, das 1804 uraufgeführt wurde, beugte die habsburgische Herrschaft, mit Sitz in der „Zwing Uri“, die Innerschweizer^innen unter ihre autoritäre Gewaltherrschaft:

„Zweiter Gesell:

Fronvogt, wie wird die Veste denn sich nennen,

Die wir dir bau'n?

Fronvogt:

Zwing Uri soll sie heißen,

Denn unter dieses Joch wird man euch beugen.“27

Der Vergleich zwischen Liebknechts revolutionärer Forderung nach einer demokratischen Wissensmacht, welche das ,arbeitende[...] Volk“ intellektuell erleuchten, emotionspolitisch beherrschen und ihm „welterobernde[...] Kraft“ spenden sollte, steht im wissenshistorischen Kontrast zur Arbeitsmoral „Kraft durch Freude“ und der Theaterpolitik im Nationalsozialismus.

Um bei Liebknechts Metapher des Schweizer Freiheitshelden zu bleiben: Schillers „Wilhelm Tell“ gehörte bis zu dessen Aufführungsverbot $1941 \mathrm{zu}$ den

25 Ebd., 8.

26 Ebd., 10.

27 Friedrich Schiller: Wilhelm Tell, 1. Aufzug, 3. Szene, V. 369-371, Schiller 1980, 148. 
Lieblingsdramen Hitlers. ${ }^{28}$ Tell und dessen moralisches Handeln in der Auflehnung eines Unterdrückten gegen den Tyrannen ist ein Beispiel für einen ambivalenten, transnational rezipierten Heldentypus einer affirmativen Gefühlspolitik im Untersuchungszeitraum 1933-1945. Für die „geistige Landesverteidigung“ diente Tell als stereotypisierte Ikone und Vorbild eines wehrhaften Schweizer Freiheitskämpfers, der im Kriegsfall sein Land auf der Grundlage von sogenannten Schweizer Werten gegen ausländische Eindringlinge verteidigen würde. So schreibt Eberle in seinem Vorwort zum Aktualitätsbezug des von ihm herausgegebenen Urner Tell-Spiels, welches 1512 in Uri als „Volkspiel“ entstanden war:

„Schlicht und kraftvoll wie das Spiel sei die ganze Feier, in der der ,Tell ‘ als Höhepunkt erscheinen soll. Vor und nach der Aufführung singe das Volk seine alten Lieder. Und wenn am Schluß Spieler und Schauende einen Hügel hinanziehen und gemeinsam das Feuer entzünden und Schulter an Schulter stehen im Anblick der Flammen, die in den nächtlichen Himmel hinauflodern, muß da nicht jedem bewußt werden, daß wir uns zu einem festen Ring zusammengeschlossen haben, wie einst die Eidgenossen auf dem Rütli, um den Schwur in unseren Herzen zu erneuern: Daß wir keinen Tyrannen dulden - schwören wir!“²9

Der Theaterwissenschaftler Eberle ging 1942 in wissenshistorischer Kontinuität zur eidgenössischen Gründungslegende von einer mystisch überhöhten, „völkerpsychologischen“ Wirkungsmacht des Laienspiels aus. Die überzeitliche Idee eines eidgenössischen Gemeinschaftsgefühls und der daraus „organologisch“ gewachsene Verteidigungswille würden ihre „völkerpsychologische“ Wirkungsmacht im theaterästhetischen Gemeinschaftserlebnis des Laienspiels jedes Mal aufs Neue durch die emotionspolitische Partizipation der Zuschauerinnen entfalten.

In NS-Deutschland galt Tell als Inbegriff eines „arischen“ Führungstypus. Im Sinne der „rassischen“ „Blut-und-Boden“-Ideologie war er Sinnbild für einen opferbreiten Freiheitskämpfer, der seine Heimat verteidigen und sich für die vereidete „Volksgemeinschaft“ gegenüber fremden Mächten, die in antisemitischen Weltverschwörungstheorien oder in einer bolschewistischen Gefahr gesucht wurden, zur Wehr setzen würde. Ab der Spielzeit 1932/33 gehörte „Wilhelm Tell“ zu den meistaufgeführten Dramen während des NS-Regimes (1932/33: 22 Inszenierungen, 0,82\%, mit dem Höhepunkt im Schillerjahr 1934-1933/34: 29 Inszenierungen, 1,09\%, 1934/35: 28 Inszenierungen, 1,06\%). ${ }^{30}$ Den Auftakt zum

28 Vgl. Eicher 2000, 327.

29 Eberle 1942, 4.

30 Vgl. Eicher 2000, 327. 
Kult um den nationalsozialistisch gedeuteten „arischen“ Führungstypus Tell bildete Carl Ludwig Achaz' (1889-1958) Inszenierung am 5. Mai 1933 im Deutschen Theater in Berlin. Tell wurde vom Regisseur zum Retter der Nation stilisiert und die Aufführung zur „nationalen Kulthandlung“, wie der „Völkische Beobachter“ schrieb. ${ }^{31}$ In den Spielzeiten 1938/39 und 1939/40 stiegen die Aufführungszahlen im Kontext des „Anschlusses“ Österreichs nochmals an. Danach nahmen die Tell-Aufführungen sukzessive ab. Die theaterhistorische Forschung nennt mehrere Gründe. Eine plausible Begründung ist das gescheiterte Attentat des Schweizer Medizinstudenten Maurice Bavaud (1916-1941) auf Hitler. 1939 wurde Bavaud verhaftet und im Mai 1941 hingerichtet. Im selben Jahr wurde die Weisung ausgesprochen Schillers Tell als Schullektüre nicht mehr zu behandeln. ${ }^{32}$ Ein weiterer Grund könnte die forcierte Stilisierung der Tell-Figur zum Schweizer Nationalhelden im Kontext der „geistigen Landesverteidigung“ gewesen sein, wie der folgende Abschnitt zeigt.

Schillers Drama endet mit dem Schwur Bertas, „die erste Glückliche“ als „freie Schweizerin“ zu sein, die in den Bund der „Eidgenossen“ aufgenommen werde. Dieser Bund würde mit „Gut und Blut“ beschützt:

„Alle Es lebe Tell! Der Schütz und der Erretter!

Indem sich die vordersten um den Tell drängen und ihn umarmen, erscheinen noch Rudenz und Berta, jener die Landleute, diese die Hedwig umarmend. Die Musik vom Berge begleitet diese stumme Szene. Wenn sie geendigt, tritt Berta in die Mitte des Volks.

Berta Landleute! Eidgenossen! Nehmt mich auf In eurn Bund, die erste Glückliche, Die Schutz gefunden in der Freiheit Land. In eure tapfere Hand leg ich mein Recht, Wollt ihr als eure Bürgerin mich schützen?

Landsleute Das wollen wir mit Gut und Blut.

Berta Wohlan!

So reich ich diesem Jüngling meine Rechte, Die freie Schweizerin dem freien Mann!

Rudenz Und frei erklär ich alle meine Knechte.

Indem die Musik von neuem rasch einfällt, fällt der Vorhang.“33

31 Vgl. Eicher 2000, 327.

32 Vgl. ebd., 328. Zur Biografie von Maurice Bavaud vgl. Weibel 2004.

33 Friedrich Schiller: Wilhelm Tell, 5. Aufzug, Letzte Szene, V. 3281-3291, Schiller 1980, 277. 
Mit der Aufführung von Schillers „Willhelm Tell“ am Zürcher Schauspielhaus in der Spielzeit 1938/39 positionierte sich die „Pfauen-Bühne“ unter der Leitung Oskar Wälterlins nach dem jahrelangen Zürcher-Theaterstreit um die Direktionsleitung des von rechts-konservativer Seite scharf kritisierten ,Emigranten-Theaters' Ferdinand Riesers neu als eine Schweizer Nationaltheaterbühne. Bereits im Vorfeld der Premiere, am 25. Januar 1939, betonte die Schauspiel AG die theaterpolitische Bedeutung von Wälterlins Tell-Inszenierung für die „geistige Landesverteidigung“. Zu den Aufgaben des Schauspielhauses zählte Wälterlin explizit die Erfahrung eines „Gemeinschaftserlebnis[ses]“ im Sinne einer affirmativen Gefühlspolitik der „geistigen Landesverteidigung“34, der sich das gesamte Theaterensemble verpflichtet fühlte, wie der Theaterdirektor seinen Skeptiker*innen gegenüber versicherte:

„Unser Volk hat sich gesammelt, es ist aufgerufen worden durch ein Gemeinschaftserlebnis und wenn dieses auch vorläufig nur die gemeinsame Sorge um die Existenz von ideellen Gütern ist, so ist diese Sorge doch aktiv, indem sie Vorsorge wird, in dem sie zur Selbstbesinnung mahnt, zur Erkenntnis der Kräfte, Zusammengehörigkeit innewohnt, zum Entschluss, für Werte einzustehen, die heute selten geworden sind und die es gilt zu bewahren und hinüberzuretten in die Zukunft für kommende Generationen [...]. Unser Spielkörper folgt unseren Intentionen mit einer Hingabe und Arbeitsfreudigkeit, die selten ist. Wir bekennen uns zu einer Form, die die Einfachheit sucht [...], entsprechend auch dem einfachen Wesen unseres Landes und seiner Einrichtungen, entsprechend wohl auch den zurückhaltenden Tendenzen unserer politischen Staatsform. Und wo sie fremd aus anderen Ländern zu uns gekommen sind, ehren und lieben sie unsere Ziele und haben sie zu ihren eigenen gemacht. [...] Wenn wir dazu beitragen können, den Zusammenhalt zu festigen, Mut zu machen und zum Einsatz zu mahnen, dann sind wir eine Notwendigkeit geworden, die man nicht mehr missen kann. Und das ist unsere Aufgabe.“35

Wälterlin sieht einen zentralen Legitimitätsgrund der „Pfauen-Bühne“ nicht in erster Linie in ihrer Bedeutung als Kulturinstitution, sondern in arbeitspsychologischer Wissenskontinuität einer leistungsorientierten Selbstdarstellung eines kulturnationalistischen Wertesystems der Schweiz. Diese affirmative Darstellung des Zürcher Schauspielhauses, als „moralische Anstalt betrachtet“, sowie die kollektivistische Ensembleleistung ermögliche es, als erziehungspolitisches Propagandainstrument Schweizer Werte zu vermitteln. Der kulturnationalistische Aspekt der Tell-Inszenierung wurde durch die Zurschaustellung des Bühnenbilds bei der Landesausstellung 1939 in der von Oskar Eberle kuratierten Ausstellung zur Geschichte des Schweizer Theaters in der Rubrik „Staatsfestspiel“ unterstri-

34 Wälterlin 1955, 69.

35 Wälterlin 1955, 69 ff. 
chen. ${ }^{36}$ Einen wesentlichen Beitrag zum emotionspolitischen Gemeinschaftserlebnis während der Tell-Aufführung dürfte der Schweizer Schauspieler Heinrich Gretler (1897-1977) in seiner Rolle als Wilhelm Tell geleistet haben (Abb. 16). Während der Kriegs- und noch in der Nachkriegszeit galt Gretler aufgrund seines patriotisch ausgerichteten Theater- und Filmrollenrepertoires als Symbol der Schweizer „Vaterfigur im familialen Gemeinschaftsdiskurs“ der „geistigen Landesverteidigung“ “. ${ }^{37}$ Gretler wurde über die Jahre von der Schweizer Bevölkerung zur Ikone eines Schweizer Nationalhelden stilisiert.

Auf dem Theaterplakat (Abb. 16) betrachtet die Figur des Tell sein Gegenüber mit einem durchdringenden Blick aus einer erhöhten Blickposition als Zeichen seiner Wehrbereitschaft, trotz bescheidener Ausrüstung in Form einer Armbrust. In ikonografischer Kontinuität zu Richard Kesslings Altdorfer Telldenkmal von 1895 stilisiert der Fotograf Richard Schweizer Gretler zum vaterländischen Helden. Bezeichnenderweise wurden in der Wälterlin-Ära, die das Schauspielhaus in den erziehungspolitischen Dienst der „geistigen Landesverteidigung“ stellte, die übrigen Ensemblemitglieder, welche zum Teil Exilant*innen waren, auf dem Theaterplakat nicht genannt. ${ }^{38}$

Der nationalsozialistisch orientierte Theaterwissenschaftler Heinz Kindermann wiederum veranschaulicht in seiner Schrift „Volk und Nation“ exemplarisch anhand des Heldentypus der Tell-Figur, wie die wissenshistorische Kontinuität vom selbstbestimmten Akt eines „politischen Volkswillens“ im Kontext der NS-Theaterpolitik instrumentalisiert wurde:

„Wir brauchen uns auch nur in Erinnerung zu rufen, dass im Saargebiet in den Wochen knapp vor der Saarabstimmung Abend für Abend Schillers „Wilhelm Tell“ gespielt wurde und dass bei der Rütli-Szene jeden Abend wieder sich das gesamte Publikum erhob und - als machtvolles Bekenntnis der Treue zum angestammten Reich - den Schwur: ,Wir wollen sein ein einig Volk von Brüdern` im Chor mitsprach. Wir wissen heute, wie hier die Stimme des Volkstheaters und die des politischen Volkswillens selbst in einem Akkord verschmolzen.“"39

Der Akt eines „politischen Volkswillens“, symbolisiert im Bündnisschwur angeblich Gleichgesinnter, sollte auf der „gleichgeschalteten“ Theaterbühne der nationalsozialistischen Gefühlspolitik zur Selbstdarstellung, Emotionalisierung und Mobilisierung dienen.

36 Vgl. Amrein 2004, 514f. Mehr zur Landesausstellung s. Kap. 16.6.

37 Vgl. ebd., 281.

38 Mehr zur Zürcher Inszenierung vgl. Amrein 2004, 514-521. Mehr zu „Tell“-Inszenierungen und der Schweiz vgl. u.a. Utz 1984, Blatter und Groebner 2016.

39 Kindermann 1943a, $56 \mathrm{f}$. 


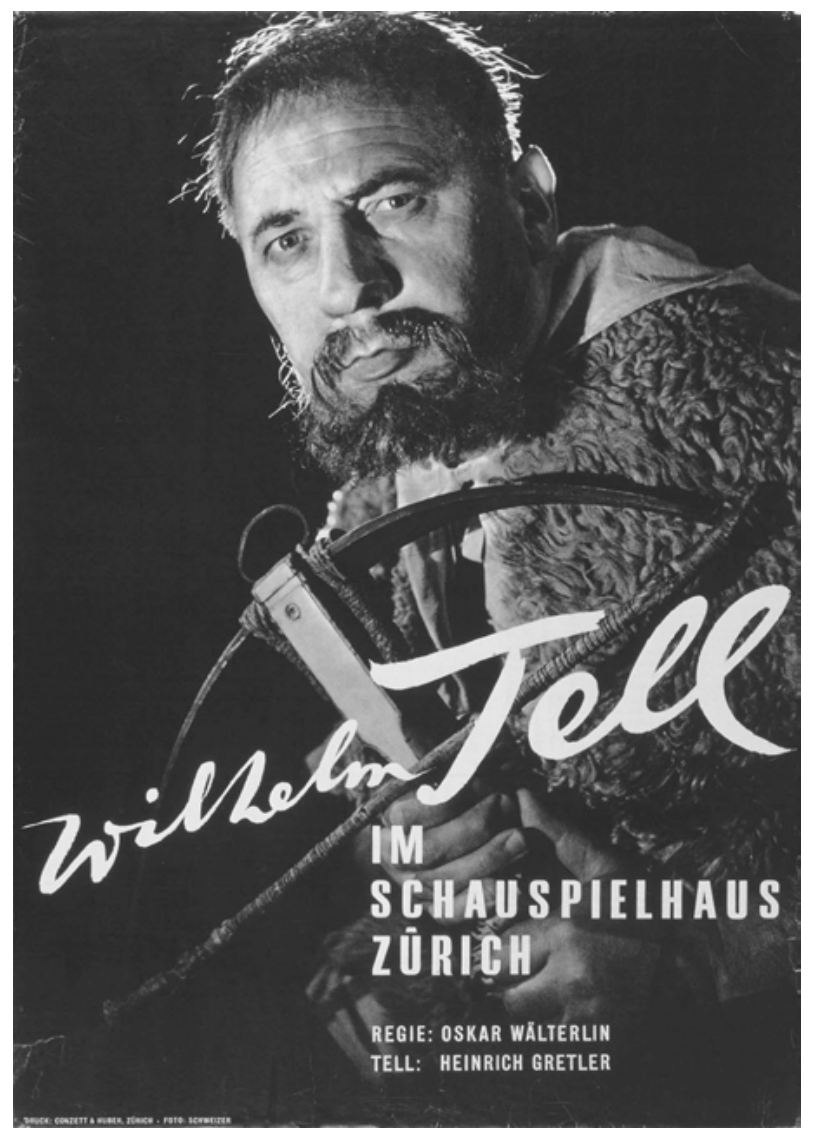

Abb. 16: [Gretler als Tell: Eine Ikone der „geistigen Landesverteidigung“], „Willhelm Tell im Schauspielhaus Zürich“ von Friedrich Schiller, Regie: Oskar Eberle, [Plakat], Schauspielhaus Zürich, 1939

Sowohl die Nationalsozialisten als auch Vertreter der „geistigen Landesverteidigung “ entwarfen, wohl zum Entsetzen Bacons und Liebknechts, ihre eigenen „Idola Theatri“, gemäß ihrer Auffassung einer emotionspolitischen Theaterdramatik. Unter dem Deckmantel eines politischen Volkswillens konnten sich die Wissenschaft, die Politik und die Künste wechselseitig auf bereits bestehende „Idola Theatri“ ausrichten und diese kontextspezifisch umdeuten. Dabei griffen Theaterwissenschaftler und Theaterpraktiker, wie bei Kindermann, Eberle und Wälterlin gesehen, in wissenshistorischer Kontinuität auf Glückswissen der Massenpsychologie und Arbeitspsychologie zurück, wie sie bereits Hendrik de Man in seiner empirischen Studie über den „Kampf um die Arbeitsfreude“ ver- 
treten hatte. ${ }^{40}$ Welche „Idola Theatri“ de Man auf der Grundlage seines arbeitspsychologischen Glückswissens in seiner dreifachen Funktion als Wissenschaftler, Dramatiker und Sozialist entworfen hatte, soll das folgende Beispiel aus Zürich zeigen.

\section{3 „Wir! Ein sozialistisches Festspiel“: Arbeitspsychologisches Glückswissen in Hendrik de Mans Massenspiel an der 1. Maifeier in Zürich 1933}

„Der Kampf um die Arbeitsfreude““41 beschäftigte Hendrik de Man nicht nur als Arbeitspsychologen, sondern auch als Dramatiker des Massenspiels „Wir! Ein sozialistisches Festspiel“. ${ }^{42}$ Das Festspiel hatte zur 1. Maifeier 1932 in der Frankfurter Festhalle vor 18.000 Zuschauer*innen Uraufführung gefeiert. ${ }^{43}$ In der Schweiz wurde es 1933 im transnationalen Kontext der sozialistischen 1. Maifeier und der als Bedrohung wahrgenommenen Errichtung der NS-Diktatur veranstaltet. ${ }^{44}$ In Zürich selbst fand das sozialistische Massenspiel vor dem Hintergrund des lokalen Gemeinderatswahlkampfs statt. ${ }^{45}$ Das Zürcher Festspiel wurde 1933 an sechs Aufführungen von rund 10.000 Zuschauer`innen gesehen. ${ }^{46}$

40 Vgl. Hitler 2016a, 220, Fußnote 203.

41 Vgl. Man 1927.

42 Zur Produktion: Wir. Ein Sozialistisches Festspiel, Text: Hendrik de Man, Musik: Ottmar Gerster, Regie: Otto Zimmermann, Besetzung: 2 Flügelhörner in B, 4 Trompeten, 4 Hörner, 3 Posaunen, 2 Tuben in C, 2 Schlagzeuge (Pauke, Trommel, Timbale), Gemischter Chor, Männerchor, Frauenchor, Sprech- und Bewegungschöre mit Solosprechern, UA: 01.05.1932, Festhalle, Frankfurt a Main. Vgl. Man 1932a (Premieren-Programmheft). Zürcher Aufführung: 3 Aufführungen zur 1. Maifeier in Zürich, 23.04., 29.04. und 01.05.1933, Limmathaus Zürich, Arbeitersängerkartell Zürich (Veranstalter). Vgl. Man 1933a (Zürcher Programmheft).

43 Zum Festspiel vgl. Eichberg 1977, 91 f., 99, 100, 102, 104, Mennen 2013, $132 \mathrm{f}$.

44 De Man verfasste mehrere antifaschistische Schriften u.a. „Sozialismus und Nationalsocialismus“ (1931) und „Masse und Führer“ (1932) über die affirmative, massenpsychologische Gefühlspolitik der NSDAP im Gegensatz zu den sozialdemokratischen Parteien Europas sowie einen „Plan d'action“ (1933), einen antifaschistischen Aktionsplan. Vgl. Man 1931, Man 1932b, Man $1933 \mathrm{~b}$.

45 Vgl. Amstutz, Käser-Leisibach und Stern 2000, 218.

46 Laut Programmheft waren es drei Aufführungen, die Forschungsliteratur erwähnt 6 Aufführungen. Vgl. Amstutz, Käser-Leisibach und Stern 2000, 218. Dem der Untersuchung vorliegenden Programmheft zufolge fanden drei Aufführungen am 23.04., 29.04., 01.05.1933 um jeweils $20 \mathrm{Uhr}$ im Limmathaus in Zürich statt. Vgl. Man 1933a, 3. Zur Zürcher Aufführung liegen im SSA die gedruckte und handschriftl. Partitur und Notenblätter, das Programmheft und das Regiebuch vor, Mappe 1-3, Ar 58.31.15, SSA. Zum Programmheft vgl. Man 1933a. 
Im Folgenden werden die Dramatik des Festspiels, die Regieüberlegungen und die Aufführung anhand folgender Forschungsfragen historisch analysiert:

1. Was war die Handlung des Festspiels und wie wurde sie in der Inszenierung von Regisseur Otto Zimmermann umgesetzt?

2. Inwieweit ließ der Dramatiker arbeitspsychologisches Glückswissen aus seiner Forschung in das Festspiel einfließen?

Anstelle einer dramatischen Handlung entschied sich de Man für eine „Darstellung von gegenwärtigen, zum Erlebniskreis aller Proletarier und aller Menschen gehörigen Gefühlsspannungen. “47 Aufgrund dieser emotionspolitischen Theaterästhetik verleiht „der große sprechchor [...] den empfindungen des proletariats ausdruck“, wie der Regisseur Otto Zimmermann (1894-1956) ${ }^{48}$ seine Inszenierung erklärt. ${ }^{49}$ „Das Proletariat“ wird während der ganzen Aufführung durch den großen Sprechchor dargestellt. ${ }^{50}$ Sprech-, Bewegungs-, und Gesangschöre, die von einem Orchester begleitet werden, stellen den emotionspolitischen Vorgang auf einer pyramidenförmigen Bühne in vier Teilen dar: 1. „Welt der Entsagung“, 2. „Die Geißeln“, 3. „Der Weckruf“, 4. „Versuchung und Erlösung““.51

Die Aufführung wird durch ein Orchester-Vorspiel und einen vierstimmigen, gemischten Chor eröffnet, welcher die sozialistische Forderung nach einer affirmativen Gefühlspolitik aus der anthropologischen Prämisse „allgemeinmenschliche[...] Bedürfnis[se] des natürlichen Lebensdranges und Glücksstrebens“ “52 herleitet:
„Von allem Anfang an
Ruft Natur den Menschen zur Freude.
Ihr Reichtum ernährt ihn.
Sein Blut ist Saft ihrer Wurzeln
Und gebietet ihm Streben nach Glück,
vom gestillten Hunger des Leibes
zum höchsten Fluge der Seele!“53

$\mathrm{Zu}$ Beginn der Aufführung steht der große Sprechchor an der untersten Schwelle einer Stufenpyramide. Im Handlungsverlauf wird das Proletariat als Symbol für

47 De Mans „Vorbemerkung“ im Premieren-Programmheft, vgl. Man 1932a, 5.

48 Zur Biografie vgl. Wüthrich 2005.

49 Vgl. Zimmermann 1933a, 6. [Die typografische Kleinschreibung ist dem Original entnommen.].

50 De Man, „Regiebemerkungen“, vgl. Man 1932a, 9 ff., 9.

51 Zürcher Festspieltext, vgl. Man 1933a, 1-19.

52 De Man, „Vorbemerkung“, vgl. Man 1932a, 3.

53 Zürcher Festspieltext als Beilage des Zürcher Programns, Man 1933a, 1. 


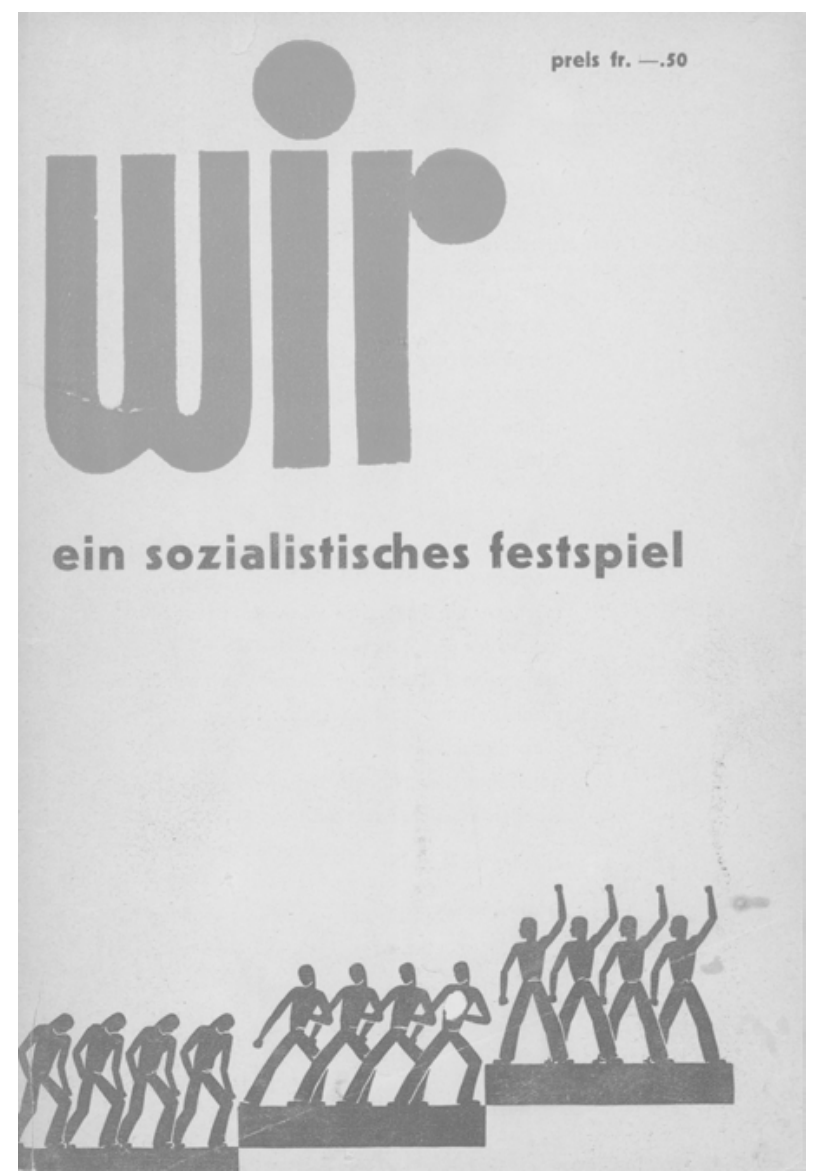

Abb. 17: „Wir! Ein sozialistisches Festspiel“ von Hendrik de Man, Musik: Ottmar Gerster und Hanns Eisler, Regie: Otto Zimmermann, [Zürcher Programmheft], Limmathaus, Zürich, 1933

den teleologischen Verwirklichungsprozess des Sozialismus diese Pyramide etappenweise erklimmen. Im Festspielplakat (Abb. 17) wird dieser herbeigesehnte Aufstiegsprozess „des Proletariats“, die symbolische Wandlung vom ,Knecht“ zum ,Sieger“ der „sozialistischen Revolution“, ikonografisch mit einer gesteigerten affirmativen Emotionspolitik in Verbindung gebracht, die sich in der final emporgestreckten Faust als Siegeszeichen symbolisiert.

Auf der obersten Stufe der Pyramide warten jedoch die emotionspolitisch destruktiven „Stimmen“, welche „das Proletariat“ vom Erklimmen des Gipfels bzw. von der Verwirklichung des Sozialismus abhalten möchten. Die Gesangschöre wie auch Teile des Orchesters nehmen nicht an der Handlung teil, sondern 
stehen betrachtend daneben. Auf beiden Seiten der Festspielhalle sind die Gruppen der Sprech- und Bewegungschöre aufgestellt, die im letzten Teil in den „großen Sprechchor“ einstimmen und gemeinsam zum Podium schreiten werden. Der Theaterraum ist bis zum vierten Teil der Handlung im Dunkeln. Nur einzelne Scheinwerfer konzentrieren sich auf die Handlungsabläufe der Chöre. Im vierten Teil erhellt sich der gesamte Theaterraum ,plötzlich stark“54 als Symbol der autosuggestiven, leistungsorientierten und selbstdisziplinarischen Erlösung des Proletariats. Diese im Kollektiv herbeigeführte Erlösung als emotionspolitscher Ausdruck des Gemeinschaftsgefühls im Sozialismus verleiht dem Festspiel seinen „kultischen“ bzw. gemeinschaftsstiftenden Charakter einer affirmativen Gefühlspolitik, wie de Man erklärt ${ }^{55}$ :

„Kultisch bedeutet viel mehr als kirchlich. Kultisch ist jeder gemeinsame Ausdruck eines religiösen Gefühls, und religiös ist jedes Gefühl, das Menschen miteinander verbindet im Bekenntnis eines Glaubens an überpersönliche Werte und Ziele, in der Bereitschaft zum Opfer für ihre Verwirklichung, in der Hingabe an eine allen Menschen aufgetragene Bestimmung, in der Ergriffenheit durch etwas, das höher steht als sie und zu dem sie sich emporheben wollen. “56

Der Regisseur Otto Zimmermann verfolgte mit seiner symbolhaften Theaterästhetik und seiner zurückgenommen Regie eine „schlichte“ Form, die mit einem „Mindestmaß an theatralischen Mitteln“ arbeite. ${ }^{57}$ Ziel der theaterästhetischen Wirkungsmacht sei es, den Zuschauer`innen das „eigene Erleben vor Augen zu führen“, schreibt Zimmermann im Zürcher Programmheft:

„Lichtregie, Ausstattung, Kostümierung, Bewegungsregie und Mimik sollen möglichst schlicht sein und mit einem Mindestmaß an theateralischen Mitteln arbeiten. Der Sinn des Spieles ist, den Zuschauern eigenes Erleben vor Augen zu führen, die Regie soll daher alle Effekte vermeiden, die über die sinnbildliche Verdeutlichung des Handlungssinnes hinausgehen oder die Aufmerksamkeit auf äußere Vorgänge lenken.“58

Die folgende theaterhistorische Analyse bezieht sich auf die drei Aufführungen im Limmathaus in Zürich 1933. ${ }^{59}$ Im Vergleich zur Uraufführung in Frankfurt 1932

54 De Man, „Regiebemerkungen“, Man 1932a, 9.

55 De Mans „Vorbemerkung“, vgl. Man 1932a, 3.

56 Ebd.

57 De Man, „Regiebemerkungen“, vgl. Man 1932a, $9 f$.

58 Ebd.

59 Zur Produktion: „Wir. Ein sozialistisches Festspiel“ Text: Hendrik de Man, Regie: Otto Zimmermann, Musik: Ottmar Gerster und Hanns Eisler, Musikalische Leitung: Rudolf Wipf und Carl Danioth. Mitwirkende bei den Eislerchören: „Männerchor der Eisenbahner“, „Freiheit“, des ge- 
weist die Zürcher Aufführung von 1933 Kürzungen auf. So wurden die vier Handlungsteile zu drei zusammengefasst. Dieses Verfahren war vom Dramatiker beabsichtigt worden. De Man schlägt in seinen „Regiebemerkungen“ Anpassungen vor, damit das Festspiel auch auf kleineren Bühnen mit weniger Darsteller*innen realisiert werden könne. ${ }^{60}$

Im ersten Teil mit dem Titel „die welt der entsagung“ fordert die „gemeinschaft junger menschen“ das in der „welt der entsagung“ lebende „Proletariat“ in vier sogenannten „intermezzi“ dazu auf, affirmative „Lebensführungen“ auszuleben: „naturfreude“, „spielfreude“, „erkenntisfreude“ und „anbetungsfreude“. Doch der „proletarische sprechchor“ erklärt den jungen Menschen jedes Mal aufs Neue, warum sie keine „glückliche“ Lebensführung bestritten und folglich deren Gefühlsaudruck nicht affirmativ ausleben könnten:

„Intermezzo 2 (Spielfreude). Mit Orchesterbegleitung.

Chor:

Im Takt pocht unser Blut, im Takt tanzt Freude darin.

Komm, Mensch, genieße mit uns die Freude, das Spiel!

Großer Sprechchor:

Wir können uns nicht freuen! Wir müssen schuften ums Brot.

Intermezzo 3 (Schaffensfreude). Mit Orchesterbegleitung.

Chor:

Höher als Freude am Spiel steht Freude am

Schaffen.

Wie wachsende Frucht und werdendes Stück

Erfüllt seinen Sinn das vollendete Werk.

Komm! Schaffe, kämpfe, siege mit uns!

mischten Chores „Freundschaft“, der Straßenbahner, der Typographie, Arbeitermännerchor Wiedikon. Bei dem Festspiel: Sängerbund Zürich, Männer- und Damenchor „Vorwärts“, Gemischter Chor „Freundschaft“, Männer- und Damenchor „Sängerbund Neumünster“, Arbeitermänner- und Frauenchor Höngg, Sängerbund Adliswil, gemischter Chor Affoltern bei Zürich, Arbeitersängerinnenverein Örlikon, Arbeitermusik Zürich, Satussektionen Zürich, Sozialistische Arbeiterjugend Zürich, Tanzgruppe „der Schaffenden“. Vgl. Man 1933a, 2f.

60 „Das Werk kann in kleineren Räumen mit bescheideneren Mitteln ohne Musik, als reines Sprech- und Bewegungschorwerk aufgeführt werden [...] sogar die Pyramide kann ganz weggelassen werden, indem die Aufwärtsbewegung im vierten Teil durch eine Vorwärtsbewegung ersetzt wird.“ De Man, „Regiebemerkungen“, Man 1932a, 10. 
Großer Sprechchor:

Unsre Arbeit ist Müssen, nicht Wollen.

Fremdes Hirn denkt sie, fremder Wille lenkt sie, fremde Macht befiehlt sie, fremder Reichtum besitzt sie. Unsre Arbeit ist Fron, nicht Freude. [...]“61

Die stereotypisierte „proletarische Masse“ schildert ihre Existenz als unglückliche, menschgewordene Maschine (Intermezzo 6), die schließlich in Arbeitslosigkeit und Hunger (Intermezzo 7) die „laster der unterdrückten“ (Intermezzo 8) auslebt. Die Gegensätze zwischen affirmativen und destruktiven Gefühlen, zwischen Natur und Stadt, der „Schaffensfreude“ und der „Fronarbeit“ veranschaulichen kurze Filmausschnitte auf einer Projektionswand, die oberhalb der Pyramide angebracht wurde. Film- und Orchesterintermezzi sind Teil der theaterästhetischen Wirkungsästhetik, die sich in den jeweiligen suggestiv-emotionspolitischen Handlungsabschnitten entfaltet, und lösen die Chorhandlung ab. ${ }^{62}$

Am emotionalen Tiefpunkt angelangt, tritt der dramaturgische Wendepunkt ein. ${ }^{63}$ „Der Weckruf“ im zweiten Teil beschreibt den „Ruf des Sozialismus“: „Der Weckruf“ lässt die „Masse“ in zwei Lager teilen: in den „Chor der Vorkämpfer“ als ein stereotypisiertes erfolgs- und leistungsorientiertes Führungskollektiv und in den „Chor der Entmutigten“, die „Zweifel“ an der sozialistischen Revolution hegen. Eine Einzelstimme, als Symbol der überpersönlichen, ideologischen Werte und Ziele, verkündet, das Ziel sei der Sozialismus und der Weg zu diesem Ziel die Organisation $^{64}$ :

„Sozialismus heißt das Ziel,

Organisation der Weg.

Habt ihr die Rufe nicht gehört, die Stimmen, die seit Jahrtausenden den Menschen sprechen vom Glück und von der Würde des Menschseins? Sie verhallten, denn kein Mensch allein, kann die Ketten des Schicksals sprengen, die das Elend den Massen schmiedet. Sein Leben gestaltet fremde Macht [...] Erobert die Arbeitsmittel, macht sie zum Besitz der Gesellschaft,

61 Zürcher Festspieltext, Man 1933a, 2f.

62 De Man, „Regiebemerkungen“, vgl. Man 1932a, 9.

63 Zürcher Festspieltext, vgl. Man 1933a, $7 \mathrm{ff}$.

64 Vgl. Zimmermann 1933a, 6. 
macht euch zu Herren des Staates, dann habt ihr das Schicksal bezwungen, das euch hindert, Mensch zu sein!“65

Die moralische Erkenntnis „ein Mensch zu seyn“ sollte bei den Festspielzuschauer*innen in wissenshistorischer Kontinuität zu Schillers humanistischem Erziehungsauftrag der „Schaubühne als moralische Anstalt betrachtet“ geweckt werden. Das erziehungspolitische Ziel de Mans war im Unterschied zu Schiller, eine emotionspolitische Forderung basierend auf dem humanistischen Wissen über eine moralisch begründete Menschenwürde und dem utilitaristischen Recht auf ein „Glücksstreben“ im real existierenden Sozialismus zu propagieren ${ }^{66}$ :

„Darum habe ich in diesem Spiel die Not des Proletariats dargestellt als das, was der junge Marx die Entmenschlichung genannt hat; darum habe ich die darin vorgebrachten sozialistischen Forderungen humanistisch begründet, d.h. abgeleitet aus den allgemeinmenschlichen Bedürfnissen des natürlichen Lebensdranges und Glücksstrebens, der Spielfreude, der Schaffensfreude, der Erkenntnisfreude und der Anbetungsfreude; und darum habe ich den Sieg des Proletariats als Verwirklichung von sittlichen Forderungen dargestellt. “67

Anders als bei Schiller war die kulturnationalistische Antwort auf de Mans sittliche Forderungen eine affirmativ-moralisierende Gefühlspolitik eines glückverheißenden Kultursozialismus, der sich in der „Spielfreude“ der Laiendarsteller`innen selbstdarstelle. De Mans Glückswissen beruhte im Wesentlichen auf seinen arbeitspsychologischen Forschungen über den Verlust der „Arbeitsfreude“ und einem angeblich weit verbreiteten „Minderwertigkeitsgefühl“ in der Arbeiterschaft (Kap. 10).

Im dritten und letzten Teil (,versuchung und erlösung“) wird der stufenweise erklommene Aufstieg der „schaffenden“ geschildert, wie es das Zürcher Festspielplakat als emotionspolitische Klimax symbolisiert (Abb. 17). Auf ihrem Weg lauern Gefahren, Versuchungen und destruktive „stimmen der selbstsucht, der machtgier, des imperialismus und des nationalismus“, die sowohl von außen (als Stimmen) als auch von innen (die „Entmutigten“ und „Stimmen des Zweifels“) den „emporstrebenden menschen“ ${ }^{“ 68} \mathrm{zu}$ behindern versuchen. Doch die proletarischen Vorkämpfer^innen wissen sich zur Wehr zu setzen: Den inneren „Stimmen des Zweifels“, die behaupten, dass es sich bei der „Idee des Sozialismus“ nur

65 Zürcher Festspieltext, Man 1933a, 8.

66 De Mans „Vorbemerkung“, vgl. Man 1932a, 3.

67 Ebd., 3.

68 Vgl. Zimmermann 1933a, 6. 
um einen „schönen Traum“ handle, entgegnet der große Chor des Proletariats im Sinne der affirmativen Gefühlspolitik des Sozialismus:

\author{
„[...] Der Wille ist stark! \\ Wir wollen Freude, glückliches Leben. Wir wollen, \\ frei sein von der Angst vor Hunger! \\ Wir wollen freudige Arbeit! \\ Wir wollen gesund wohnen! \\ Wir wollen frohe Frauen! \\ Wir wollen glückliche Kinder! \\ Wir wollen Freizeit! \\ Wir wollen Wissen und Schönheit! \\ Wir wollen Menschenwürde für alle! \\ Wir wollen die Einheit der Welt!“69
}

Gegen die Stimme der „Selbstsucht“...

„[...] Für einen Traum,

setzt ihr alles aufs Spiel:

das Brot und das Glück eurer Lieben. [...]“70

... erhebt ein Sprecher aus dem Chor der Vorkämpfer^innen die Stimme der „Solidarität“. Dabei wird eine Fahne mit demselben Schriftzug hochgehalten:

„[...] Brüder! Laßt euch nicht beirren!

Selbstsucht macht Lohndrücker, Streber

und Knechte des Kapitals!

Eine bessere Losung lehrte uns die Not:

Einer für alle, alle für einen!

Solidarität!“71

Der mühselige Aufstieg des Proletariats, als entwicklungshistorischer Prozess symbolisiert, fördere „die solidarität, die demokratie, die völkerfreiheit, die internationale“72 in der „Sehnsucht“73 nach dem Tag der „verwirklichung des sozialismus“. ${ }^{74}$ So lauteten zentrale Wissensbestände des sozialistischen Glückswissens, welche 1. die Laienspielerinnen in der Hoffnung auf realpolitische

69 Zürcher Festspieltext, Man 1933a, 11.

70 Ebd., 13.

71 Zürcher Festspieltext, Man 1933a, 13.

72 Vgl. Zimmermann 1933a, $6 \mathrm{f}$.

73 Zürcher Festspieltext, Man 1933a, 10.

74 Vgl. Zimmermann 1933a, 7. 
Verwirklichung auf der Schaubühne als Spiegel der Gesellschaft selbst darstellten und welche 2. den Kern der Baconschen Kritik an den „Idola Theatri“ verkörpern, die von Wissenschaftlern (wie de Man) geschaffen worden waren und als Fabeln zirkulierten. Das Ziel war die Welt in eine ,Schaubühne' einer sozialistischen Gefühlskultur zu verwandeln.

Kurz vor dem Gipfelziel angekommen, schwinden die Kräfte: „Wer gibt uns neue Kraft?“, fragt der Chor verzweifelt. „Wir!“, ruft die herannahende „Jugend“. Und das Proletariat erwidert erleichtert und wieder voller freudigem Tatendrang:

„Chor:

Kampferprobte Fahnen, neue Menschen!

Junges Blut bringt neue Kraft!

So komm, Jugend, zu uns!“75

Der Regisseur ist davon überzeugt: „[...] die jugend, wird das werk vollenden. das ist unser glaube“. ${ }^{76}$ Das Festspiel endet mit dem „Arbeiterjugendlied (Wir)“, das im Sinne einer affirmativen Gefühlspolitik unter der eingangs erwähnten anthropologischen Prämisse eines „Streben[s] nach Glück“"77 zur kollektivistischen Tat aufruft.

Das Ziel „proletarischer festgestaltung“ war, das Publikum emotionspolitisch $\mathrm{zu}$ aktivieren. ${ }^{78} \mathrm{Um}$ diese politische Emotionalisierung und zielgerichtete Mobilisierung zu erreichen, wurde im Schlussteil die ,Vierte Wand' durchbrochen, indem die Zuschauerinnen dazu aufgefordert wurden, als theaterästhetisches Symbol einer sozialistischen Vergemeinschaftung sich gegenseitig die Hände zu reichen und nach dem „Arbeiterjugendlied Wir!“ in den „allgemeinen Schlußchor“ (Abb. 18) miteinzustimmen:

\footnotetext{
„Arbeiterjugendlied (Wir!)

Allein sind wir nichts, zusammen sind wir alles!

Du und du und du Gehörst auch dazu! Faß die Hand, bist auch ein Mensch! Wir sind die Kette, die umspannt die Welt! Wir! Wir Wir!
}

75 Zürcher Festspieltext, Man 1933a, 18.

76 Zimmermann Man 1933a, 7.

77 Zürcher Festspieltext, Man 1933a, 1.

78 Vgl. Zimmermann 1933b, 11. 


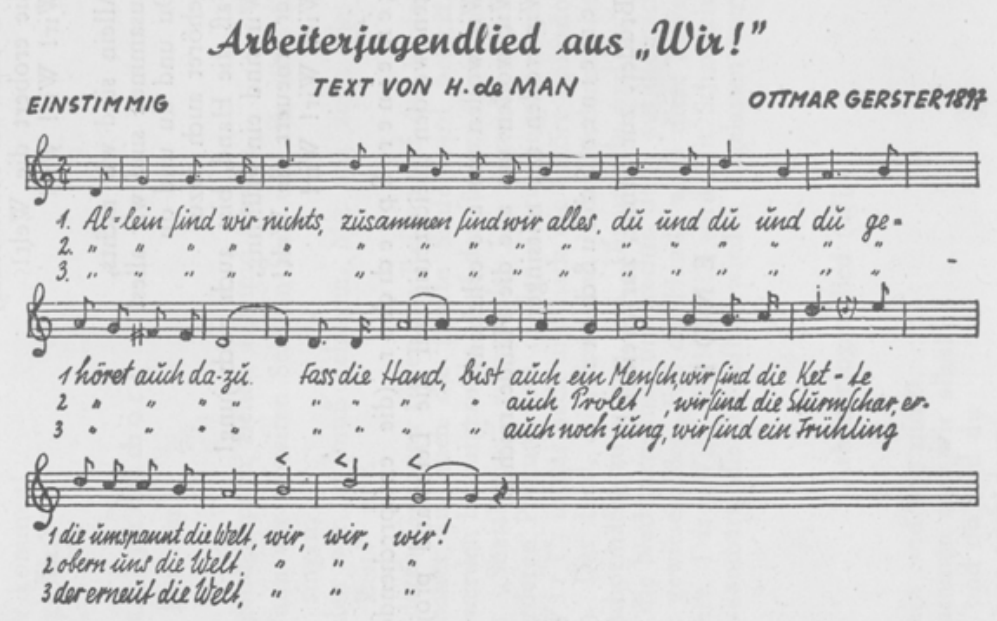

Abb. 18: „Arbeiterjugendlied aus „Wir!““ von Hendrik de Man (1932), Musik: Ottmar Gerster (1897), [Premieren-Programmheft], Frankfurt a. Main, 1932

$[\ldots]$

Wir sind die Sturmschar, die erkämpft die Welt

Wir! Wir! Wir!

[...]

Allgemeiner Sprechchor:

Wir wollen uns alle erheben!

Wir wollen uns alle die Hände reichen!

Wir wollen alle mitsingen!

Allgemeiner Schlußchor:

,Brüder, zur Sonne, zur Freiheit!““79

Der theaterhistorischen Kontextualisierung und quellenkritischen Analyse des Festspiels liegen folgende Forschungsfragen zugrunde:

1. Welche massenpsychologische Wirkung erhofften sich der Dramatiker de Man und sein Regisseur, Otto Zimmermann, mit ihrer Aufführung in Zürich?

79 Zürcher Festspieltext, Man 1933, 19. 
2. Welche wissenshistorischen Kontinuitäten, Brüche und Ambivalenzen hinsichtlich einer affirmativen Gefühlspolitik können zwischen 1. dem sozialistischen Festspiel de Mans, 2. der NS-Theaterästhetiktheorie „des deutschen Volkstheaters“ und 3. Eberles Vorstellung eines Schweizer Laienspiels aufgezeigt werden?

3. Welche „Aufgabe der Kunst“ wurde im Wissensbestand der sozialistischen Ideologie manifestiert und welchen Sinn und Zweck verfolgte de Man mit seinem Festspiel?

De Mans Festspiel stand in der wissenshistorischen Kontinuität zur sozialistischen und kommunistischen Massenspieltradition. Das Festspiel „Wir!“ war im Auftrag des „Kulturkartells“ der Arbeiterbewegung in Frankfurt a. Main entstanden, um im Rahmen der 1. Maifeier 1932 dem „Tag der Arbeit“ eine „Gestalt zu geben, die der sozialistischen Auffassung von der Aufgabe der Kunst entspricht. “80

Das Laienspiel war ebenfalls ein emotionspolitisches Instrument der Arbeitsideologie „Kraft durch Freude“ und deren affirmativer Gefühlspolitik. Das Ziel der nationalsozialistischen Massenspiele war die „Idee der Gemeinschaft“"81 als kulturnationalistische und „rassenhygienische“ Einheit aus „Volksgemeinschaft“ und „NS-Staat“ darzustellen. Das gemeinschaftsstiftende Theatererlebnis sollte durch die leistungsorientierte Selbstdarstellung sowohl bei den beteiligten Laienspieler*innen als auch beim Publikum eine autosuggestive Emotionalisierung sowie eine selbstdisziplinarische Mobilisierung erwirken. Auf welche Weise? Die totalitäre Intention einer theaterästhetischen Gefühlspolitik sollte einerseits bei den Laiendarsteller`innen andererseits beim betrachtenden Publikum eine wirkungsmächtige Wiedererkennung der stereotypisierten Rollen auslösen und dadurch zur Nachahmung der szenischen Handlung, die eine nationalsozialistische Lebensführung propagierte, anregen (s. Kap. 15.7, 16.5).

Die Kontinuität von Glückswissen im wissenshistorischen Rückblick auf die sozialistische Massenspieltradition ist von transnationalen Brüchen, Kontinuitäten und Ambivalenzen geprägt, wie die folgende Analyse anhand de Mans Festspiel „Wir!“ exemplarisch aufzeigen wird.

80 „Vorbemerkung“, vgl. Man 1932a, 2. In Frankfurt a. Main war zudem de Mans Arbeitsort als Dozent an der „Akademie der Arbeit“ 1929-1933.

81 Vgl. Das Deutsche Volksspiel. Jugendliche Propagandisten im Visier und Dienst der „Volksgemeinschaft“. In: Anne Keller 2018, 375-383, 383. Mehr zum „deutschen Volksspiel“ vgl. Annuß 2019. 
Dem proletarisch-revolutionären Konzept des politischen Theaters nach Erwin Piscator und Leopold Jeßner lag eine politische Aufgabe zugrunde, wie später auch der NS-Massenspielpolitik. Die politischen Ideologien waren jedoch dichotom: Im Unterschied zum Nationalsozialismus sollten gesellschaftliche, wirtschaftliche und politische Themen im sozialistischen Massenspiel im Rahmen des sogenannten Kultursozialismus verhandelt werden. ${ }^{82}$ Der „Sozialismus als Kulturbewegung“"83, wie das gleichnamige Werk de Mans von 1929 lautete, hatte eine zentrale Botschaft an das Theaterpublikum: Den Zuschauer*innen sollte die Dringlichkeit der Abschaffung der bürgerlichen Gesellschaft und die Errichtung einer klassenlosen Gesellschaft über die Schaubühne als Propagandainstrument vor Augen geführt und theaterästhetisch erfahrbar gemacht werden. Die revolutionäre „Idee“84 einer klassenlosen Gesellschaftsutopie sollte insbesondere über das Massenspiel der Laienbühne eine emotionspolitische Verbreitung finden. Das Medium ,Theater‘ diente dem Sozialismus als wissenshistorische „Waffe im Klassenkampf “ ${ }^{85}$ Folglich wussten sich sowohl Sozialisten (de Man), Nationalsozialisten (Jedzek) als auch Schweizer Demokraten (Eberle) das „Theater als politische Kraft“"86, als Propagandamittel einer affirmativen Gefühlspolitik, für ihre Ideologien dienstbar zu machen.

Welche theaterästhetischen Mittel standen de Man und Zimmermann zur Verfügung, um die massenpsychologische Wirkungsmacht ihrer Politik einer sozialistischen Gefühlskultur im Festspiel beim Publikum auszulösen? Theaterästhetisch war ein Durchbruch der ,Vierten Wand', die eine Öffnung zum Zuschauerraum bewirkte, ein avantgardistisches Mittel, um im Mikrokosmos eines gemeinschaftsstiftenden Theatererlebnisses, je nach Kontext, eine klassenlose, demokratische oder nationalsozialistische Gesellschaftsutopie zu symbolisieren.

Die wirkungsästhetische Konzeption der Zuschauer*innen war beispielsweise für Piscators emotionspolitische Regiearbeit, die sich nach 1927 radikalisierte, zentral: Zuschauer`innen wurden auf die Bühne entführt, um das gemeinschaftsstiftende Theatererlebnis kollektiv erfahrbar zu machen. ${ }^{87}$ Es ist daher nicht verwunderlich, dass allein die emotionspolitisch intendierte Wirkungsmacht der sozialistischen Theaterbewegung in der Weimarer Republik Skandale provozieren

82 Vgl. Mennen 2013, 130.

83 Vgl. Man 1929.

84 Vgl. Brauneck 2003, 397-410.

85 Vgl. Lilje 1992, 254, $261 \mathrm{ff}$.

$86 \mathrm{Zu}$ Jedzek vgl. Jedzek 1935. S. Kap. 15.3.

87 Vgl. Brauneck 2003, 423. 
konnte und deren Aufführungen von nationalsozialistischen Trupps regelmäßig gestört wurden. ${ }^{88}$

Zimmermann benennt drei theaterästhetische Formen, welche die „neue festgestaltung“ kennzeichnen würden:

1. die Forderung nach einem ,neuen, dem proletarischen empfinden gemäßen stil“,

2. die „forderung freude [zu] wecken“, und

3. ideologisch „zielweisend zu sein“. ${ }^{89}$

Zimmermann erläutert insbesondere sein neues Verständnis einer proletarischen Gefühlskultur im Abgrenzungsgestus zur bürgerlichen Vergnügungskultur:

„von einem proletarischen feste kann auch gefordert werden, daß es freude wecke. nicht aber freude um der freude willen allein, etwa um des bloßen vergnügens willen. unsere feste sollen freude wecken, um kraft zu geben für den kampf." ${ }^{00}$

Das sozialistische Festspiel sollte emotionspolitische Kraft durch Freude wecken. So ließe sich pointiert die arbeitspsychologische Wirkungsintention des Festspiels „Wir!“ als Teil einer sozialistischen Gefühlskultur deuten, zu welcher, in ambivalenter Wissenszirkulation, das später entwickelte rassenideologische NSMassenspiel im Kontrast stand.

Zentral für die neue Festspielgestaltung sei, laut Zimmermann, die ,zielweisend[e]“ emotionspolitische Aktivierung der Zuschauer^innen. Wie sollte die emotionspolitische Aktivierung der Zuschauer*innen theaterästhetisch bewirkt werden? Zimmermann schwebte eine affirmative Körperpolitik vor, die auf der Grundlage von Glückswissen ihre theaterästhetische Wirkungsmacht beim beobachtenden Zuschauenden entfalten könne:

„aktivierung der massen ist das letzte ziel neuer proletarischer festgestaltung. zunächst aktive beteiligung der zuhörenden und zuschauenden massen! sie sollen mitsingen, mitsprechen, mitgestalten. sodann aber auch aktivierung des proletarischen wollens überhaupt! sie sollen bei sich selbst anfangen, unsere ideale zu verwirklichen.“91

Das zentrale ,ausdrucksmittel dieser neuen gestaltungen ist der entfesselte menschliche leib“, so Zimmermann. In wissenshistorischer Kontinuität zur Körperpolitik im Ausdruckstanz sollte der „proletarische chor“ „von dem, was er

88 Vgl. Petersen 1995, 206-244. Vgl. Brauneck 2003, 418-425

89 Zimmermann 1933b, 11.

90 Ebd.

91 Ebd. 
gestalten will, so erfüllt sein, daß er mit dem ganzen bewegten leib sich äußern muß“:

„alle ihm zur verfügung stehenden ausdrucksmittel, so also in erster linie sprache und körperliche bewegung zusammen, sollte er anwenden, um die massen zu überzeugen, zu werben und mitzureißen.“92

Die Fotografie (Abb. 19), vermutlich eine Probenaufnahme, illustriert im Zürcher Programmheft, wie sich der Bewegungschor als Symbol für den proletarischen Massenkörper darstellte. Der homogen und dennoch aus Einzelindividuen autosuggestiv $\mathrm{zu}$ handeln wirkende Bewegungschor veranschaulicht mit Hilfe choreografisch aufeinander abgestimmter Gesten und Mimik eine emotionspolitische Abwehrhaltung. Deren fließende Bewegungen scheinen aus einem als Kollektiv erfahrenen Gemeinschaftsgefühl zu entspringen.

Die ambivalente Gefühlspolitik der Selbstdarstellung, Emotionalisierung und Mobilisierung war folglich bereits beim sozialistischen Massenspiel zentral, um die

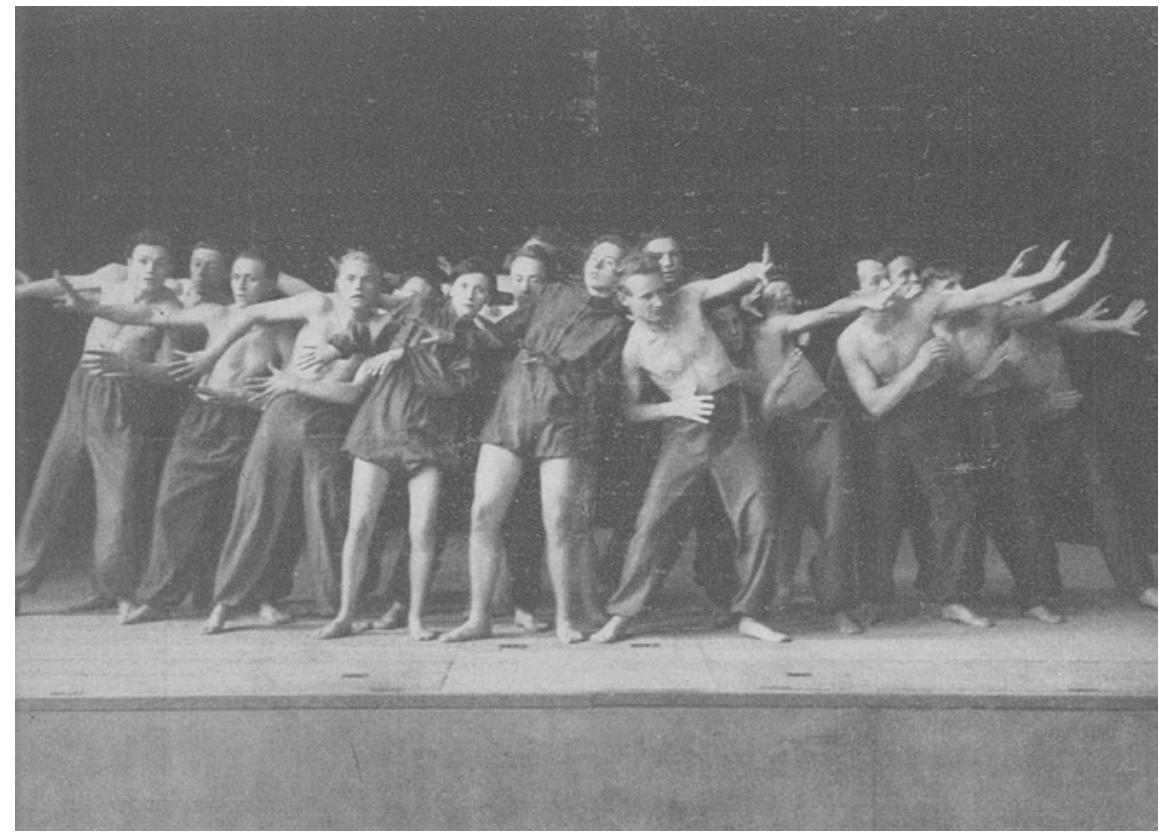

Abb. 19: [Emotionspolitischer Bewegungschor in Otto Zimmermanns Festspielregie „Wir!“], [Zürcher-Programmheft], Limmathaus, Zürich, 1933

92 Ebd. 
Utopie einer ,glücklicheren“ „Lebensführung“ auf der Schaubühne zu propagieren. ${ }^{93}$ Dieser Grundsatz basierte auf einem arbeitspsychologischen und massenpsychologischen Wissen über eine leistungsorientierte Selbstdisziplinierung, welche de Man mit seiner Theaterkunst verfolgte:

„Wir erwarten vom Sozialismus [...] einen neuen Kulturaufstieg der Menschheit, weil die sozialistische Idee den von ihr ergriffenen Menschen einen neuen Lebenszweck und einen neuen Lebenssinn gibt. Wir sehen die neuen Kunstformen, die zu dieser entstehenden Kultur gehören, als Ausdruck dieses Zweckes und Sinnes.“94

De Man sah im Festspiel eine „neue Kunstform“, welche 1. die sozialistische Ideologie als „Ausdruck“ selbst darstellen und deren Sinn und Zweck verbreiten, 2. die Menschen über ihre theaterästhetische Erfahrung emotionspolitisch ergreifen und 3. einen entwicklungsgeschichtlichen Prozess hin zur Utopie eines revolutionären Gesellschaftsumsturzes auslösen sollte.

De Man und Zimmermann griffen ohne den Einsatz einer dramatischen Handlung auf den multimedialen Einsatz von Orchestermusik und Chorgesang sowie auf kurze Filmausschnitte zurück, um ein theaterästhetisches Massengefühl auszulösen. Diese Elemente sollten zu Beginn jeder neuen Handlung als Hilfsmittel zum Verständnis der zugrundeliegenden Vorstellung dienen und das Publikum in den jeweiligen „Gefühlskreis“ einführen. ${ }^{95}$ Im Sinne der sozialistischen Kulturkritik wurden laut dem Dirigent Rudolf Wipf absichtlich Lieder von Hanns Eisler ${ }^{96}$ gewählt, die mit ihrem Jazz-Stil ein „rückhaltloses sich-in-siehineinarbeiten“97 ermöglichen. Die Kompositionen von Ottmar Gerster (18971969) wiederum seien, wie seine früheren Werke „Lied vom Arbeitsmann“ und „Rote Revue“, von einer „bewundernswerten leichtigkeit“ erfüllt. ${ }^{98}$ Ihre Wirklichkeitsnähe zum Musikgeschmack des Publikums, in Kombination mit einer „überzeugende[n] ausdruckstärke“ seiner Musik, erlaubten, „mit aller individualistischen und naturalistischen aufmachung“ und „theatralische[n] gesten“

93 Weiterführende Forschungen könnten die Politik der ,Glückskulturen“ in sozialistischen und kommunistischen Kulturbewegungen systematisch vergleichen. Zum „Happines Soviet Style“, wobei der Theaterbereich in der Untersuchung marginalisiert wurde, vgl. Balina und Dobrenko 2011.

94 Man 1932a, 2.

95 Vgl. Man 1932a, 6.

96 „Lied der Baumwollpflücker“, Musik: Hanns Eisler, Text: Bruno Traven, „Ballade von der Wohltätigkeit“, Musik: Hanns Eisler, Text: Kurt Tucholsky, „Lieder der Bergarbeiter“, Musik: Hanns Eisler, Text: Anna Gmeier, vgl. Man 1933a, 4.

97 Rudolf Wipf. 1933. „die musik von hanns eisler und ottmar gerster“, vgl. Man 1933a, 8.

98 Vgl. ebd. Zur Musik vgl. auch Man 1932a, 8. 
zu brechen und Gersters sozialistischer „kunst“ den „ausdruck eines wahren massenerlebnis“ zu geben. ${ }^{99}$

Der „große Sprechchor“ sollte von der Regie so aufgestellt und verwendet werden, „daß die Zuhörer sich sozusagen von selbst mit ihm identifizieren. “100 Der „Gegensatz zwischen produzierenden Künstlern und konsumierendem Publikum“ sollte möglichst aufgelöst werden. ${ }^{101}$

Wie ist die sozialistische Massenspielästhetik im theaterhistorischen Kontext zu verorten? Um 1930 stellte die Inszenierung großer Menschenmengen einen theaterästhetischen Abgrenzungsgestus zum vorherrschenden Repertoire an den Berufstheatern dar: Kollektiv inszenierte Massenspiele mit Laienspieler`innen, wie sie in Berlin von Erwin Piscator und Ernst Toller prominent vertreten wurden, sollten das Ende des professionellen „Berufsspielers“ einläuten. ${ }^{102}$ Sprech- und Bewegungschöre, wie sie transnational als Mittel zur Ästhetisierung des stereotypisierten Arbeiterkörpers im Ausdruckstanz bereits eingesetzt worden waren, gehörten spätestens seit 1926 zu den theaterästhetischen Stilmitteln der Massenspiele der deutschsprachigen Arbeiterbewegung. ${ }^{103}$

Zusammenfassend lässt sich festhalten: Das massenpsychologische Moment eines autosuggestiv erfahrbar gemachten Gemeinschaftserlebnisses der Laienspieler*innen war bereits im sozialistischen Laienspiel der Weimarer Republik ein zentrales Element der affirmativen Gefühlspolitik. Die theaterästhetische Selbstdarstellung der Laienspieler`innen im charakterologischen Rollentypus der Arbeiter*innen verfolgte ein arbeitspsychologisches Ziel: Sowohl die Laienspie-

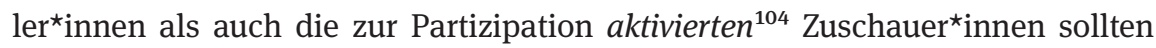
sich im Fall des sozialistischen Massenspiels

1. in der übergeordneten (sozialistischen) Idee einer (klassenlosen) Gesellschaft wiedererkennen,

2. sich über das theaterästhetische Gemeinschaftserlebnis für die politische Aufgabe des revolutionären Handelns autosuggestiv emotionalisieren,

99 Rudolf Wipf. 1933. „die musik von hanns eisler und ottmar gerster“, vgl. Man 1933a, 8.

100 Vgl. Man 1932a, 6.

101 Vgl. ebd.

102 Vgl. Mennen 2013, 132.

103 Zur Theaterästhetik des Regisseurs Otto Zimmermann vgl. Zimmermann 1928. Zum Ausdruckstanz von den Anfängen der Reformbewegung um 1900 bei Emile Jaques-Dalcroze, Robert v. Laban, den avantgardistischen Mitteln Mary Wigmans, zu den sozialistischen, zionistischen und nationalsozialistischen Ausprägungen, vgl. Hardt 2004, Hardt 2005, Brandstetter und Wulf 2007, Baxmann 2009, Brandstetter 2013, Haffter 2015.

104 Vgl. Zimmermann 1933b, 11. 
3. sich in das emotionspolitische Kollektiv eines imaginierten Proletariats selbstdisziplinarisch einfügen, um sich schließlich

4. selbst zur leistungsorientierten Nachahmung der Handlung zu mobilisieren. ${ }^{105}$

De Man war sich in seiner dreifachen Funktion 1. als Arbeitspsychologe, 2. als Politiker und 3. als Theaterpraktiker der massenpsychologischen Wirkungsmacht des Laienspiels bewusst. Geprägt vom massenpsychologischen Glückswissen des arbeitspsychologisch geschulten Dramatikers, konzipierte de Man sein Festspiel als ein emotionspolitisches Instrument, um das sogenannte proletarische Klassenbewusstsein im Kampf gegen den Nationalsozialismus zu stärken.

De Man betont in seinen 1933 veröffentlichten Überlegungen „Pour un Plan d'action“, dass der Grund für den Zulauf zur nationalsozialistischen Bewegung die affirmative, arbeitspsychologische Gefühlspropaganda („Kraft durch Freude“) sei. ${ }^{106}$ Dieser Umstand werde von den sozialdemokratischen Parteien Europas bisher unterschätzt. Gegenüber dieser affirmativen Gefühlspolitik müsste die transnational vernetzte sozialistische Bewegung dringend konkurrenzfähig werden, um ihre Attraktivität gegenüber den Wählerinnen längerfristig unter Beweis stellen zu können (wie es später auch Neff von Bundesrat Etter fordern sollte). ${ }^{107}$

De Man propagiert, im Unterschied zum länderspezifischen Kulturnationalismus, wie gesehen bei den Theaterschaffenden Eberle und Kolbenheyer, einen transnationalen Kultursozialismus. De Man räumte zwar gewisse „völkerpsychologische“ Unterschiede zwischen einem „fascisme allmand, le fascisme autrichien, le fascisme italien, le fascisme hongrois“ ein. Dennoch war der Arbeitspsychologe der Ansicht, dass die affirmative Gefühlspolitik dieser Bewegungen jede einzelne Person ergreifen könne:

„Assurément, on ne peut comprendre le triomphe de Hitler et la physionomie spéciale du fascism allemand qu'en function de certaines particularitiés du milieu national et de la psychologie nationale. Mais cela ne donne encore nullement raison à certain pharisaïsme, au fond nationaliste, et même quelquefois raciste, qui est répandu, hélas! jusque dans nos milieux socialistes. Je songe à ceux qui se complaisent à dire: ,Heureusement que nous ne sommes pas ainsi! Jamais on ne pourra voir se produire chez nous pareilles manifestations de caporalisme, de passivité dans la résistance, de manque de spontanéité dans l'esprit de révolte, et, après la réussite du coup d'Etat de sadisme dans la façon d'excercer le pouvoir et de soumission morale chez la masse de ceux sur qu' il s'exerce!'“108

105 Zur „inszenierung des festspiels ,wir““ und der „,neuen festgestaltung“ in der Auffassung des Regisseurs Otto Zimmermann, vgl. Zimmermann 1933a, 6f und 1933b, $10 \mathrm{ff}$.

106 Vgl. Man 1933b.

107 Vgl. Man 1933b, 5-7.

108 Man 1933b, 7. 
De Man wusste genau, wovon er sprach, wenn er seine Genoss`innen vor der massenpsychologischen Wirkungsmacht der affirmativen Gefühlspolitik warnte, die er in der nationalsozialistischen Arbeitsmoral „Kraft durch Freude“ zu erkennen glaubte: Wie ambivalent der Arbeitspsychologe selber dem psychopolitischen Glückswissen des Nationalsozialismus im Laufe seines Lebens gegenüberstehen sollte, wurde bereits im Kap. 10.4 aufgezeigt.

Welche massenpsychologische Wirkung versprach sich de Man von seinem Festspiel und welche Aufgabe erfüllte dabei arbeitspsychologisches Glückswissen? De Man fasst den Sinn und Zweck eines sozialistischen Massenspiels im Vorwort zu seinem Maifestspiel „Wir!“ zusammen:

„Also sollen Zweck und Sinn der Maifeier Inhalt und Gestalt eines Maifestspieles bestimmen. Die Maifeier aber ist kein bloßes Fest. Sie ist in erster Linie eine Demonstration von Massen, die den gemeinsamen Willen zum Kampfe für den Sozialismus bekunden und durch diese Kundgebung bewußter und stärker gestalten wollen. Der Hauptzweck eines Maifestspieles ist also eine Darstellung der sozialistischen Idee. Darum ist dieses Spiel in erster Linie ein Lehrstück.“109

De Man gibt an, dass er aufgrund seiner theaterästhetischen Auffassung das Festspiel zur 1. Maifeier als emotionspolitisches Massenspiel konzipiert habe. ${ }^{110}$ Im Sinn eines kollektiven, kultischen Kunsterlebnisses sollte es als sozialistisches „Lehrstück“"111 dienen. ${ }^{112}$

Der Begriff des „Lehrstücks“ wurde in der politischen Theaterbewegung Ende der 1920er Jahre in der Weimarer Republik von Piscator und Brecht geprägt: „Alles, was man Zeitstück oder Piscatorbühne oder Lehrstück nannte, gehört zum epischen Theater“, schrieb Brecht. ${ }^{113}$ Das Ziel des Lehrstücks war es einerseits, in der aktiven Beteiligung der Laienspieler`innen eine kritische Auseinandersetzung mit dem Zeitgeschehen, welches in der Theateraufführung verhandelt wurde, zu bewirken sowie in der körperpolitischen Ensembleleistung emotional ein arbeitspsychologisches Gemeinschaftserlebnis zu erzeugen. Andererseits sollte die wirkungsästhetische Durchbrechung der ,Vierten Wand“ die Zuschauer^innen aktivieren und sie zum kritischen Denken und einer Urteilserwägung bewegen. ${ }^{114}$

109 Man 1932a, 2.

110 Vgl. Man 1932a, 2, 8.

111 Man 1932a, 2.

112 Vgl. Man 1932a, 2, 8.

113 Vgl. Brecht 1973c, 262.

114 Vgl. Primavesi 2014, 95. 
Erwin Piscator erarbeitete zur selben Zeit das Konzept des „Politischen Theaters“ (1929). ${ }^{115}$ Mit der Betonung einer politischen Stoßrichtung lag Piscators Ansatz nicht in erster Linie eine autonome Kunstauffassung zugrunde. ${ }^{116}$ Stattdessen stellte er die Theateraufführung „in den Dienst des Kampfes der proletarischen Klasse“. ${ }^{117}$ Um seiner theaterpolitischen Forderung gerecht $\mathrm{zu}$ werden, benötigte Piscator (wie Brecht) eine neue, nicht-illusionäre Theaterästhetik. Diese umfasste eine auf Einfühlung weitgehend verzichtende Erzähltechnik und Inszenierungsstrategie mit Hilfe von Projektionen, Filmausschnitten und Förderbändern. Dennoch war sie nicht emotionslos. ${ }^{118}$ Im Gegenteil. Brecht argumentiert in seiner „Kritik der Einfühlung“ über eine nichtaristotelische Dramatik emotionshistorisch:

„Die Verwerfung der Einfühlung kommt nicht von einer Verwerfung der Emotionen und führt nicht zu einer solchen. [...] Die Emotionen haben immer eine ganz bestimmte klassenmäßige Grundlage; die Form, in der sie auftreten, ist jeweils historisch, spezifisch, begrenzt und gebunden. Die Emotionen sind keineswegs allgemein menschlich und zeitlos. “119

In diesem historischen Kontext einer explizit politischen Theaterbewegung ist de Mans sozialistisches Festspiel zu verorten. De Man beabsichtigte, mit seiner sozialistischen Dramatik einen Abgrenzungsgestus zum „bürgerlichen Konzertwesen“, zu den „bürgerlichen Vereinsfeste[n]“ und der damit einhergehenden bürgerlichen Moral zu demonstrieren. Den bürgerlichen Kulturformen unterstellte der Theaterpraktiker und Arbeitspsychologe - in ähnlich polemischem Vokabular wie Hitler in „Mein Kampf“ - eine „Entartungserscheinung“, die sich „,rein ästhetischen Genüsse[n]“ und „virtuosenhafte[n] Einzelleistungen“ im „Amüsier- und Zerstreuungsbetrieb“ widme. ${ }^{120}$ Es gelänge ihnen aber nicht, „eine sozialistische Idee“ zu vermitteln, von der die Menschen angesichts eines „neuen Lebenszweck[s] und eine[s] neuen Lebenssinn[s]" ergriffen würden. ${ }^{121}$

Die übergeordnete Erziehungsmoral einer affirmativen Gefühlspolitik war in de Mans Dramatik ein zentrales Element. Darin lag, im Unterschied zu Brechts Kritik an einer anthropologisch konstanten Emotionsgeschichte, eine wissenshistorische Ambivalenz, welche de Man über eine arbeitspsychologische und leistungsorientierte Anleitung zu einer idealisierten sozialistischen Lebensfüh-

115 Vgl. Piscator 1929.

116 Vgl. Fischer-Lichte 2014, 259.

117 Vgl. Piscator 1986, 216.

118 Vgl. Fischer-Lichte 2014, 259.

119 Brecht 1973d, 242.

120 Vgl. Man 1932a, 2.

121 Vgl. ebd. 
rung sowohl gegenüber den Laiendarsteller`innen als auch gegenüber den $\mathrm{Zu}$ schauer*innen zu verdecken versuchte. Mit Begriffen wie „kultische feier“ offenbart de Man seine wissenshistorische Kontinuität zur christlichen Messe und der ihr inhärenten Doktrin eines totalitär „einheitlich denkende[n], einheitlich fühlende[n] [...] ,wir““:

\begin{abstract}
„dieses werk ist der großartige versuch, eine kultische feier für die arbeiterschaft künstlerisch einheitlich zu formen. gesangschöre, sprechbewegungschöre, bewegungschöre, tanzgruppe, orchester und film werden verbunden zur gestaltung einer idee. ziel ist die aktivierung der zuhörenden und zuschauenden. Am ende des werkes sollen die gestaltenden und aufnehmenden menschen eine einheit werden: ein großes einheitlich denkendes, einheitlich fühlendes, von einheitlichem willen beseeltes ,wir‘ “"122
\end{abstract}

Das emotionspolitische Ziel der „kultischen feier für die arbeiterschaft“, ein „,von einheitlichem willen beseeltes, wir““ aus „gestaltenden und aufnehmenden menschen" zu schaffen, verfolgte auch das NS-Regime, wie das folgende Fallbeispiel zeigen wird.

\title{
16.4 Wir und die Anderen. Die Festhalle als Schauplatz eines exklusiven Glückserlebnisses im Bericht eines Auslandschweizers 1936
}

„Ich bin allein und sie sind eine Gemeinschaft.“123 Mit diesen Worten beschrieb der Schweizer Philosoph Denis de Rougemont (1906-1985) 124 seine emotionspolitische Exklusionserfahrung, als er 1936 Zeuge einer NSDAP-Veranstaltung in

122 Zimmermann 1933a, 6.

123 Rougemont 2004, 112. „Je suis seul et ils sont tous ensemble.“ Denis de Rougemont. 1938. Journal (1935-1936). In: Ders. Journal d'Allemagne. Paris: Gallimard, 11. März 1936, 49. [Abk.: Rougemont 1938]

124 Denis de Rougemont (1906-1985) war ein Schweizer Philosoph und politisch engagierter, antifaschistischer Intellektueller, der u. a. von 1935-1936 das NS-Regime und dessen nationalsozialistischen Alltag als Lektor an der Frankfurter Universität beobachten konnte. 1940 verfasste er das Manifest des „Gotthardbundes“, eines Zusammenschlusses von rund 8.000 Mitgliedern (männlich, christlich, mehrheitlich großbürgerlich, unterschiedlicher politischer Ausrichtung), die im Sinne der „geistigen Landesverteidigung “ noch bis in die Nachkriegszeit aktiv waren. Nach 1945 machte R. sich für die Idee eines vereinten Europas stark und gründete dazu u.a. 1963 das Institut universitaire d'études européennes in Genf. Zu seiner Person, Jeanneret-de Rougemont 2012. 
der Festhalle in Frankfurt a. Main im Kontext der Wiederbesetzung des Rheinlands wurde. Wie lässt sich das emotionspolitische Erlebnis in jener Festhalle, in welcher vier Jahre zuvor de Mans sozialistisches Massenspiel „Wir!“ aufgeführt wurde, wissenshistorisch untersuchen? Was de Rougemont in der Festhalle beobachtete, wird anhand seiner autobiografischen Aufzeichnung als eine Politik der ,Glückskulturen' gedeutet. Die Parteiveranstaltung diente der emotionspolitischen Selbstdarstellung eines vermeintlich kollektiv erfahrbaren Gemeinschaftserlebnisses, das auf einem massenpsychologischen Glückswissen basierte. ${ }^{125}$ Die Festhalle als Schauplatz eines exklusiven Glückswissens diente der affirmativen Gefühlspolitik als Versammlungsort gemeinschaftsstiftender Inklusions- (Wir) bzw. ausschließender Exklusionserfahrung (die Anderen). Die Festhalle wird als ein Ort einer massen- und arbeitspsychologischen Wissenspraktik begriffen, an welchem, je nach Wahrnehmungsperspektive, „Glück“ 1. top down in der Selbstdarstellung des Regimes propagiert und 2. bottom up als selbstdisziplinarisches Erlebnis und autosuggestive Erfahrung von Inklusion beziehungsweise Exklusion im Bericht des Auslandschweizers kritisch reflektiert wurde. Die Festhalle diente als Schauplatz einer politischen Selbstdarstellung von Glückswissen, an dessen affirmativer Gefühlspolitik das Publikum als Akteur^innen aktiv beteiligt war.

Aus einer wissenshistorischen Perspektive stellen sich folgende Fragen: Welche Vorstellungen, Begrifflichkeiten und Denkrichtungen über „Glück“ werden über de Rougemonts Selbst- und Fremdwahrnehmung in der Quelle dokumentiert? Welche emotionspolitischen Propagandamechanismen sowie medientechnischen Kommunikationsmittel (seitens der Produktion) und individuellen Handlungsspielräume (seitens der Rezeption) werden beschrieben, die aus Sicht des Auslandschweizers eine massenpsychologische Wirkungsmacht entfalteten?

Die Wirkungsmacht, welche die nationalsozialistische Gefühlspolitik im Kontext der Wiederbesetzung des Rheinlands auslöste, beschrieb der Schweizer Philosoph de Rougemont 1936 als „leicht obszön“ anmutende „Erregung der ,befreiten“ Bevölkerung“, einem „Geschlechtsakt“ ähnlich, der sich in einer „[...] seltsame[n] Euphorie [...], die in der Luft der Stadt, im Betrieb der Menge, in den sich zugeworfenen Blicken und in den verstreuten Äußerungen liegt“, zur Schau stellte. ${ }^{126}$ De Rougemont nahm die geschlechterübergreifende, euphorisch-se-

125 Zur Aktualität der Deutung der Frankfurter Festhalle als Erlebnisraum vgl. Homepage: „Emotionale Event- Kulisse unter der 29 Meter hohen Glaskuppel“, https://festhalle.messefrank furt.com/frankfurt/de.html, 21.01.2020.

126 Denis de Rougemont „Der Traum von sechzig Millionen“, 9. März 1936, Frankfurt a. Main, vgl. Rougemont 2004, 108f. „Comment expliquer autrement cette euphorie bizarre qui est dans l'air de 
xualisiert anmutende Stimmung bei der Frankfurter Bevölkerung als ein Vorspiel wahr, welches auf den emotionspolitischen Höhepunkt, nämlich die Festrede Hitlers am 11. März 1936, zielte. ${ }^{127}$ De Rougemont wurde Zeuge von Hitlers affirmativer Gefühlspolitik:

\begin{abstract}
„[...] da geht ein Murmeln durch die wogende Menschenmenge, Trompeten sind von draußen zu hören Die Bogenlampen unten in der Halle verlöschen, während an der Hallendecke Lichtpfeile angehen, die sich auf eine Tür im ersten Rang richten. Ein aufleuchtender Scheinwerfer läßt einen kleinen braungekleideten Mann auf der Schwelle erscheinen, mit bloßem Haupt und ekstatischem Lächeln. 40000 Menschen, 40000 Arme haben sich in einer einzigen Bewegung erhoben. Der Mann schreitet sehr langsam vorwärts, grüßt unter einem betäubenden Donnern rhythmischer Heil-Rufe mit langsamer, bischöflicher Geste. [...] Schritt für Schritt schreitet er voran und nimmt die Huldigungen entlang des schmalen Verbindungsganges entgegen, der zur Tribüne führt. Es dauert sechs Minuten, das ist sehr lang." 128
\end{abstract}

Drei Techniken sind dabei bezeichnend: Das dramaturgische Zusammenspiel zwischen 1. einer choreografierten Bewegungsabfolge des kostümierten Rednerkörpers, dessen zum Publikum gewandter Mimik, Gestik und Stimmführung, 2. einer gezielten Lichtführung, die von musikalischen Trompetenklängen begleitet wurde, und 3. der rhetorisch ausgeklügelten Rede, die sich mit der bevorstehenden „Neuwahl“ des Reichstages nach der militärischen Besetzung des Rheinlandes“ befasste. Diese Rede hielt Hitler, mit kleinen inhaltlichen Abweichungen, in den folgenden Wochen in mehreren Städten. In wissenshistorischer Kontinuität zu kultischen Feiern entfaltete die multimediale Ästhetik der affirmativen Gefühlspolitik, die auf Wort, Klang, Mimik, Bewegung und Gestik aufbaute, eine synästhetische Wirkungsmacht, die sich in der freiwilligen Aktivierung der Zu-

la ville, dans la circulation de la foule, dans les regards croisés, les propos égarés?“ Vgl. Rougemont 1938, 45.

127 Den Recherchen der Autorin im Hessischen Staatsarchiv Darmstadt zufolge, hielt Hitler am 16. März 1936 in einer Festhalle in Frankfurt a. Main eine Rede, von der auch Fotoaufnahmen vorhanden sind, aber nicht vom 11. März 1936.

128 De Rougemont, 11. März 1936, Frankfurt a. Main, Rougemont 2004, 111. „Mais voici une rumeur de marée, des trompettes au dehors. Les lampes à arc s'éteignent dans la salle, tandis que des flèches lumineuses s'allument sur la voûte, pointant vers une porte à la hauteur des premières galeries. Un coup de projecteur fait apparaître sur le seuil un petit homme en brun, tête nue, au sourire extatique. Quarante mille hommes, quarante mille bras se sont levés d'un seul coup. L'homme s'avance très lentement, saluant d'un geste lent, episcopal dans un tonnerre assourdissant de heil rythmés. [...] Pas à pas il s'avance, il accueille l'hommage, le long de la passerelle qui mêne à la tribune. Pendant six minutes c'est très long.“ Rougemont 1938, 48. 
schauer*innen (vgl. Piscator/De Man) und der daraus resultierenden arbeitspsychologischen Mobilisierung manifestierte.

Während das Spektakel seinen Lauf nahm, erwachte in de Rougemont heimlicher Widerstand gegenüber dieser ambivalenten Körperpolitik eines selbstdisziplinarischen und zugleich ekstatischen Glückserlebnisses, das von einem ohrenbetäubenden Chor aus Heil-Rufen stimmlich und rhythmisch mitorchestriert wurde. ${ }^{129}$ Beharrlich weigerte sich de Rougemont an diesem kollektiven „Kult“ der „Huldigungen“ teilzunehmen: „Niemand kann bemerken, daß ich die Hände in den Taschen habe: Sie stehen aufrecht, unbeweglich und im Takt brüllend, während sie mit den Augen auf [...] dieses Gesicht mit dem ekstatischen Lächeln [starren], und ihnen im Dunkeln die Tränen über die Gesichter rinnen. “130 Diese euphorischen Gefühlsausbrüche beim Anblick des „Führers“ und dessen religiös anmutende „kultische“ Zelebrierung durch die Zuschauermasse jagten dem ausländischen Beobachter einen gehörigen „Schrecken“ ein. Er fühlte sich inmitten der Menschenmenge emotional isoliert:

„Ich hatte gedacht, an einer Massenveranstaltung teilzunehmen, an einer politischen Kundgebung. Aber sie zelebrieren ihren Kult! Und dabei wird eine Liturgie abgehalten, die große sakrale Zeremonie einer Religion, der ich nicht angehöre und die mich überrollt und

129 „(Bald höre ich nichts anderes mehr als die heiseren Schreie meiner Nachbarn vor einem Hintergrund aus Sturm und dumpfen Schlägen.)“, de Rougemont, 11. März 1936, Frankfurt a. Main, Rougemont 2004, 111.

130 De Rougemont, 11. März 1936, Frankfurt a. Main, Rougemont 2004, 111. Zu Rausch, Kult, Glück, Ekstase in Diktaturen vgl. u. a. Balina und Dobrenko 2011, Pyta 2010, Klimó und Rolf 2006, Brockhaus 1997. Gudrun Brockhaus versucht in ihrer Studie, Motive für die breite Akzeptanz des Nationalsozialismus in der Bevölkerung, ausgehend von verschiedenen Untersuchungsfeldern, darzulegen: die Erfolge in der Außenpolitik, die totalitäre Politikstruktur, den Autobahn-Mythos sowie die ambivalenten NS-Frauenbilder. Im Rückgriff auf soziologische Studien kommt sie zum Schluss, dass insbesondere der hohe propagandistische Erlebnischarakter und die Ästhetisierung politischer Ereignisse und des NS-Alltags ein Gemeinschaftsgefühl förderten, welches das Trauma des Ersten Weltkriegs überwinden und eine neue kollektive Identitätsbildung stärken sollte. Aus heutiger Sicht sind diese Erkenntnisse nicht neu. 1997 grenzte sich die Autorin jedoch gegen eine gängige Forschungsthese ab, die Hitler ins Zentrum der NS-Machtstrukturen stellte und ihn als „Verführer“ der deutschen Bevölkerung beschrieb. Kritisch an der Studie zu beurteilen sind die subjektiv ins Zentrum gestellte autobiografische Betroffenheit der Sozialpsychologin der zweiten „Täter“-Generation sowie ihr Versuch, Parallelen zwischen der NS-Zeit und dem soziokulturellen Erlebnischarakter der Nachkriegszeit der 1950er bis 1980er Jahre herzustellen. Aus einer emotionshistorischen Perspektive ist die Studie dennoch interessant, da B. in ihrer Quellenauswahl den Fokus auf die Analyse positiv konnotierter Gefühle im Kontext von Propagandastrategien legt. 
mich mit sehr viel mehr Kraft, sogar physischer Kraft zurückdrängt als diese schrecklich strammen Körper. Ich bin allein, und sie sind eine Gemeinschaft.“"131

Am nächsten Tag verarbeitete der Philosoph das Erlebte, indem er die Geschehnisse in der Festhalle mit den Berichten seiner ,jüdischen Freunde“, den Schweizer Journalist“innen und den „Vorurteilen der Durchschnittsfranzosen“ verglich und diese in einen transnationalen Zusammenhang zeittypischer Machtsysteme einzuordnen versuchte:

„[...] comment faire sentir aux Français ce que j'ai senti, ce que j’ai miterlebt? (Le mot n'est même pas traduisible). Les plus puissantes réalités de l'époque sont affectives et religieuses, et l'on ne me parle que d'économie, de technique politique et de droit.“"132

Mit einem zeitkritischen Blick verweist de Rougemont auf die von seinem Umfeld bisher unterschätzte politische Wirkungsmacht des massenpsychologischen und ästhetischen Zusammenspiels aus affirmativen Gefühlen und kultischer Feierkultur gegenüber wirtschaftlichen, politischen und juristischen Aspekten. Dieser Politik einer affirmativen NS-Gefühlskultur müsste, de Rougemont zufolge, in zukünftigen Berichterstattungen und politischen Analysen mehr Aufmerksamkeit geschenkt werden. Die bereits publizierten soziologischen Schriften Max Webers zu Herrschaftstypologien in „Wirtschaft und Gesellschaft“ (posthum 1922), Karl Mannheims „Ideologie und Utopie“ (1929), Hendrik de Mans „Sozialismus und Nationalfacismus“ (1931), die sozialpsychologischen Arbeiten Gustav Le Bons „Psychologie der Massen“ (1895) oder Wilhelm Reichs „Die Massenpsychologie des Faschismus“ (1933) waren dem Lektor offenbar nicht geläufig. ${ }^{133}$ Schließlich war ihm auch Sigmund Freuds kulturkritische und sexual-psychoanalytische Abhandlung, u.a. zur Frage nach „Glück“ und „Unglück“ in einer modernen Gesellschaft in „Das Unbehagen in der Kultur“ (1930), scheinbar entgangen. ${ }^{134}$

131 Rougemont 2004, 112. „Je me croyais à un meeting de masses, à quelque manifestation politique. Mais c'est leur culte qu'ils célèbrent! Et c'est une liturgie qui se déroule, la grande cérémonie sacrale d'une religion dont je ne suis pas, et qui m'écrase et me repousse avec bien plus de puissance même physique, que tous ces corps horriblement tendus. Je suis seul et ils sont tous ensemble." Rougemont 1938, $48 \mathrm{f}$.

132 13.-21.5. 1938, Rougemont 1938, 50. „[...] wie kann ich die Franzosen jetzt spüren lassen, was ich gespürt habe, was ich miterlebt habe? (Nicht einmal das Wort kann man übersetzen.) Die wirkungsmächtigsten Realitäten der Epoche sind affektiv und religiös, aber man erzählt mir nur von Wirtschaft, politischem Handwerk und Recht.“

133 Zur Massenpsychologie s. Kap. 15.5-15.7.

134 Vgl. Weber 2009c, Mannheim 2015, Man 1931, Le Bon 2008, Reich 1933, Freud 2010. Norbert Elias’ Buch „Über den Prozeß der Zivilisation“ erschien erst 1939. Lucien Febvres Aufsatz „Sur la 
Neben seiner Kritik gegenüber der Ignoranz betreffend des Propagandainstruments einer affirmativen Gefühlskultur wurde dem politischen Philosophen die sprachliche Unzulänglichkeit, die eigenen Gefühle und die ,der Anderen` zu beschreiben, um das „Geheimnis“ der nationalsozialistischen Gefühlspolitik für Außenstehende möglichst objektiv und gleichzeitig eindrucksvoll zu erläutern, bewusst:

\begin{abstract}
„Wenn ich versuche, von diesem Auftritt zu erzählen, der mir ,ihr‘ Geheimnis offenbart hat, so werde ich, kaum erzähle ich auch nur mit ein wenig Leidenschaft, belehrt, ich sei Anhänger Hitlers! [...] Erzählen Sie ihnen [den Menschen] nicht von einem Massaker mit dem Maschinengewehr an einer Menschenmenge: Weit davon entfernt, sich zu empören, werden sie Sie bitten, mehr davon zu erzählen. Aus diesem Grund glauben sie - da sie von sich auf mich schließen - nicht einen Augenblick, daß ich das nicht so liebe [...] wie sie es bereits lieben." ${ }^{135}$
\end{abstract}

Aus einer wissenshistorischen Perspektive macht de Rougemonts selbstreflektive Zeitzeugenaussage vom Sprechen von und über Gefühle der Anderen auf ein zentrales methodisches Problem der Emotionsgeschichte aufmerksam. Er weist auf die Schwierigkeit hin, Gefühle Dritter, deren „emotionale Praktiken“136 und das darin spezifisch erlernte Gefühlswissen in Worte $\mathrm{zu}$ fassen. Denn Historiker^innen teilen weder die emotionspolitischen Erfahrungen (Mannheim) der Zeitzeug^innen noch deren spezifisches Glückswissen. Die methodische Herausforderung für eine kritische Geschichtswissenschaft besteht darin, die ambivalent auftretenden Wissens- und Gefühlsbestände aus einer zeitlichen, geografischen und politischen Perspektive für eine Leserschaft in einer möglichst objektiven Darstellung und kontextualisierenden Analyse zu erläutern, ohne dabei in den Leser*innen eine Sensationslust am Hitler-Kult zu wecken.

De Rougemont erkennt im obigen Textausschnitt ebenfalls, dass die unmittelbare, da körperlich erfahrbare Wirkungsmacht von politisch gelenkten und im Kollektiv praktizierten Gefühlen viel eindrücklicher sei als jede „,objektive““ Berichterstattung von Journalist*innen, welche „eine unechte Welt $\mathrm{zu}$ beschreiben scheinen“137. Diese Beobachtung liefert der vorliegenden Untersuchung ein wei-

doctrine nationale-socialiste. Un conflit de tendances“ erschien erst 1939 in den „Annales d'histoires sociales“, die deutsche Übersetzung „Der Nationalsozialismus - eine Doktrin?“ wurde 1988 in „Gewissen des Historikers“ publiziert, vgl. Febvre 1988, und „La sensibilité et l'histoire: Comment reconstituer la vie affective d'autrefois?“ erst 1941, vgl. Febvre 1941.

135 De Rougemont, 13.-21. März 1936, Frankfurt a. Main, Rougemont 2004, 113.

136 Vgl. Scheer 2009, Scheer 2012. Vgl. auch Eitler und Scheer 2009, s. Kap. 4.1.

137 Vgl. De Rougemont, 13.-21. März 1936, Frankfurt a. Main, Rougemont 2004, 112. Forschungen zu „collective emotions“ vgl. Scheve 2014. 
teres quellenbasiertes Argument für das Forschungsinteresse am Zusammenspiel von Gefühlswissen, kulturellen Praktiken, Massenpsychologie und Theaterwissenschaft als Teil einer affirmativen Gefühlskultur, die von Selbstdarstellung, Emotionalisierung und Mobilisierung gekennzeichnet ist.

\section{5 „Reist ins fröhliche Deutschland“: Das Festspiel „Glückliches Volk“ als leistungsorientierte Selbstdarstellung nach dem „Anschluss“ Österreichs 1938}

In den folgenden Kapiteln 16.5 bis 16.6 werden die historischen Aufführungen des Festspiels „Glückliches Volk“, die vom 18. bis 28. August 1938 im Rahmen der Berliner Sommerfestspiele im Olympiastadion stattfanden, und „Das eidgenössische Wettspiel“, das 1939 als offizielles Festspiel der Landesausstellung in Zürich veranstaltet wurde, aus einer transnationalen Vergleichsperspektive analysiert und historisch kontextualisiert. Dem Forschungsvorhaben liegt die These zugrunde, dass nationale Festspiele zwischen 1933 und 1945 massenpsychologische Propagandainstrumente politischer Festkulturen in NS-Deutschland und in der Schweiz darstellten und als solche zur Untersuchung einer Politik der ,Glückskulturen' wissenshistorisch analysiert werden können. Die Festspielleitungen griffen in wissenshistorischer Kontinuität zur Weimarer Republik ${ }^{138}$ auf Glückswissen aus der transnational rezipierten Arbeitspsychologie und Theaterwissenschaft zurück und deuteten dieses kulturnationalistisch auf die länderspezifischen Werte- und Machtsysteme um. Die in den Festspielen transportierte „Sendung“ diente der Konsensbildung über die ideologischen Werte einer Nation und die Vorstellung einer nationalistisch konstruierten Kultur, Lebensführung und Arbeitsmoral. Die Fallbeispiele zeigen, dass die Festspiele verschiedene Lebensführungen moralisierend darstellten. Mit Hilfe einer emotionspolitischen Abgrenzungs- und Distinktionsstrategie propagierten sie die Dichotomie eines ideologisch begründeten Wir, das sich von den Anderen unterscheide. Die historische Komplexität der eigenen Nationalgeschichte sowie der Aktualitätsbezug der Festspielbotschaft wurden im Zuge einer emotionspolitischen Theaterästhetik simplifiziert.

Ziel der Festspiele war die Schaffung eines imaginierten Gemeinschaftsgefühls, welches 1. auf einer leistungsorientierten Selbstdarstellung aufbaute, 2.

138 Wie bereits in Kap. 16.3 exemplarisch anhand des sozialistischen Festspiels von Hendrik de Man im Zäsurjahr 1933 aufgezeigt wurde. 
eine autosuggestive Emotionalisierung erwirken sollte und sich damit 3. eine selbstdisziplinarische Mobilisierung versprach. $\mathrm{Zu}$ diesem Zweck wurde auf arbeits- und massenpsychologisches sowie theaterwissenschaftliches Glückswissen zurückgegriffen, um im Rahmen der Festspielkultur eine gemeinschaftsstiftende Gefühlspraktik („emotional practice“139) von und für Berufs- und Laienspieler*innen und deren Zuschauer*innen $\mathrm{zu}$ entfalten.

Die vorliegende Untersuchung schließt an die geschichtswissenschaftliche Forschung über Prozesse der Nationenbildung an, wie sie exemplarisch in der vergleichenden Studie „Nation und Emotion. Deutschland und Frankreich im Vergleich. 19. und 20. Jahrhundert“ von Etienne François, Hannes Siegrist und Jakob Vogel 1995 betrieben wurde. ${ }^{140}$ Diskussionen über ein kollektives Selbstverständnis einer Nation sind seit den 1990er Jahren in den öffentlichen Diskurs zurückgekehrt. Zuvor galt das Konzept der Nation nach 1945 im Kontext der internationalen und supranationalen Organisationsgründungen (UNO, NATO oder EU) allmählich als überholt. 1994, nach dem Ende des Kalten Kriegs, konstatierten die Historiker*innen des Sammelbands zu ihrem Erstaunen einen wiederkehrenden Nationalismus, der heute, 27 Jahre später, in Form rechtspopulistischer Parteibildungen in zahlreichen europäischen Ländern (Schweiz, Deutschland, Österreich, Frankreich, Polen, Ungarn, den Niederlanden u.a.) immer mehr Zuspruch gewinnt.

Die Historiker*innen begriffen, beeinflusst von konstruktivistischen Studien wie jenen des angloamerikanischen Politikwissenschaftlers Benedict Anderson $^{141}$, die Nationenbildung als ein soziales Produkt eines fortlaufenden, sich zeitlich wandelnden gesellschaftlichen Prozesses. Die Nation besäße eine kollektive Identität, der ein kollektives Gedächtnis zugrunde liege und die eine ambivalent-selektive Erinnerungskultur hervorbringe. ${ }^{142}$ Die Nation wurde, um es im Sinne Andersons pointiert auszudrücken, als eine „imaginierte Gemeinschaft“ aufgefasst. ${ }^{143}$ Vor diesem theoretischen Hintergrund wurde die Nation von der Geschichtswissenschaft vermehrt als kulturelle Praxis in den Fokus genommen. Nationale Denkmäler, Rituale, Mythen und Symbole sowie nationale Stereotypen und Feindbilder rückten ins Blickfeld der Historiker*innen. Turnfeste, Paraden und Massentänze wurden als kulturnationalistische Verkörperungen gedeutet, die in ihren synchronen Bewegungen die Selbstdarstellung einer Nation de-

139 Vgl. Scheer 2012. Mehr zum methodischen Ansatz s. Kap. 4.

140 Vgl. François, Siegrist und Vogel 1995.

141 „Imagined communities. Reflections on the origin and spread of Nationalism“ von 1983, Anderson 2016.

142 Vgl. Assmann 1988, vgl. Assmann 2013.

143 Vgl. François, Siegrist und Vogel 1995, 14. 
monstrierten. „Dem Zuschauer bot sich die Möglichkeit zur Identifikation mit der Nation und zum Erleben von Gemeinschaftsgefühl.“144

Diese theoretischen und methodischen Überlegungen lassen sich für die vorliegende transnational angelegte Analyse einer Politik von, Glückskulturen“ in NS-Deutschland und der Schweiz mit Fokus auf die historische Aufführungspraxis von nationalen Festspielen in den Transitstädten Berlin und Zürich in den Jahren 1938/1939 fruchtbar machen. Aus methodischer Sicht stellt sich die Frage: Welche Funktionen wurden Emotionen in der historischen Nationenforschung zugesprochen und welche Forschungsfragen entwickelten sich daraus?

Den Historiker`innen ging es erstens um die Frage, „wie in Ritualen, Kulten und Mythen nationale Emotionen erzeugt und ausgelegt, verstärkt, ausgerichtet und synchronisiert wurden. “145 Zweitens wurde in der Untersuchung sogenannter „,nationale[r]“ Emotionen“ danach gefragt, wie diese in „vorhandenen Emotionsregeln sozial und kulturell umdefiniert und auf das politische Werte- und Herrschaftssystem ausgerichtet wurden“. Drittens wurde aufgezeigt, wie „,Geschichte in der Gestalt von Mythen, Geschichtsbildern und Erinnerungen bei der Interpretation, Definition und Steuerung von Emotionen - etwa als Schuld, Trauer, und Hoffnung - mitwirke.“146 Die Autor*innen kamen zum Schluss, dass Nationalgefühle erstens eine „diffuse Mischung aus kognitiven und emotionalen, kollektiven und individuellen Elementen, formellen und informellen Rollen und Erwartungen“ seien. ${ }^{147}$ Zweitens würden Emotionen wie „Liebe“ und „Hass“ im Kontext von Nationalismus und Nation eine neue Intensität und Bewertung erfahren, so zum Beispiel die patriotische Vaterlandsliebe im deutschen Kaiserreich oder der antisemitisch geprägte Judenhass im NS-Regime. Eine Schlussfolgerung daraus sei, dass im Verlauf des Nationenbildungsprozesses vom 19. ins 20. Jahrhundert das Individuum und dessen freiwillige Bindungen an die Nation immer wichtiger wurden und die Gefühle für die Nation sich aus unterschiedlichen Gründen veränderten. ${ }^{148}$

Spätestens seit dem von den Sozial- und Geisteswissenschaften proklamierten emotional turn räumen Historiker*innen (National-)gefühlen eine wichtige Bedeutung im Rahmen sozialhistorischer Nationenbildungsprozesse ein. ${ }^{149}$ Diese gelten im Sinne von Georg Simmels „Untersuchung über die Formen der Vergesellschaftung“ (1908) als der notwendige „Kitt“, der das imaginierte Gebilde einer

144 Ebd., 95, 28.

145 Vgl. ebd., 15.

146 Vgl. ebd., 15.

147 Vgl. ebd., 15.

148 Vgl. ebd., 15.

149 S. Einleitung, Kap. 2.1., Kap. 4, Kap. 7. 
Nation zusammenhält. ${ }^{150}$ Die Autor^innen des Sammelbands zu „Nation und Emotion“ fassen den sozialhistorischen Forschungsstand der 1960er bis 1980er Jahre wie folgt zusammen: „Die Nation habe die ,Identität‘ von Individuen und Kollektiven stabilisiert, die im Zuge von Modernisierungs-, Rationalisierungs- und Differenzierungsprozessen aus den traditionellen politischen, sozialen, kulturellen, emotionalen und wirtschaftlichen Zusammenhängen und Bindungen freigesetzt worden waren." ${ }^{151}$

Die Problemstellung, mit der sich die vorliegende Untersuchung in ihrer zunächst paradox anmutenden Forschungsperspektive auf eine affirmative Gefühlspolitik zur NS-Zeit befasst, wird virulent, wenn Nationalgefühle wie „Ehre“ oder „Stolz“ in Verbindung mit Glückswissen, z. B. im Rahmen eines nationalen Festspiels, als konstruierter Nationalkult eine gemeinschaftsstiftende Wirkungsmacht nur für eine exklusive, als homogen gedachte Kollektivkultur entfalten. In einem solchen Fall basiert der emotionspolitische „Kitt“ einer Gemeinschaft auf Identifikationsfiguren und -bildern, Zielen und Werten einer Lebensführung, die im Rückgriff auf eine vermeintlich gemeinsame Vergangenheit (Mannheim) legitimiert werden, aber nicht für alle Bürger`innen einer Nation gelten. Dann hat die affirmative Gefühlspolitik einer national konstruierten ,Glückskultur zwangsläufig den Ausschluss „der Anderen“ zur Folge. Sie konstruiert eine emotionspolitische Dichotomie aus Eigenem und Fremdem, bzw. einem affirmativen Wir und einem diffamierenden Anderen.

Vor diesem Hintergrund soll die wissenshistorische Analyse exemplarisch aufzeigen, wie das Festspiel „Glückliches Volk“ als Schauplatz eines ambivalenten Glückswissens und als Teil einer affirmativen Gefühlskultur zur leistungsorientierten Selbstdarstellung nach dem „Anschluss“ Österreichs am 12. März 1938 emotionspolitisch wirken sollte und wie diese affirmative Suggestion vom Publikum rezipiert wurde.

Warum fiel die Wahl zur Erforschung emotionshistorischer Nationalgefühle auf die Gattung Festspiel als Untersuchungsgegenstand einer Politik von ,Glückskulturen' im Zeitraum 1933 bis 1945? Das Festspiel gilt für den Zeitraum 1933 bis 1945 als repräsentativ. ${ }^{152}$ Die Fallbeispiele können diese Annahme im transnationalen Vergleich zwischen NS-Deutschland und der Schweiz exemplarisch bestätigen. $\mathrm{Zu}$ zahlreichen Anlässen wurden Festspiele veranstaltet, sei es im Rahmen des parteipolitischen Feierkalenders der NSDAP, von Firmen- und Vereinsjubiläen, nationalen Feierspielen an der Schweizer Landesausstellung

150 Vgl. Simmel 1908, 34.

151 François, Siegrist und Vogel 1995, $17 \mathrm{f}$.

152 Vgl. Das Festspiel, 126-157. In: Stern 2000, 157. 
1939 oder zur Jubiläumsfeier des Schweizer Bundesstaates 1941. ${ }^{153}$ Darüber hinaus galten „Zweckoptimismus“ und „Positivität“ von den 1930ern bis in die 1950er Jahre für die jeweiligen Auftraggeber`innen und Veranstaltungsorganisationen als ein unverzichtbares Erfordernis der Gattung Festspiel. ${ }^{154}$ Aus diesem Grund eignet sich das Festspiel besonders als Untersuchungsgegenstand für eine transnationale Politik der ,Glückskulturen“.

Die folgende Analyse baut auf dem Forschungsstand zur Geschichte der Festspielkultur in NS-Deutschland und in der Schweiz auf. ${ }^{155}$ Martin Stern definiert in seiner theaterhistorischen Untersuchung über die Schweizer Festspielkultur, im Vergleich zum „NS-Thingspiel“, für den Zeitraum 1930 bis 1950 drei Gattungsfunktionen, die mit dem Erkenntnisinteresse der vorliegenden Untersuchung zur Politik der ,Glückskulturen“ in Bezug gestellt werden können: 1. „enkomiastisch-verklärend“, 2. „utopisch-verheißend“ und 3. „satirisch-realitätsbezogen“. ${ }^{156}$ Ein Festspiel weist eine „enkomiastisch-verklärende“ Funktion auf, wenn es sich als Referenzpunkt mehr oder weniger zutreffender wirtschaftlicher und sozialer ,Erfolge“ präsentiert, die in der vorliegenden Untersuchung als leistungsorientierte Selbstdarstellung bezeichnet werden. Das Festspiel tritt in einer „utopisch-verheißenden“ Funktion auf, indem es auf ein zukunftsorientiertes Gesellschaftsbild (oder eine Lebensführung) verweist. Eine „satirisch-realitätsbezogene“ Funktion nimmt ein Festspiel in Fällen ein, in denen es eine Kritik an aktuellen Verhältnissen äußert, welche einer realen Wahrwerdung der auf der Bühne bereits erfüllten Utopie im Wege stehen. Diese theaterhistorischen Funktionen des Festspiels sollen in den folgenden Kapiteln als Vergleichskategorien herangezogen, kritisch geprüft und gegebenenfalls im Kontext der transnationalen Fallbeispiele weiterentwickelt werden. ${ }^{157}$

Folgende Forschungsfragen gehen der Analyse voraus:

1. Welcher Entstehungskontext, welche Organisationsstruktur, Handlung, Dramaturgie und Theaterästhetik lagen dem Festspiel „Glückliches Volk“ zugrunde?

2. Welche „Nationalgefühle“ werden in den Festspielen benannt? An welche Gefühle appelliert die affirmative Gefühlspolitik im Rahmen des Festspiels und zu welchem Zweck?

153 Vgl. Engler und Kreis 1988, Reichel 2006.

154 Vgl. Das Festspiel, 126-157. In: Stern 2000, 147.

155 Zum Festspiel in NS-Deutschland und in der Schweiz vgl. u.a. Eichberg u. a. 1977, Stommer 1985, Kreis 1988, Stern 1998, Das Festspiel, 126 -157. In: Stern 2000, Reichel 2006, Kleiner 2013, Anne Keller 2018, Hoffmann-Allenspach 2018, Annuß 2019.

156 Vgl. Das Festspiel, 126-157. In: Stern 2000, 157.

157 Vgl. ebd., 157. 
3. Welche Bedeutung und Funktion werden seitens der Festspielleitung den theaterästhetisch zu evozierenden Gefühlen zugesprochen und in welchem Zusammenhang standen diese zum NS-theaterpolitischen Auftrag der Gattung „deutsches Festspiel“?

4. Wie rezipierten die Zuschauerinnen das Festspiel?

Der Aufbau des Kapitels sieht, entsprechend der Forschungsfragen vor, dass im ersten Teil der historische Entstehungskontext des Festspiels „Glückliches Volk“ erläutert wird, um im zweiten Teil eine wissenshistorische Analyse des „Festspiels“ durchzuführen.

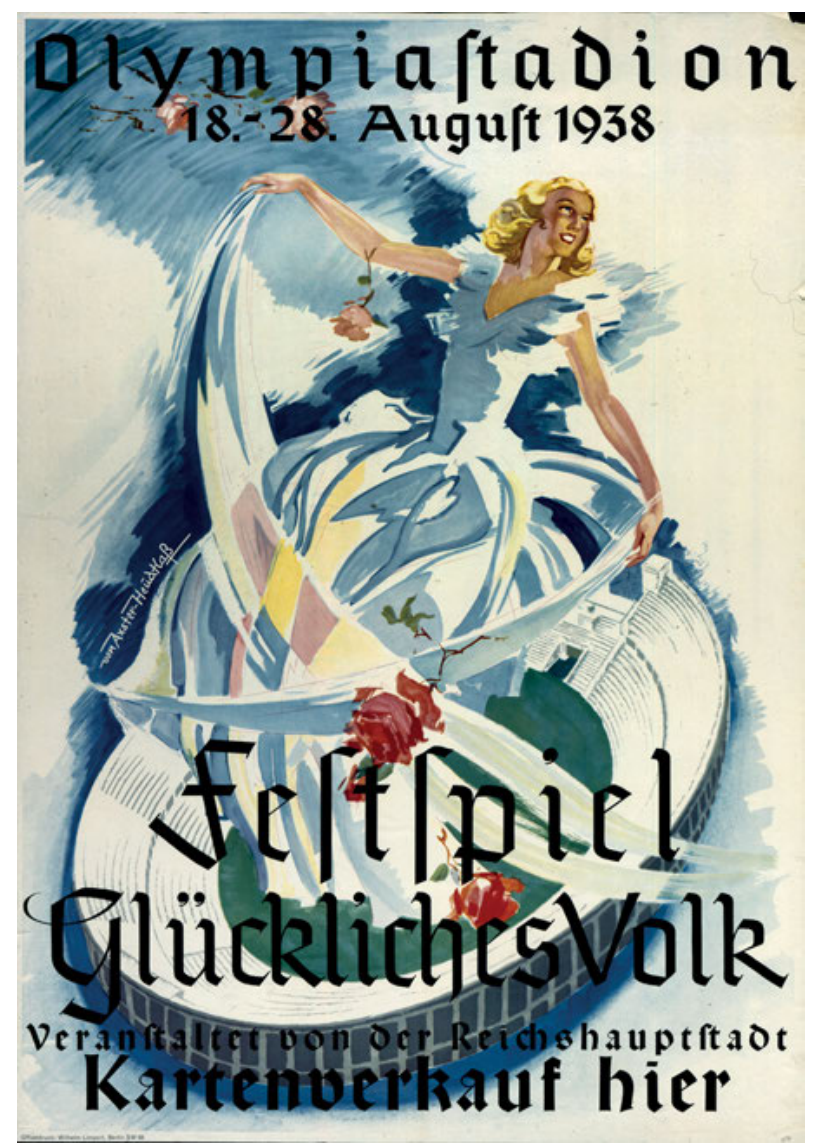

Abb. 20: Festspiel „Glückliches Volk“ unter der Festspielleitung von Hanns-Niedecken-Gebhard, [Plakat], Olympiastadion, Berlin, 1938 
Das 94-minütige Festspiel „Glückliches Volk“ wurde im Rahmen der Berliner Sommerfestspiele, die unter dem Motto „Berliner Sommerfreuden“ standen, vom 18. bis 28. August 1938 im Olympiastadion aufgeführt. ${ }^{158} 5.000$ Teilnehmerinnen waren für das Festspiel vorgesehen, darunter Mitglieder des Musikkorps der „Schutzpolizei“, des „Nationalsozialistischen Kraftfahrkorps“ (NSKK), der SA, der „Deutschen Arbeiterfront“, der „Ausbildungshundertschaft österreichischer Polizeianwärter des Schutzpolizeikommandos Berlin“, der „NS-Frauenschaft“, der „Hitlerjugend“ und des „Bund[es] deutscher Mädel“ aus dem Gebiet Berlins sowie Berufs- und Laientänzer^innen. ${ }^{159}$ Die Gesamtspielleitung oblag dem erfahrenen Festspiel- und Opernregisseur, Musik- und Theaterwissenschaftler sowie NSDramatiker Hanns Niedecken-Gebhard (1889-1954) ${ }^{160}$. Zusätzlich standen dem Festspielleiter 20 Mitarbeiter*innen für Regie, Dramaturgie, Kostüm, Maske, Bühnenbild und zur musikalischen sowie tänzerischen Leitung zur Verfügung. ${ }^{161}$

Zum Zeitpunkt der Berliner Sommerfestspiele 1938 konnte Niedecken-Gebhard auf eine lange Karriere zurückblicken, die bereits in der Weimarer Republik ihren Anfang genommen hatte. ${ }^{162}$ Nach dem Ersten Weltkrieg erhielt er als

158 Die theaterhistorische Untersuchung bezieht sich im Wesentlichen auf das Archivmaterial (Regiebuch, Fotografien, Berichte, Probepläne, Etat, Korrespondenzen, theaterwissenschaftliche Aufsätze zur Festspielästhetik), welches im Nachlass von Niedecken-Gebhard in der Theaterwissenschaftlichen Sammlung (TWS) der Universität Köln aufbewahrt wird. Das Programmheft „Glückliches Volk“ wurde im Archiv des Deutsches Historischen Museums in Berlin ausfindig gemacht. Im Landesarchiv Berlin befindet sich unter der Signatur Rep. 037-08 Nr. 507 ein Schreiben zum Kartenvorverkauf durch die Freizeitorganisation „KdF“ sowie ein Werbeplakat (Abb. 20). Im Archiv des Olympia Stadions sind laut Kontaktanfrage keine Unterlagen zur Aufführung erhalten geblieben.

159 Vgl. Niedecken-Gebhard, Frohes, freies, glückliches Volk. Festspiel. Aufführung im Olympia Stadion, Berliner Sommerfestspiele 1938, Szenische Gestaltung: Dr. Hanns Niedecken-Gebhard, Veranstalter von der Reichshauptstadt, Regiebuch, TWS [Abk.: Niedecken-Gebhard, Regiebuch]. Vgl. Brief vom „Gaupropagandaamt Berlin d. NSDAP“ an die „Kreispropagandaleiter“, „Leiter der Kreisringe“, „Gauringmitglieder“ und „Verbindungsmänner der Organisation“, Berlin, 07.07.1938, 2, Nachlass Niedecken-Gebhard, TWS. [Abk.: Vertraulicher Vorbericht, 07.07.1938].

160 Zur Biografie vgl. Dultz 1977, 214, 216f., 220 -223.

161 Vgl. Niedecken-Gebhard, Regiebuch, 5.

1621914 promovierte Niedecken-Gebhard mit seiner musikwissenschaftlichen Dissertation über den Tänzer und Choreographen Jean Geogres Noverre. Von 1922-1954 wirkte Niedecken-Gebhard mit Unterbrüchen als Oberspielleiter der Göttinger Händelspielfeste, von 1922-1924 als Oberspielleiter an den Städtischen Bühnen Hannover, 1924-1927 als Intendant des Stadttheaters Münster. In Niedecken-Gebhards Regiearbeit galt sein besonderes Interesse dem Einsatz choreografischer Stilelemente des Ausdruckstanzes Mary Wigmans, Gret Paluccas, Kurt Joos' und der Schweizerin Berthe Trümpy (1895-1983). Im NS-Regime fand mehrfach eine Zusammenarbeit (u.a. für die Olympischen Spiele 1936) mit der „Wigman-Schulgruppe im D.K.V“ statt, zu der sich die Palucca- und Trümpy-Schule 1934 zusammengeschlossen hatten. Trümpy lieferte Choreo- 
Opernregisseur Engagements an verschiedenen Theaterhäusern, u.a. in Berlin und Genf. Darauf folgte zwischen 1931 und 1933 eine Anstellung als stage director an der Metropolitan Opera in New York. Nach seiner Rückkehr nach Deutschland im Frühjahr 1933, zur Zeit der NS-Machtergreifung, etablierte sich NiedeckenGebhard in seiner Doppelrolle als Theaterwissenschaftler und Theaterschaffender zum Experten für Massen- und Festspielinszenierungen und zählte zu den Mitbegründern der „NS-Thingspiele“ ${ }^{163}$ Höhepunkt seines Schaffens im NS-Regime war sein Mitwirken am Festspielprogramm der Olympischen Spiele 1936 in der „Reichshauptstadt“ Berlin. 1940 erhielt Niedecken-Gebhard von Goebbels die Leitungsposition der „Deutschen Tanzbühnen“ in Berlin, einer Dienststelle innerhalb des Propagandaministeriums. Nachdem er seit 1936 in Berlin gelehrt hatte, wurde Niedecken-Gebhard 1941 zum Professor an der Musikhochschule in Leipzig ernannt. Nach kurzzeitigem Berufsverbot war er ab 1947 Dozent für Theaterwissenschaft an der Universität Göttingen. ${ }^{164}$ Niedecken-Gebhards akademische wie auch künstlerische Karriere kann als Beispiel für eine Biografie in der ersten Hälfte des 20. Jahrhunderts stehen, die von ambivalenten Kontinuitäten geprägt war und sich innerhalb der transnationalen Festspiel- und Musiktheaterkultur über zeitliche, geografische und politische Achsen im Kontext einer affirmativen Gefühlspolitik wissenshistorisch untersuchen lässt.

Im Folgenden wird der historische Entstehungskontext des Festspiels aufgezeigt. Die Freizeitorganisation „Kraft durch Freude“ unterbreitete dem „Fremdenverkehrsamt“ der „Reichshauptstadt“ Berlin den Vorschlag, nach dem Erfolg der Sommerfestspiele 1937 im Rahmen der „700 Jahrfeier der Reichhauptstadt“ Niedecken-Gebhard für das Jahr 1938 erneut die Festspielleitung zu übertragen. ${ }^{165}$ Das wirtschaftliche Interesse am Festspieltourismus seitens des „Fremdenverkehrsamts“ sorgte für eine positive Rückmeldung. Unter der Festspielleitung

grafien sowohl für Niedecken-Gebhards „700-Jahrfeier der Reichshauptstadt“ im Olympia Stadion in Berlin, das „Deutsche Turn- und Sportfest“ 1938 in Breslau als auch für das Festspiel „Glückliches Volk“ in Berlin. Mehr zu Trümpy vgl. Forster 2005.

163 Vgl. Dultz 1977, 214, 216f., 220 - 223. Der Kölner Professor für Theaterwissenschaft, Carl Niessen, erinnerte sich in einem Brief an Michael Dultz 1965 daran, dass er die Pläne für ein „Thing“Spiel im Sinne einer „rechtlich-politischen Versammlung im Steinring“ zum ersten Mal während einer Bahnfahrt zu einer Aufführung von Niedecken-Gebhard gegenüber seinem Fachkollegen Wilhelm Karl Gerst geäußert habe. Vgl. Brief an Michael Dultz, zit. nach Dultz 1977, 214.

164 Zur Biografie vgl. Helmich 1989. Vgl. Niedecken-Gebhard, Hanns. In: Klee 2009, $391 \mathrm{f}$.

165 Vgl. Niedecken-Gebhard, „Glückliches Volk“, „Bericht über die Durchführung der Berliner Sommerfestspiele 1938“, S. 1, Nachlass Niedecken-Gebhard, TWS, [Abk.: Niedecken-Gebhard, Bericht über die Durchführung, TWS], vgl. Niedecken-Gebhard, „Glückliches Volk“, [Bericht für Wiederaufführung], 25.02.1938, 2, TWS. [Abk. Niedecken-Gebhard, Bericht für Wiederaufführung]. 
Niedecken-Gebhards beschloss man, auf der „Dietrich-Eckart-Bühne“ des Olympia-Areals das barocke Musiktheater „Orfeo ed Euridice“ (UA 1762 in Wien) des österreichischen Komponisten Christoph Willibald Gluck (1714-1787) aufzuführen. Für das Olympiastadion sollte Niedecken-Gebhard mit seinen Mitarbeiter^innen ein monumentales Festspiel schaffen, welches sich an der touristischen Parole „Reist ins fröhliche Deutschland“ orientieren und sich explizit ans Ausland und insbesondere an die österreichische Bevölkerung richten sollte. ${ }^{166}$

Der historische Kontext für diese Programmatik war der sogenannte „Anschluss“ Österreichs ans „Dritte Reich“, der im Frühjahr 1938 stattgefunden hatte. Am 12. Februar zitierte Hitler den damaligen österreichischen Kanzler Kurt Schuschnigg (1897-1977) nach Berchtesgaden und stellte ihm ein Ultimatum, welches Österreich zum Satellitenstaat degradierte. Für den 14. März berief Schuschnigg eine Volksabstimmung über die Unabhängigkeit Österreichs ein, die jedoch durch den nationalsozialistischen Staatsstreich in Form eines propagandistisch wirkungsmächtigen Einmarschs deutscher Truppen, die von einer jubelnden Menschenmasse willkommen geheißen wurden, „zunichte“ gemacht wurde. ${ }^{167}$ Bei der Volksabstimmung vom 10. April 1938 stimmte die österreichische Bevölkerung mit 98\% JA-Stimmen für die Annexion durch das NS-Regime. ${ }^{168}$ Seither zählte der „arische“ Bevölkerungsanteil zur „rassenideologisch“ konzipierten „Volksgemeinschaft“ unter Ausschluss aller jüdischen Österreicher^innen und sogenannter „staatsfeindlicher Elemente“. Ein Ziel der Festspielaufführung „Glückliches Volk“ war, die militärische Annexion Österreichs im Kontext der „völkischen“ Expansionsparole „Heim ins Reich“ (als ,herzlichen“ Verschleierungsgestus eines gemeinschaftsstiftenden Zusammenführens zweier „Brüdervölker") im Rahmen der nationalsozialistischen Gefühlskultur einer nationalen Sendung zu propagieren.

Im Folgenden soll aufgezeigt werden, was das inhaltliche Konzept des Festspiels war, welche theaterästhetischen Absichten Niedecken-Gebhard verfolgte

166 Der Werbeslogan „Reist ins fröhliche Deutschland“ war bei den Fremdenverkehrsvereinen in NS-Deutschland populär, wovon propagandistische Werbeplakate zeugen, die im Archiv des Deutschen Historischen Museums in Berlin vorliegen. Im besetzten Teil Russlands wurde während des Zweiten Weltkriegs das Leben im „Dritten Reich“ mit Fotoreportagen im Sinne der affirmativ propagierten NS-Gefühlskultur „Kraft durch Freude“ illustriert und mit Parolen versehen: „Das Leben in Deutschland ist wunderbar! Wir sind glücklich hier in Deutschland, komm auch Du hierher“ (Signatur P96/977). Ein weiteres Beispiel wären die „Kdf“-Schiffsreisen, die auf ihren Fahrkarten eine „Glückliche Fahrt“ wünschten (Signatur Do2 89/1000.1).

167 Vgl. Wildt 2008, 140.

168 Vgl. Wildt 2008, 140. 
und in welcher Beziehung das Regiekonzept zur offiziellen NS-Theaterpolitik stand.

In einem vertraulichen Vorbericht des „Gaupropagandaamts Berlin“ an die „Kreispropagandaleiter“, „Leiter der Kreisringe“, „Gauringmitglieder“ und „Verbindungsmänner der Organisation“ vom 7. Juli 1938 wurde das inhaltliche Konzept des Festspiels „Glückliches Volk“ mitgeteilt. Gemäß dem Motto „Berliner Sommerfreude“ und der Parole „Reist ins fröhliche Deutschland“ sollte das Festspiel in einer Reihe von Schaubildern „das Volksleben“ im „Dritten Reich“ in „sinnfälliger Anschaulichkeit vermitteln, um dadurch für weiteste Kreise von Volksgenossen eine Unterhaltung im besten Sinne zu schaffen. "169

Vier ideologische Grundgedanken lagen der Festspieldramaturgie, laut Niedecken-Gebhards Erläuterungen, zugrunde: 1. „Volk am Feiertag“, 2. „Volk in Leibesübungen“, 3. „Wehrhaftes Volk“ und 4. „Glückliches Deutsches Volk“. ${ }^{170}$ Freizeitvergnügen, Sportsgeist, Wehrhaftigkeit und „Glück“. Mit diesen vier Schlagwörtern ließen sich die emotionspolitischen Pfeiler, auf denen die im Festspiel propagierten Nationalgefühle aufbauten, zusammenfassen. Sie verweisen auf ein arbeits- und massenpsychologisches Glückswissen im Kontext einer leistungsorientierten Gefühlspolitik.

Am Schauplatz dieses spezifischen Glückswissens, dem Berliner Olympiastadion, wurde die Selbstdarstellung der nationalsozialistischen Gefühlskultur in sechs Bilderbögen theaterästhetisch visualisiert. Zur „größtmöglichen Allgemeinverständlichkeit“ orientierten sich die Bilder an Niedecken-Gebhards klarem Aufbau seiner „Bewegungsregie“171, welcher in der Regel ein dramaturgisch dreistufiges Konzept aus 1. „Steigerung“, 2. „Gegensätze[n]“, 3. „Ausklang“ zugrunde lag. ${ }^{172}$

Die Eröffnung des Festspiels wurde als „festlicher Aufklang“ zelebriert, bei welchem das Hissen der Berliner Stadtflagge am olympischen Fahnenmast zu den Trompetenklängen des „Musikkorps der Schutzpolizei“ stattfand. ${ }^{173}$ „[A]uftragsgemäss“ musste die Festspielhandlung „alle seelisch belastenden Momente“

169 Vertraulicher Vorbericht, 07.07.1938, 2.

170 Ebd.

171 Niedecken-Gebhard, „Aufgaben und Probleme der monumentalen Festspielgestaltung“, 19.11.1938, 4, [deutsche, NS-ideologisch überarbeitete Fassung des Vortragtexts am internationalen Kongress für Singen und Sprechen, Frankfurt a. Main, 09.-16.10.1938]. [Abk.: NiedeckenGebhard, Aufgaben und Probleme].

172 Niedecken-Gebhard, Aufgaben und Probleme, 3. Beim Festspiel „Glückliches Festspiel“ wurden keine ,Gegensätze‘ aufgezeigt, sondern rein affirmative Darstellungen verwendet.

173 Vgl. Niedecken-Gebhard, Regiebuch, 6. 
vermeiden und im „Spiel auf eine politische Kundgebung“ verzichten. ${ }^{174}$ Im Sinn der affirmativen Gefühlspolitik sollte „eine leicht spielerisch heitere Note mit der Parole ,Berliner Sommerfreuden“ eine „stilistisch[e]“ Festspielform finden. ${ }^{175}$ Wie dieser theaterpolitische Auftrag von der Festspielleitung umgesetzt wurde, zeigt die folgende theaterhistorische Analyse.

Das 1. Bild „Volk am Feiertag. Ein Berliner Festtag zur Biedermeierzeit“ zeigt eine scheinbar „bunte“, „rassenideologisch“ jedoch stereotypisiert homogene Selbstdarstellung der Berliner „Volksgenossen“, welche als dramaturgischen Höhepunkt den Aufstieg der Luftballons feierten. Ursprünglich war eine Eisenbahnfahrt vorgesehen gewesen, welche die „deutsche“ Innovationskraft und industrielle Leistungsfähigkeit am Beispiel des 100-jährigen Jubiläums der „Ersten Eisenbahnfahrt“ von Berlin nach Potsdam am 19. Oktober 1838 als emotionspolitisches Ereignis und „freudiges Volkserlebnis“ demonstrieren sollte. ${ }^{176}$ Der Regieeinfall musste jedoch aus finanziellen und logistischen Gründen aufgegeben werden. ${ }^{177}$ Um Kosten zu sparen, wurde die Ausstattung der Biedermeierzeit mit 248 Kostümen aus dem Fundus des Berliner Jubiläumsfestspiels von 1937 und mit 160 Kostümen des „Deutschen Reichsbundes für Leibesübungen“ bestückt. Um dem theaterästhetischen Konzept des „Tableau vivant“ (der szenischen Darstellung von Werken aus der Malerei) gerecht zu werden, traten vielfältige choreographische Tanzformationen auf, die in historisch , getreuer' Rekonstruktion zu Ludwig van Beethovens „Deutschen Tänzen“ und „Contre Tänzen“ die „Stiche der Biedermeierzeit auf dem Rasen lebendig werden“ ließen. ${ }^{178}$

Das 2. Bild „Volk am Feiertag. Ein Berliner Festtag um die Jahrhundertwende“ stellt ein dynamischeres Treiben dar als jenes zur „Biedermeierzeit“. Ausgehend von der im Programmheft abgebildeten Zeichnung eines Berliner Biergartens um 1900 (Abb. 21), sollte ein „typisches Berliner Volksleben“ präsentiert werden. Über eine langsame Temposteigerung der Choreografie entwickelte sich das Bild vom „behaglichen Feiertagstreiben zur Fülle eines großen Blumenkorso[s]“, was in der theaterästhetischen Vorstellung des Regisseurs einen „wirkungssicheren Ausklang“ auslösen sollte. ${ }^{179}$ Die Ausstattung des Berliner „Volksleben[s]“ um 1900 war mit hohen Kosten verbunden, da keine entsprechenden Kostüme zur Verfü-

174 Vgl. Niedecken-Gebhard, Bericht über die Durchführung, 3.

175 Vgl. ebd., 3.

176 Vgl. Vertraulicher Vorbericht, 07.07.1938, 2.

177 Die Rechnung ging nicht auf: Statt 1.000.- RM für die Eisenbahn mussten 4.000.- RM für die Luftballons bezahlt werden. Vgl. Niedecken-Gebhard, Bericht über die Durchführung, 4.

178 Vgl. Niedecken-Gebhard, Bericht über die Durchführung, 4.

179 Vgl. Niedecken-Gebhard, Regiebuch, 2. 


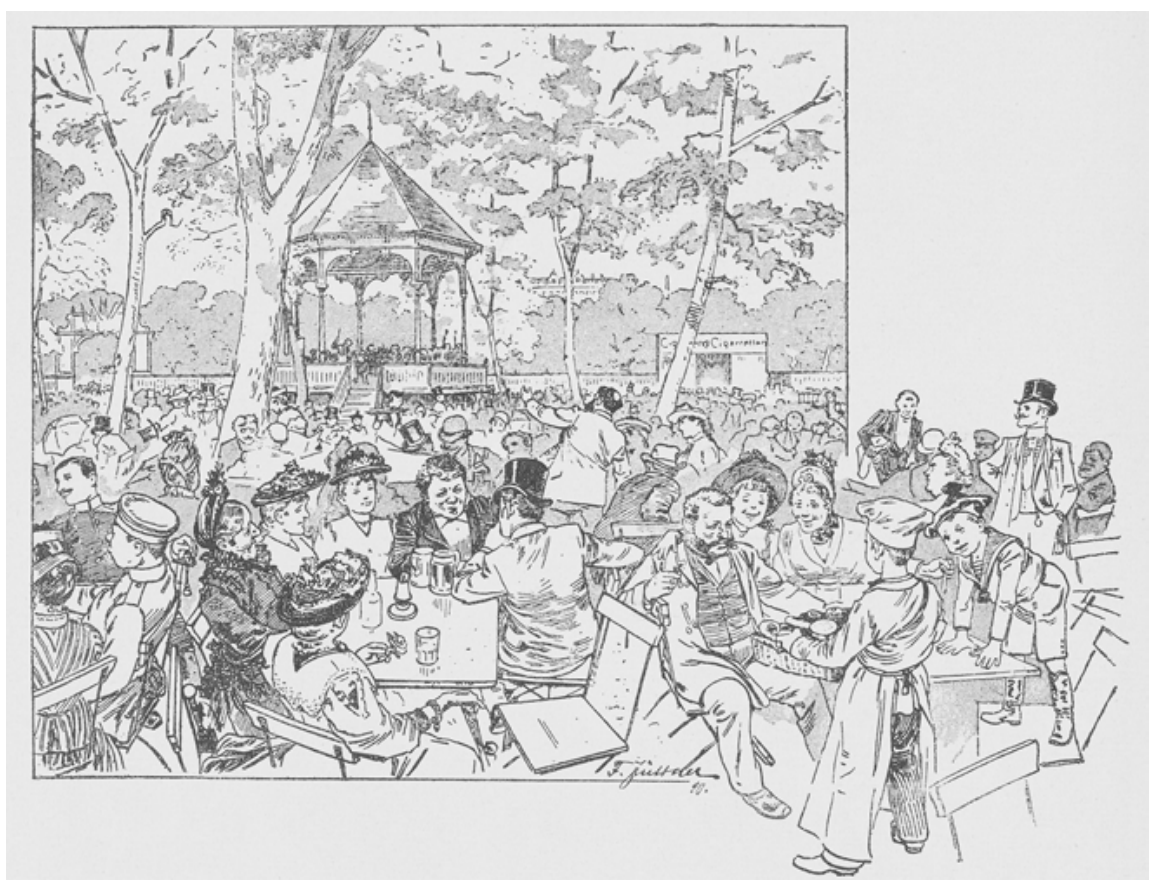

Abb. 21: „Zweites Bild: Volk am Feierabend. Ein Berliner Festtag um die Jahrhundertwende“, [Programmheft], „Glückliches Volk“, Berlin, 1938

gung standen und das Stadion erst mit Hilfe eines Bühnenaufbaus in ein Berliner Gartenlokal ,verwandelt' werden konnte, das allein 30.000.- RM kostete (Abb. 22).

Das 3. Bild zum Thema „Volk in Leibesübungen“ widmete sich der nationalistischen Verklärung des „Ersten Deutschen Turn- und Jugendfest[s] zu Coburg 1860“ (Abb. 23). Gemäß Niedecken-Gebhards Regiekonzept „Theater auf dem Theater", das als kommentiertes Zwischenspiel über die Verdoppelung der dramatischen Handlung auf der Bühne eine selbstreferentielle Funktion übernahm, sollte die Gründung der „deutschen Turnerschaft“ durch eine „geschichtlich getreue Darstellung“ widergespiegelt werden:

„Der heutige Zuschauer soll von den großen Ideen dieser früheren Turnbewegung ergriffen werden, und die hinreißende Gewalt der Ansprache durch den Begründer der deutschen Turnerschaft [Karl Kallenberg] muß jedem zum Bewußtsein bringen, daß aus dem Grundgedanken auch das hohe Ziel der politischen Einigung der deutschen Stämme erwachsen ist." ${ }^{180}$

180 Ebd., 3. 


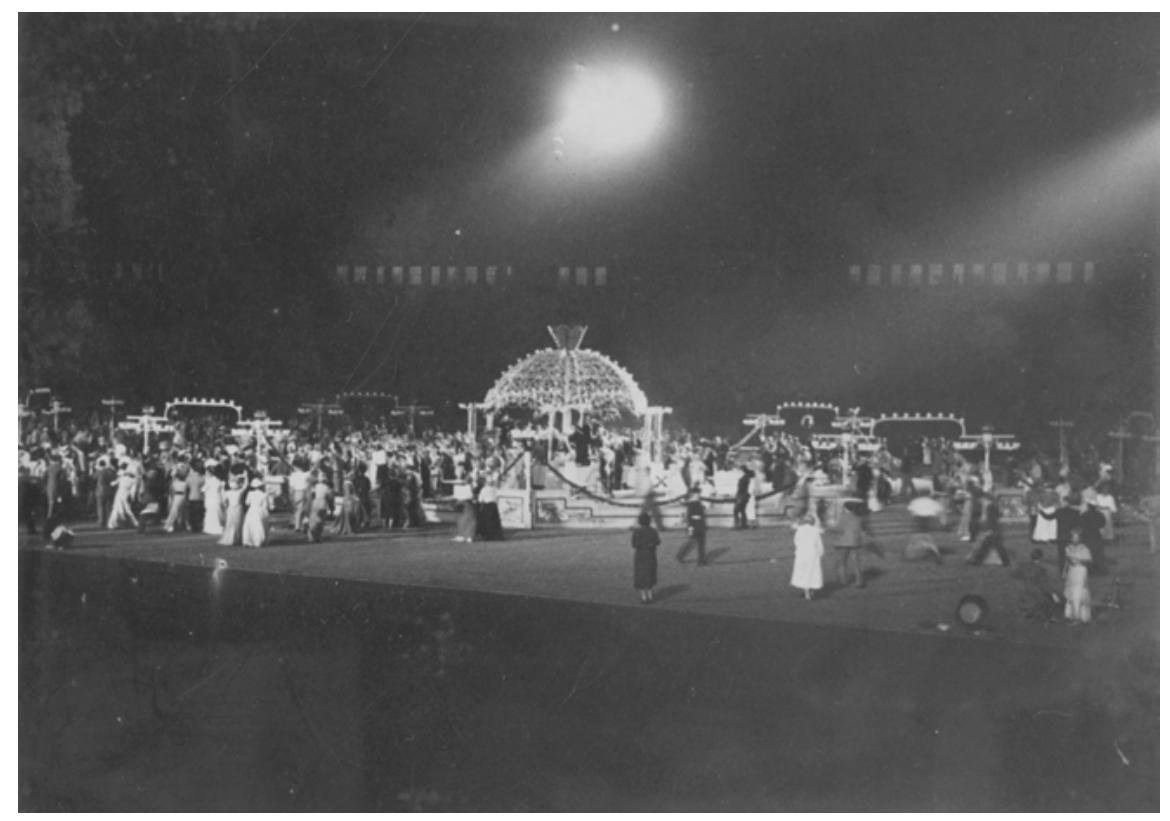

Abb. 22: „Zweites Bild: Volk am Feierabend. Ein Berliner Festtag um die Jahrhundertwende“, [Tableau vivant des 2. Festspielbilds], „Glückliches Volk“, Berlin, 1938

Karl Kallenbergs (1825-1900) Rede von 1860 stand in der Tradition der sogenannten „Feuerrede“ am Wartburgfest von 1817, einem scheinbar unpolitischen Turnfest der „Vormärz“-Bewegung. An diesem Fest fand neben Fackelumzügen auch eine Bücherverbrennung statt, bei welcher, in Referenz zu Martin Luthers Verbrennung der Päpstlichen Bulle von 1520, ,undeutsche‘ Literatur verbrannt wurde. Mit Kallenbergs „Ruf zur Sammlung“ wurde die Wiedergründung deutscher Turn- und Sportvereine nach deren kurzzeitigem Verbot anlässlich des „Ersten deutschen Turn- und Jugendfest[s]“ in Coburg 1860 gefeiert. Dieses Turnund Jungendfest geriet zur nationalistischen Massenveranstaltung, welche die „politische Einigung der deutschen Stämme“ ${ }^{\text {"181 }}$ symbolisch vorweg zu nehmen schien. ${ }^{182}$

Das Ziel dieses kommentierenden Zwischenspiels im Festspiel war, das historische Entwicklungsnarrativ von der Gründung der "deutschen Turnerschaft“ über den „Reichsgedanken“ einer „politischen Einigung der deutschen Stämme“

181 Vgl. Niedecken-Gebhard, Regiebuch, 3.

182 Vgl. Bergmann 2009, Ulfkotte 2014. 


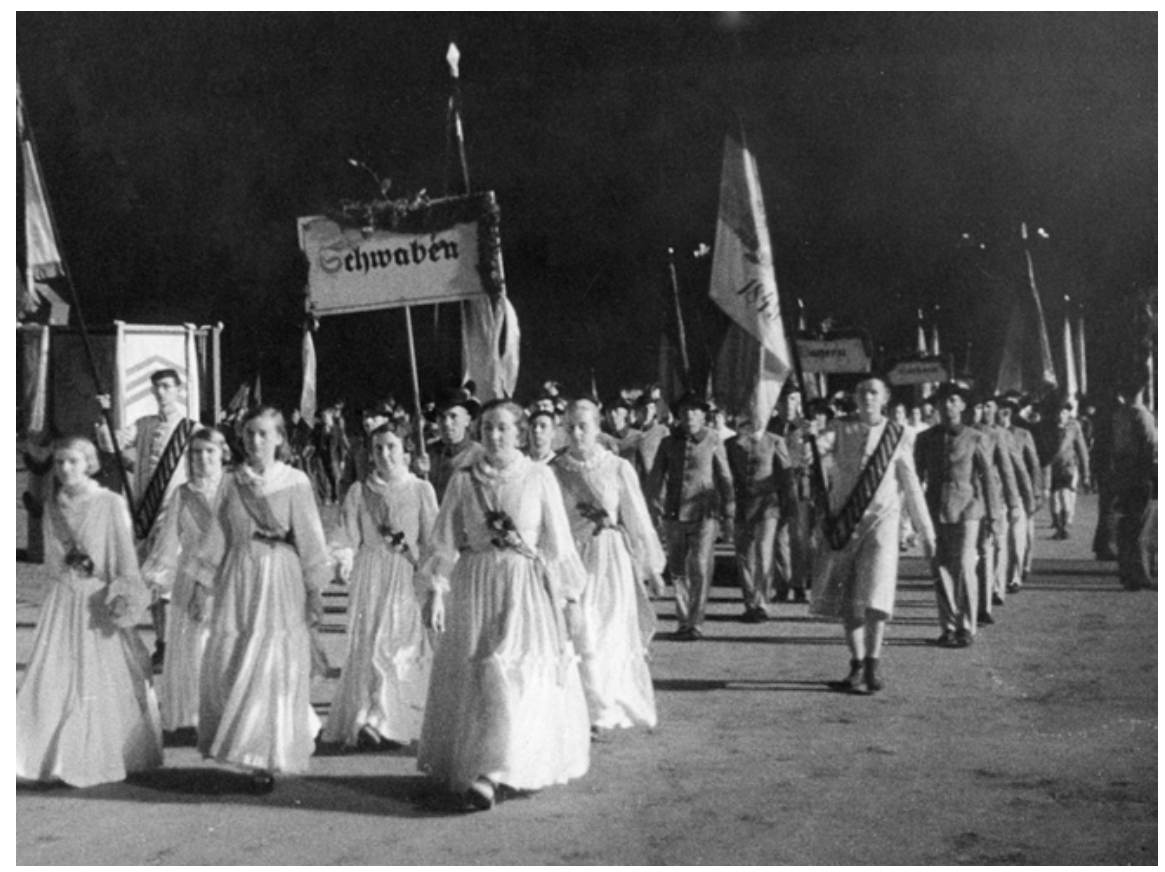

Abb. 23: „Probe zum Festspiel Glückliches Volk im Berliner Olympiastadion. Die Darsteller stellen den Einmarsch des Coburger Turnfestes von 1860 dar. Vorne die Ehrenjungfrauen“, [Originaler Fototext], [Tableau vivant des 3. Festspielbilds „Das erste deutsche Turn- und Jugendfest zu Coburg 1860“], Berlin, 1938

bis zum aktuellen „Anschluss“ Österreichs an „das Großdeutsche Reich“ darzustellen.

Der historische Kontext der deutschen Turnerbewegung ist für eine quellenkritische Analyse des Festspiels aufschlussreich: 1811 errichtete der sogenannte „Turnvater“ Friedrich Ludwig Jahn (1778-1852) den ersten Turnplatz in Berlin. Jahn sprach sich zeitlebens für eine politische Nationenbildung aus. Die deutsche Turnerbewegung war seit ihrer Entstehung nicht nur eine sportliche Vereinigung, sondern auch eine politisch-bürgerlich-nationale Vergemeinschaftung in Form einer Burschenschaft. Nach der Reichsgründung 1871 traten nationalistische Aspekte vorerst in den Hintergrund. In den 1920er Jahren griff die NS-Bewegung den nationalistischen Sportsgeist der Turnerbewegung wieder auf und legte diesen ideologisch als einen Gründungsmythos für ihre Legitimationsstrategie einer 
rassistisch-paramilitärisch konzipierten Körperkultur aus. ${ }^{183}$ Die historischen Gemeinsamkeiten und Unterschiede zwischen der deutsch-nationalen Turnerbewegung und den Sportveranstaltungen im NS-Regime sind von der Geschichtswissenschaft in den letzten Jahren eingehend erforscht worden. ${ }^{184}$

Die Ausstattung des Coburger-Bilds im Festspiel „Glückliches Volk“ wurde aus dem Breslauer Festspiel, das im Mai 1938 stattgefunden hatte, entnommen. Dieses hatte, Niedecken-Gebhard zufolge, unter der Parole „Ein Volk in Leibesübungen“ denselben „rassenideologischen“ Expansionsgedanken einer militärstrategischen „Einigung Deutschlands“ durch die Annexion Österreichs als „wichtiges Zeitgeschehnis“ gefeiert wie das Festspiel „Glückliches Volk““. ${ }^{185}$

Die Gegenüberstellung des 4. Bildes „Volk in Leibesübungen“ vollzog einen teleologisch konstruierten Zeitsprung von 1860 ins Jahr 1938, indem es ein sporthistorisches Entwicklungsnarrativ vom „Ersten deutschen Turn- und Jugendfest in Coburg“ $1860 \mathrm{zu}$ den „[T]urnerisch[en] Vorführungen der Berliner Schuljugend“ entwarf. Im Programmheft wurde dem Publikum das Bild emotionspolitisch gedeutet:

„Die Übungen der Berliner Schuljugend sind nicht nur ein Ausdruck an Genauigkeit, an Anmut und Schönheit der Bewegungen. In seinem Überschwang an Jugend und Kraft ist das Ganze zugleich eine Kundgebung wieder erblühter deutscher Volkskraft.“186

Das Bild sollte im Sinne einer affirmativen Körperpolitik und der NS-Arbeitsmoral „Kraft durch Freude“ die Gefühlskultur des selbstdisziplinarischen Jugendtypus im Nationalsozialismus vorführen. Die leistungsorientierte Selbstdarstellung sollte das Publikum autosuggestiv emotionalisieren. Die Wirkungsmacht der synchronen Bewegungschoreografien der Turnerformation, die sich als „Massen in geformten Bewegungen“187 (Abb. 24) präsentierten, sollten bei den Zuschauerinnen den autosuggestiven Wunsch wachrufen, die körperpolitische Selbstdarstellung des „Ideal[s] körperlicher Ertüchtigung“, welches „als Glaubensbe-

183 Zum Wartburgfest vgl. Hecht 2011.

184 Vgl. u.a. Pfeiffer 2015, Gand 2016.

185 Niedecken-Gebhard hatte zu Beginn der Verhandlungen sogar vorgeschlagen, das Festspiel „Volk in Leibesübungen“, welches für Breslau geschaffen worden war, als Wiederaufnahme in Berlin aufzuführen, um Kosten zu sparen. Aus „Prestige-Gründen“ wurde dieser Vorschlag jedoch abgelehnt. Niedecken-Gebhard, Bericht über die Durchführung, 4.

186 „Glückliches Volk“. Festspiel im Olympiastadion 18. bis 28. August 1938. Berliner Sommerfestspiele, veranstaltet von der Reichshauptstadt, Gesamtspielleitung: Dr. Hanns NiedeckenGebhard, Programmheft, [14]. [Abk: „Glückliches Volk“, Programmheft]

187 Niedecken-Gebhard, Bericht für Wiederaufführung, 2. 


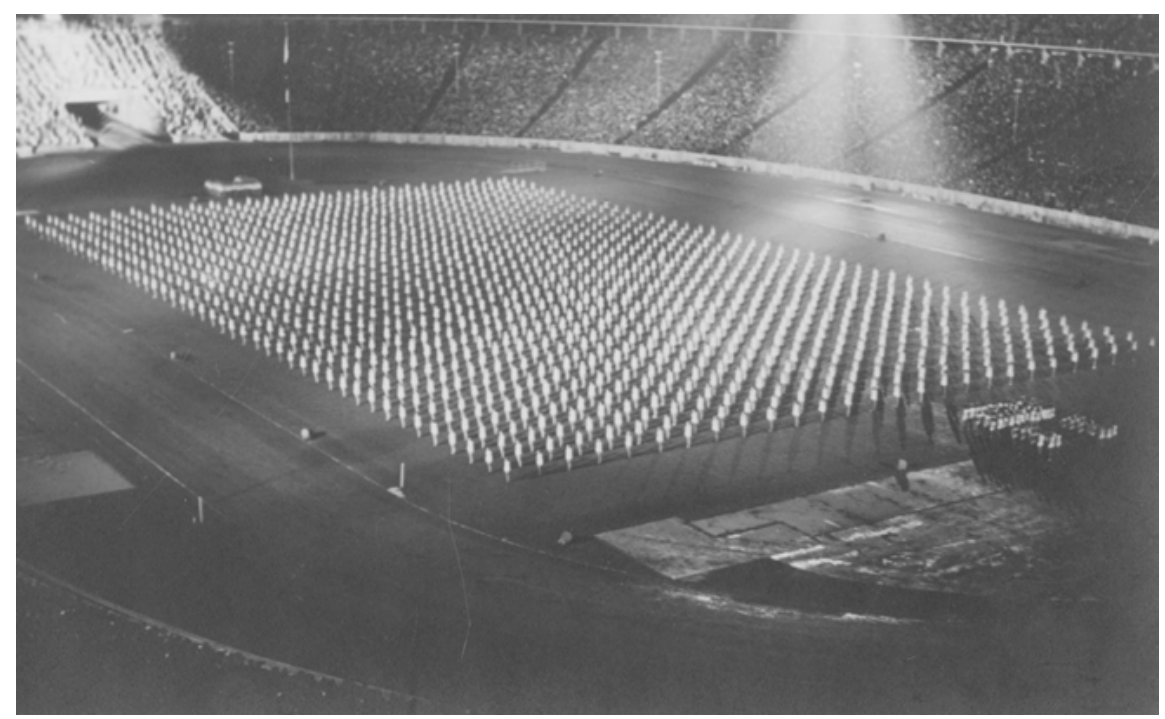

Abb. 24: [Viertes Bild: „Volk in Leibesübungen. Turnerische Vorübungen der Berliner Schuljugend“], [Programmhefttext zu 4. Festspielbild], „Glückliches Volk“, Berlin, 1938

kenntnis unserer völkischen erwachten Gemeinschaft in unseren Tagen“ scheinbar „verwirklicht wurde“, nachzuahmen. ${ }^{188}$

Die Festspielleitung hatte geplant, die Berliner Schuljugend als Laienspieler*innen für das 4. Bild zu mobilisieren. Da die städtischen Behörden jedoch den Wunsch äußerten, möglichst keine Schulen miteinzubeziehen, wurde die Bildbesetzung ein Problem. KdF hatte sich zunächst zur Bereitstellung von „Werkscharen“ verpflichtet, doch aufgrund eines Verbots durch Robert Ley, „Werkscharen ausserhalb ihrer Betriebe einzusetzen“, konnte KdF keine Laiendarsteller`innen zur Verfügung stellen. ${ }^{189}$ Verhandlungen mit der SA scheiterten aufgrund der finanziellen Forderungen der SA-Führer. Während das „Deutsche Turn- und Sportfest“ in Breslau erfolgreich durchgeführt werden konnte, fanden parallel Verhandlungen mit dem „Reichsarbeitsdienst“ (R.A.D) statt. R.A.D. erklärte sich bereit, die Besetzung des „moderne[n] Sportbild[s]“ mit 400 „Arbeitsmaiden“ und 400 Männern zu übernehmen. Am 2. August kam jedoch die Absage durch die „Reichsführung des Arbeitsdienstes“ mit derselben Begründung wie schon bei den „Werkscharen“. In letzter Minute konnte „Ober-

188 Vgl. Niedecken-Gebhard, Regiebuch, 3.

189 Vgl. Niedecken-Gebhard, Bericht über die Durchführung, 2. 
turnrat“ Rabenhorst überredet werden, das Bild mit Turner`innen zu bespielen. Der „Völkische Beobachter“ berichtete dennoch von der „Berliner Schuljugend beim Festspiel im Olympia Stadion“, wohl um den ,schönen Schein` zu wahren. ${ }^{190}$

Das 5. Bild sollte eine „Truppenschau von den Anfängen der Wehrhaftigkeit des deutschen Volkes bis zur modernen Wehrmacht“ darstellen. Nach zähen Verhandlungen erteilte die „Wehrmacht“ Ende Juni eine definitive Absage der Teilnahme. So musste mit einer Besetzung aus Laiendarsteller*innen ausgeholfen werden, damit das Publikum ,ihre‘ Soldaten des Dreißigjährigen Kriegs, der Friederizianischen Infanterie, der „Ziethenhusaren“, der „Landwehr der Freiheitskriege“, der „Lützower Jäger“ sowie des Deutsch-Französischen Kriegs 1870/ 71 zu Fuß und zu Ross im Stadion zu sehen bekam. Der historische Kontext des Bilds „Wehrhaftes Volk“ wurde den Programmleser^innen folgendermaßen erklärt:

\begin{abstract}
„Der deutsche Geist und das deutsche Heer haben die Jahrhunderte überdauert. Immer wieder durchbrachen sie in den Zeiten der Zerrissenheit und des Niedergangs alles Dunkle, das sich um die Nation gelegt. Das deutsche Heer siegte auf den Schlachtfeldern gegen seine Feinde. Der deutsche Geist siegte in den Seelen. Niemand wird ohne Ergriffenheit die Soldaten von einst vorüberziehen sehen. Die Söhne des Volkes, die jederzeit bereit waren zu sterben, damit das Vaterland das heilige, lebe.“191
\end{abstract}

Die Sakralisierung der „Wehrhaftigkeit“ des „Volkes“ zur Beschreibung eines scheinbar überzeitlichen „deutschen Geistes“, der sich symbolisch im vorbeiziehenden männlich stereotypisierten Soldatentum der „deutschen“ Militärgeschichte manifestierte, hatte eine emotionspolitische Funktion. Dieses Bild eines „wehrhaften Volkes“ sollte beim Publikum in einer gemeinschaftsstiftenden „Ergriffenheit“ Nationalgefühle von „Stolz“ und „Ehre“ auslösen und neben dem rassistischen Verbrüderungsgedanken eines „deutschen Volkes“ auch die ideologische Einheit zwischen „Volksgenossen“ und ,ihren“ Soldaten, den „Söhnen des Volkes“, betonen. Diesem 5. Bild lag, im Sinne von Bacons „Idola theatri“, die Idee eines scheinbar historischen Entwicklungsprozesses zugrunde. Dieser zeigt sich im 1. und 2. Bild („Volk am Feiertag“), einer „völkercharakterologischen“ Feier- und Vergnügungskultur, über das 3. und 4. Bild („Volk in Leibesübungen“), einer leistungsorientierten Körperkultur, bis hin zu einer totalitären Militarisierung der ,wiedervereinten“ „Volksgemeinschaft“ als „wehrhaftes Volk“ im 5. Bild.

Im Schlussbild propagierte das Festspiel „Glückliches Volk“ eine nationalsozialistische Gefühlspolitik nicht als utopischen Wunsch, sondern als einen

190 Vgl. Tägliches Beiblatt zum „Völkischen Beobachter“, Ausg. 236, 24.08.1938, [Titelseite]. 191 „Glückliches Volk“, Programmheft, [16f.]. 
scheinbar sowohl auf der Bühne als auch in der Realität wahrgewordenen IstZustand. Im Regiebuch wird die Schlussszene und deren „tiefere[...] Bedeutung“ wie folgt erläutert:

\begin{abstract}
„Als Sinnbild der Freude des ,Glücklichen Volkes‘ tanzen Hunderte von Tänzerinnen mit hinreißendem Schwung im weiten Rund des Stadions einen der großen deutschen Walzer, nämlich Johann Strauß’, an der schönen blauen Donau'. In diesen befreienden Jubel klingt das Spiel voll Heiterkeit und tieferer Bedeutung zu einem wahrhaft festlichen Erlebnis für alle Zuschauer aus.“192
\end{abstract}

Im Rückgriff auf Sterns drei Grundfunktionen des Festspiels kann mit Bezug auf Niedecken-Gebhards Dramaturgie und Regiekonzept im Kontext der NS-Theaterpolitik festgehalten werden, dass die emotionspolitische Sendung des Festspiels sowohl eine „enkomiastisch-verklärende“, „utopisch-verheißende“ als auch eine „realitätsbezogene“ Funktion verfolgte. Ob die Sendung der Realität standhalten konnte, muss bezweifelt werden. Die satirische Festspielfunktion als gesellschaftskritischer, ironisierender Kommentar kam auftragsgemäß im Sinn der totalitären NS-Theaterpolitik nicht vor. Aus Furcht vor Opposition unterband das Regime diskursive Vielstimmigkeit und untersagte eine kritische Auseinandersetzung mit der Gegenwart auf der Bühne. ${ }^{193}$

Ausgehend von diesem Fallbeispiel muss eine weitere Funktion hinzugefügt werden, welche die „rassenhygienische“ Propagandafunktion des Festspiels beschreibt. Diese wird, insbesondere im Abschlussbild „Glückliches Volk“, im scheinbar wohlwollenden Akt der Verbrüderung Österreichs mit NS-Deutschland dargestellt. Diesem imaginierten Zusammengehörigkeitsgefühl, das seine Wirkungsmacht durch die beschwingte Wiener Walzermusik und die schwebenden Tanzformen auf der Bühne unter „befreiende[m] Jubel“194 beim Publikum entfalten sollte, liegt ein rassistischer Wir-Gedanke und ein antisemitisches Konzept Der Anderen zugrunde. Dieser emotionspolitische Ansatz der euphemistischen Festspielpolitik Niedecken-Gebhards wird im Programmheft anhand des Ab-

192 Niedecken-Gebhard, Regiebuch, 3. Vgl. auch Szenenanweisung: „Glückliches Volk. Sechstes Bild. Künstlerische Leitung: Dorothee Günther mit Gertrud Ganßauge. Ausführende: 334 Tänzerinnen. ,An der schönen blauen Donau‘ Große Walzerszene. Beim Ausblenden sind Hunderte von jungen Mädchen in langen weiten Kleidern im ganzen Rund des Stadions aufgestellt und tanzen Johann Strauß’ An der schönen blauen Donau. Die Szene gestaltet sich zu einem mitreißenden, den gesamten Raum umspannenden Tanz." Niedecken-Gebhard, Regiebuch, 23. 193 Zur NS-Theaterästhetik s. Kap. 15. Ein Vergleich mit der Schweizer Festspielästhetik wird in Kap. 16.6. vorgenommen. Zum satirischen Kommentar auf der Bühne zur Zeit der Weimarer Republik s. Kap. 9.4.

194 Niedecken-Gebhard, Regiebuch, 3. 
schlussbildes deutlich, in welchem Hitler in christlicher Analogie als „Schöpfer“ eines ,wiedervereinten“ „großen deutschen Vaterland[s]“ gefeiert wird:

\begin{abstract}
„Da schwingt die volle Lust am Leben mit, die Dankbarkeit an den Schöpfer, die Liebe zu einer wunderschönen Heimat, die nun zum großen deutschen Vaterland zurückgekehrt ist. Wenn die Lichter im Stadium ringsum erglühen, tanzen unser aller die Herzen heimlich mit. Einen schöneren Abschluss für dieses ,Berliner Sommerfestspiel 1938‘ kann es nicht geben." ${ }^{195}$
\end{abstract}

Das Festspiel sollte auftragsgemäß auf eine politische Kundgebung verzichten. Die Untersuchung des Festspiels unter der Perspektive einer Politik der ,Glückskulturen' hat jedoch gezeigt, dass sowohl die militärische Expansionsparole „Heim ins Reich“, im Kontext der Annexion Österreichs, als auch die „rassenhygienische“ Selbstdarstellung der leistungsorientierten Körperkultur und der selbstdisziplinarische Mobilisierungsappel zur totalitären Militarisierung eines wiedervereinten „Deutschen Volkes“ politische Propaganda waren. Die Festspielaufführung „Glückliches Volk“ stand im Dienst der Politik einer nationalsozialistischen, Glückskultur‘.

Im Folgenden wird Niedecken-Gebhards Festspielgestaltung im Kontext seiner theaterwissenschaftlichen Festspieltheorie und der Gefühlspolitik der NSTheaterpolitik wissenshistorisch untersucht und kontextualisiert.

Der „Festspiel-Gedanke“ sei in NS-Deutschland „lebendig“, hielt NiedeckenGebhard am 25. Februar 1938 in seiner Konzeption für das Festspiel „Glückliches Volk“ fest. ${ }^{196}$

„Und in der Tat bedeutet es für unsere Zeit die Erfüllung eines natürlichen Wunsches, dass die grossen Sportarenen, in denen Abertausende von Volksgenossen zusammenströmen, als Spielstätte für festliche Veranstaltungen genützt werden, in denen Abertausende zu einem grossen Gemeinschaftserlebnis zusammengerufen werden. Es bahnt sich hier eine Entwicklung an, in der folgerichtig aus Bedürfnis und Nachfrage ein neuer monumentaler Stil festlicher Gestaltung sich herausbilden wird.“197

Niedecken-Gebhard definiert seine theaterästhetische Festspielgestaltung als eine emotionspolitische Bedürfnisbefriedigung eines Konglomerats von affirmativen Nationalgefühlen, welche als „große[s] Gemeinschaftserlebnis“ für „Abertausende von Volkgenossen“ erfahrbar gemacht werden könnten. Um das Publikum emotionspolitisch zu ergreifen, brauche es einen „neue[n] monumen-

195 „Glückliches Volk“, Programmheft, [18].

196 Vgl. Niedecken-Gebhard, Bericht für Wiederaufführung, 1.

197 Ebd., 1f. 
talen Stil festlicher Gestaltung“, an dessen Entwicklung der Theaterwissenschaftler aktiv beteiligt war.

Was verstand der Regisseur unter „monumentale[m] Stil“ und wie sollte dieser ein emotionspolitisches „Gemeinschaftserlebnis“ bewirken? Kennzeichnend für Niedecken-Gebhards Festspielregie waren laut Evelyn Annuß einerseits ornamentalisch und musikalisch begleitete Bewegungschoreografien, die als „stumme Kollektivchoreografie“198 auftraten, und andererseits Nummernrevuen und über Lautsprechanlagen eingespielte Zitate, die aus Hörspielen und Rundfunksendungen bekannt waren. Beeinflussen ließ sich Niedecken-Gebhardt vom Revue- und Propagandafilm. Davon zeugen seine Lichtdramaturgie, die Einspielung von Zitaten sowie die Vogelperspektive auf das Bühnengeschehen. Die von Niedecken-Gebhard oft angewandte Konstruktion einer ovalen Publikumstribüne ging auf die architektonische Form des antiken Amphitheaters zurück. ${ }^{199}$

Bezogen auf die theaterästhetische Konzeption „Glückliches Volk“ schrieb der Festspielautor und Regisseur:

\footnotetext{
„Über die reine Schau und blosse Revue hinaus erwächst aus den Komponenten: Massen in geformten Bewegungen, Einzelsprechern, Gesangschören, Musik, Licht und vor allem Farbkomposition bunter Kostüme und Trachtengestaltung eine künstlerisch zu verantwortende und künstlerisch zu betreuende Massendarbietung, die des lebendigsten Wiederhalls bei allen Zuschauern sicher ist.“200
}

Eine „magische Wirkung“ gehe von der „Massendarbietung“ im Olympiagelände aus, welche gemeinsam mit einem „monumentalen“ Regiestil „lebendigsten Wiederhall bei allen Zuschauern“ verspreche. ${ }^{201}$ Niedecken-Gebhard hatte über die Jahre ein Gespür dafür entwickelt, wie er, entsprechend der jeweiligen architektonischen Struktur eines Festspielgeländes, seinen Regiestil den räumlichen Gesetzmäßigkeiten anpassen musste, damit die einzelnen theaterästhetischen und dramaturgischen Elemente miteinander ,harmonisierten'. Was war damit gemeint? Niedecken-Gebhards Konzept einer gemeinschaftsstiftenden Festspielerfahrung aus der theaterästhetischen Verbindung zwischen Festspielinhalt, Theaterregie und Architektur wird dem Publikum in theaterhistorischer Kontinuität zum antiken Amphitheater als ,neuer“, „völkisch-“ „monumentaler Stil“" erklärt:

198 Vgl. Annuß 2015, 202.

199 Vgl. Annuß 2015, 202.

200 Niedecken-Gebhard, Bericht für Wiederaufführung, 2. [Die Durchstreichung ist dem Original entnommen].

201 Vgl. ebd., 4. 
„Wo könnte in gleich würdigem Rahmen ein so breiter, weiter und bunter Teppich fröhlichen Volkslebens entfaltet werden, in den viele tausend Figuren eingewebt sind? Denn das geschieht in dem Festspiel von 1938 ,Frohes, freies, glückliches Volk‘. Das Spielfeld der Fröhlichkeit umstehen die monumentalen Bauten des Stadions. Auf den Sitzreihen sind, wie einst im alten Hellas, die Scharen der Zuschauer vereint.“202

In seinem Vortrag „Aufgaben und Probleme monumentaler Festspielgestaltung“, den Niedecken-Gebhard am internationalen Kongress für Singen und Sprechen am 13. Oktober 1938 in Frankfurt a. Main hielt, nennt der Theaterwissenschaftler vier Merkmale seines „monumentalen“ Festspielstils:

„This [new style of festival play production] is determined by the space in which the performances are given.

1. The open-air natural theatre demands to the utmost a corresponding naturalness in the performance.

2. The open-air stage created by the mutual harmonization of architecture and landscape (e.g. Dietrich Eckart open-air theater in Berlin) has its own quite special intrinsic laws.

3. In places of festivals constructed on purely architectonic lines, a strict coherence and stylization of presentation should be striven after.

4. Performances in the arena of a stadium, in which the audience has to be faced on all sides at once, have to be carried out according to entirely new laws which have nothing more to do with ordinary theatrical production. “203

Der „monumentale“ Festspielstil werde im Wesentlichen vom Raum bestimmt, in welchem die Aufführung stattfände. Die ,neuen` Gesetze, nach welchen sich ein Festspiel in einer Arena ausrichten müsste, bezögen sich 1. auf die Dramaturgie, 2. auf die Aufgabe der Musik, 3. den Einsatz großer Gesangschöre sowie 4. auf die Wichtigkeit audiovisueller Installationen. Die Festspieldramaturgie musste auf die Raumdimension und deren architektonische Determination abgestimmt werden. Darin sah Niedecken-Gebhard keinen Makel, sondern eine Chance für einen größeren Handlungsspielraum betreffend innovativer, multimedialer Regieeinfälle: „The determining factor is the space embraced by the stage and auditorium. The twentythousandth spectator must be able to take in directly all he

202 „Glückliches Volk“, Programmheft, [5].

203 Niedecken-Gebhard, „The task and problems of monumental festival play production“, 13.10.1938, Internationaler Kongress für Singen und Sprechen, Frankfurt a. Main, 09.-16.10.1938, Summaries from Lectures (englisch), 35f., Nachlass Niedecken-Gebhard, TWS. [Abk.: NiedeckenGebhard, Problems and Tasks, 13.10.1938]. 
sees and hears. “204 So könne eine Einzelstimme, die mit einem Mikrofon von der Mitte der Arena aus über Lautsprecher zum Publikum spreche, auch in einem Stadion eine effektvolle Wirkungsmacht erzeugen, indem sie beispielsweise aus dem Dunkeln heraus spreche oder nur ein Scheinwerfer auf den/die Sprecher`in gerichtet eingesetzt würde. ${ }^{205}$,Neu' waren diese theaterästhetischen Konzepte der emotionspolitischen Bewegungsregie, welche auf massen- und „völkerpsychologischem“ Glückswissen aufbauten, nicht, wie in Kapitel 15 in Bezug auf die theaterwissenschaftlichen Arbeiten u. a. bei Max Herrmann und Oskar Eberle und die Festspielaufführung von Hendrik de Man (Kap. 16.3) gezeigt wurde.

Das folgende Analysebeispiel des 3. Bilds über das „erste Turn- und Jugendfest der Deutschen 1860 in Coburg“ kann anhand des auf theaterwissenschaftlichem Wissen basierenden Regiekonzepts Niedecken-Gebhards, mit Blick auf die Rede des Begründers der „Deutschen Turnerschaft“, Karl Kallenberg, aufzeigen, wie und zu welchem Zweck affirmative Nationalgefühle theaterästhetisch evoziert werden sollten.

Den Anweisungen des Regiebuchs zufolge richtete sich der Sprecher Gunther Nauhart aus dem „Dunkeln“ heraus mit folgenden Worten an das Publikum, während er von Eduard Griegs „Huldigungsmarsch“ musikalisch begleitet wurde: „Wir laden feierlich alle deutschen Turner zu unsrem [sic] Turn- und Jugendfeste in Coburg im Jahr 1860 ein!“ Gemäß dem Regiekonzept „Theater auf dem Theater“ stellte sich Niedecken-Gebhard das Bild wie folgt vor:

\footnotetext{
„Im Dunkeln ist in der Mitte des Rasenfeldes ein rechteckiger Festplatz mit Girlanden abgesteckt; auf ihm die für das historische Turnen erforderlichen Geräte (Barren, Pferd, Reck, ein Leitergerüst). Auf der Seite der Führerloge eine mit Blumen geschmückte Rednerkanzel, auf dem Westsektor eine Ehrentribüne. Vor dem Marathontunnel eine Ehrenpforte mit dem Bilde Jahn's durch die der Festzug seinen Weg nimmt.

Beim Aufblenden strömt Volk (40 Kinder, 60 Frauen, 100 Männer, Ordnungspolizei) über die Ost- und Marathontreppe und aus den Auftritten unter der Führerloge herein und bildet, in kleinen Gruppen über das Stadion verteilt, Zuschauer für den nun folgenden festlichen Einzug der Turner.“206
}

Zur Erläuterung des historischen Kontexts des Bildes wurde dem Publikum folgende emotionspolitische Interpretation nahegelegt, die einen aktuellen Bezug zum „Anschluss“ Österreichs implizierte:

204 Niedecken-Gebhard, Problems and Tasks, 13.10.1938, 35.

205 Vgl. ebd., 35.

206 Niedecken-Gebhard, Regiebuch, 15. 
„Mitte des vorherigen Jahrhunderts. Immer brennender ist die Sehnsucht aller Deutschen nach dem einigen Reich. Wie schon zu Jahns Zeiten war es das Ideal der körperlichen Jugendertüchtigung, das über die Sonderinteressen der Länder hinweg es vermocht hat, die deutschen Stämme, die Schwaben, Bayern, Sachsen, Preußen, Märken, Hessen, Friesen und Tiroler beim ersten Turn- und Jugendfest der Deutschen 1860 in Coburg zusammenzubringen. Diese geschichtliche Begebenheit wird in diesem Festspielbild nach den Originalberichten historisch dargestellt [...].“207

Nachdem die Turner abgetreten waren, sollten die Bannerträger hervorkommen, während die „Festjungenfrauen“ die Fahnen umkränzten. Am Rednerpult hielt Gunther Nauhart in der Rolle Kallenbergs die historische Rede, welche „noch heute einen Klang“ besäße, „der uns tief berührt“:

„Ich grüße euch, Brüder von Ost und West, von Süd und Nord! Wie wir hier sind, aus allen Teilen Deutschlands, sind wir hoffentlich einig im hellen Bewußtsein des Zusammengehörens. Ja, im Anschluss wohnt die Kraft und der Sieg, und siegen muß die gute Sache, denn die kranke Zeit will ein Gegengift, und das Naturwahrste ist Herstellung der Einheit in Leib und Seele, die allgemeine deutsche Turnerei. Waffentüchtig sollen unsere Söhne sein. Wir wollen in ihre Herzen die Liebe für Freiheit und Vaterland und des Lebens höchste Güter pflanzen. Tragen wir bei, was an uns liegt, sammeln und vereinigen wir unsere Kräfte, und daß der Lebensbaum des deutschen Volkes grüne und blühe und mächtig hereinrage in den Völkerfrühling, und stimmt mit ein in den Ruf: ,Heil! Heil dem ganzen ungeteilten Vaterland! Heil Deutschland, unsere[m] Vaterlande! ““208

Eine „Große Verbrüderungsszene“ schloss sich unmittelbar an Kallenbergs Rede an, in welcher die Darsteller`innen gemeinsam in Ernst Moritz Arndts Lied „Was ist des Deutschen Vaterland? [...] Das ganze Deutschland solle es sein!“ von 1813 einstimmten.

Kallenbergs Rede in Verbindung mit dem musikalischen Gesangserlebnis als Gemeinschaftschor war ein emotionspolitischer Appell an das Publikum, sich auf eine zukünftige „rassenhygienisch“ scheinlegitimierte, militärische Expansionspolitik vorzubereiten, die alle „Volksgenossen“ zum Dienst verpflichten würde. „Das glückliche Volk“ wurde emotionspolitisch zum Einsatz im Zweiten Weltkrieg mobilisiert. „Einheit“, „Waffentüchtigkeit“ und „das Heil Deutschlands“ seien vom Nationalgefühl der „Liebe für Freiheit und Vaterland und des Lebens höchster Güter“ getragen. Dieses Nationalgefühl in der Bevölkerung zu verbreiten war ein zentrales, emotionspolitisches Ziel des Festspiels „Glückliches Volk“. Um dieser emotionspolitischen Aufgabe nachzukommen, sei die Gattung Festspiel ein ideales Propagandainstrument, so der Regisseur. In Referenz zu Goebbels’ Wor-

207 „Glückliches Volk“, Programmheft, [12].

208 Ebd. 
ten, „dass der Nationalsozialismus vom Volke her zur Kunst vorstösst und von der Kunst wieder zum Volke zurückführt“, schreibt der Theaterwissenschaftler am 19. November 1938 in seiner NS-ideologisch überarbeiteten Vortragsfassung über die „Aufgaben und Probleme monumentaler Festspielgestaltung“:

„Hier, in dem Grossraum der festlichen Halle, der Freilichtbühne oder der Arena richtet sich das künstlerische Geschehen wirklich an das „Volk“ und aus dem Wiederklang, den es aus dem „Volk“ erfährt, erhält das Spiel seine Kraft, seine Wesensberechtigung, seine Bejahung. Aus dem einheitlichen Rund der Tausende[n] erwächst die wahrhafte Gemeinschaft der Zuschauer, die ohne Unterschied von Rang und ,Rängen' das grosse, umspannende ,Gemeinschaftserlebnis‘ an sich erfährt." ${ }^{\text {(209 }}$

Eine autosuggestive Emotionalisierung und individuelle Einwilligung zur selbstdisziplinarischen Ausübung der nationalsozialistischen Lebensführung versuchte Niedecken-Gebhard in seinem Verständnis von „Theater als Künderin sittlicher Ideen“210 über die theaterästhetische Wirkungsmacht der Festspielaufführungen bei den Zuschauenden auszulösen.

Ein weiteres Ziel, welches Niedecken-Gebhard verfolgte, war, die „völkische“ Zusammengehörigkeit nicht nur darzustellen, sondern als „Gemeinschaftserlebnis“211 für sämtliche Laiendarsteller`innen als Teil der kollektivistischen „Spielgemeinschaft“ individuell erfahrbar zu machen (Abb. 25).

Die emotionspolitische Wissenszirkulation eines theaterästhetischen $\mathrm{Zu}$ sammengehörigkeitsgefühls zwischen mitwirkenden Berufs- und Laiendarsteller`innen sowie den beobachtenden Zuschauenden als verklärtes Symbol der „NS-Volksgemeinschaft“ beschrieb der Spielleiter im Programmheft wie folgt:

\footnotetext{
„Aber die da unten tanzen, jubeln, turnen, marschieren in Kostümen einer verklungenen Zeit sind keine Schauspieler und keine Schauspielerinnen. Wer da in Gemeinschaft mit Schauspielern und Tänzern so vergnügt mittut im Landsknechtshabit, im Biedermeiergewande, im Turnerkleid von 1860, in der seltsamen, üppigen Frauentracht und der ein wenig komischen Männerkleidung um die Jahrhundertwende - wer also da ,auftritt ‘ ist, sozusagen aus den Reihen des Publikums herabgestiegen, hat sich einen schönen Bart geklebt, hat sich kräftig geschminkt und wohl gepudert, wo es am Platze ist, um den Zuschauern und sich selbst einen trefflichen Spaß zu machen! Dazu kommen Männer des NSKK und Hunderte von Schülern und Schülerinnen der Berliner Schulen, die zeigen werden, von welchem Geist und von welcher Fröhlichkeit die Leibesübungen im Jahr 1938 beseelt sind.“212
}

209 Niedecken-Gebhard, Aufgaben und Probleme, $1 \mathrm{f}$.

210 Ebd., 2.

211 Ebd.

212 „Glückliches Volk“, Programmheft, [5]. 


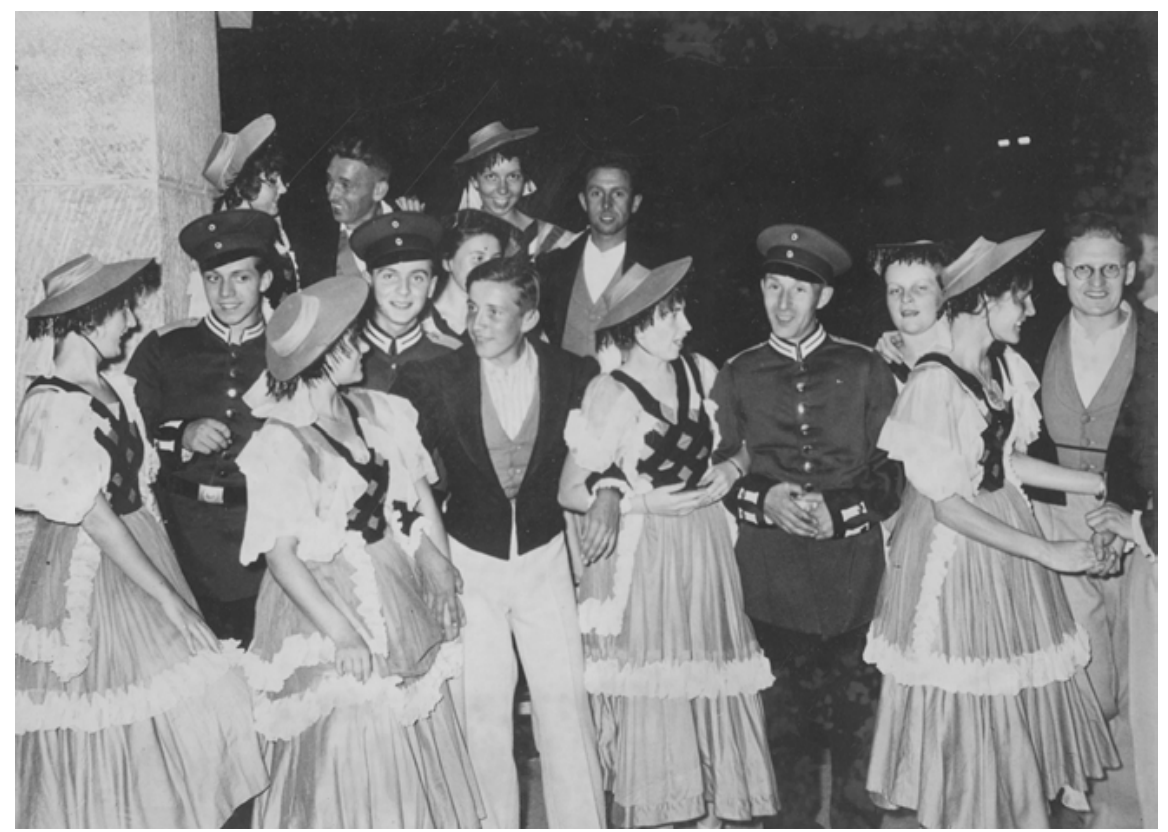

Abb. 25: „Gemeinschaftserlebnis der Spielgemeinschaft“, [Originaler Fototext], „Glückliches Volk“, Berlin, 1938

In einem Aufsatz über „Spielgemeinschaft und Regisseur. Frohe Erwartungen“ erläutert Niedecken-Gebhard in seiner Doppelrolle als Theaterwissenschaftler und Regisseur die Bedeutung der nationalsozialistischen Festspielgestaltung:

„Die besondere Aufgabe der nationalen Festgestaltung ist die alte Aufgabe der Gemeinschaftsregie, der Leitung und Vereinigung von bewegten Massen, die organische Belebung von agierenden Körperschaften, die Erweckung und Gestaltung eines einheitlichen Erlebnisses, das der Teilhabe am festlichen Spiel entspringt, das dem Leben in der Volksgemeinschaft seinen Ausdruck verdankt und ihm wiederum seinen Sinn immer aufs Neue verleiht. Wer in dieser Auffassung dem Theater gedient hat, muss heute glücklich sein $[\ldots]$. “213

213 Niedecken-Gebard, Spielgemeinschaft und Regisseur. Frohe Erwartungen, o. D., Typoskript, Nachlass Niedecken-Gebhard, TWS. [Abk.: Spielgemeinschaft und Regisseur. Frohe Erwartungen], 2. 
Niedecken-Gebhard sah sein Ideal einer Festspielgestaltung, welche der nationalsozialistischen Lebensführung in der „Volksgemeinschaft“ zum theaterästhetischen Ausdruck verhelfe, bereits verwirklicht:

„Was unsere tiefste Sehnsucht war: dass das Volk im festlichen Festspiel sich selbst darstellt und sich selbst findet, das wird nun in weitem Grundriss geplant und ermöglicht.“214

Wie entfaltete sich Niedecken-Gebhard zufolge die theaterästhetische Wirkungsmacht einer affirmativen Gefühlspolitik in der NS-Festspielästhetik?

„[...] es handelt sich immer um das Zusammenarbeiten von Einzelspielern, Spielchören, Bewegung und Musik, Raumbild und Zuschauerschaft; aus dem Ineinandergreifen der Kräfte, aus dem Kreislauf der Wirkungen nur erwachsen die wahren Erschütterungen, die reinigend und stählend über die Gemeinschaft der Spieler und Hörer hingehen.“215

Die NS-Festspielästhetik könne, Niedecken-Gebhard zufolge, durch „wahre Erschütterungen“ eine Katharsis auslösen, die sich sowohl „reinigend“ als auch „stählend“ auf die als Gemeinschaft konzipierte Einheit aus mitwirkenden Spielenden und beobachtender Zuhörerschaft auswirke. ${ }^{216}$ Niedecken-Gebhard nimmt eine wissenshistorische Umdeutung der aristotelischen Katharsis-Theorie und deren theaterästhetischer Wirkungsmacht, die ursprünglich für die antike Tragödie entwickelt wurde, vor. Der Theaterwissenschaftler interpretiert den theaterästhetischen Begriff der „Reinigung“ (Katharsis) aus einer vereinnahmenden Perspektive auf die „Spielgemeinschaft“ (aus Berufs- und Laiendarsteller`innen) als auch auf die Zuschauenden als ein imaginiertes, „rassenhygienisches“ Kollektiv um. ${ }^{217}$ Die theaterpraktische Selbstdarstellung würde den Laienspieler*innen helfen zur ideologischen Selbstfindung zu gelangen. ${ }^{218}$ Der Regisseur und Festspieldramatiker stellt hier eine theaterpädagogische Überlegung an, die wissenshistorische Ähnlichkeiten zur zeitgenössischen Ratgeberpraktik und deren autosuggestiven Selbstdisziplinierungsstrategie aufweist.

Das bindende Glied oder der emotionspolitische „Kitt“ der „Spielgemeinschaft“ ${ }^{219}$ aus Berufs- und Laiendarsteller^innen sei, ähnlich einem religiösen Verbund, der gemeinsame Glaube an die NS-Ideologie der „Volksgemeinschaft“,

214 Ebd.

215 Ebd.

216 Vgl. Ebd.

217 Gemeinsamkeiten und Unterschiede zur nationalen Festspielgestaltung beim Schweizer Dramatiker Edwin Arnet werden im nächsten Kapitel (16.6) vergleichend untersucht.

218 Vgl. Spielgemeinschaft und Regisseur. Frohe Erwartungen, 2.

219 Vgl. ebd., 1. 
welche „die Einzelnen vor dem Hervorkehren ihrer ,Personenstiles““ bewahre. ${ }^{220}$ Die Worte jeder Einzelperson, welche, wie gesehen bei der Rednerfigur Kallenberg, zwar aus der Masse heraustritt, sei nicht die Stimme eines Individuums, sondern eines heroischen Stereotyps, dessen Sendung auf „das Typische gerichtet“ sei und dessen schlichter Sprechstil den chorischen Ausdruck nicht verlassen dürfe.221 Diese „Gesinnungsbasis“ eines Spielkollektivs habe theaterhistorisch schon immer das Fundament der Festgestaltung gebildet, so der Theaterwissenschaftler. ${ }^{222}$ Von der nationalen Festspielgestaltung über das Aufmarschspiel bis zum Oratorium bauten die Gattungen auf der gemeinschaftsstiftenden „Gesinnungsbasis“ auf, so Niedecken-Gebhardt. ${ }^{223}$ Dem Ziel der „neugeschaffenen Spielgemeinschaften“ aus Berufs- und Laienspieler*innen läge die nationalsozialistische Kunstauffassung zugrunde, die der „sich aus dem Volk erneuernden Ausdrucksmacht erschlossen und gehütet werden möge“. ${ }^{224}$ So lautete der Wunsch des Regisseurs.

Der Regisseur mag in den hohen Kartenverkaufszahlen einen Beweis für die theaterästhetische Wirkungsmacht seines Festspielstils gesehen haben. Dies betraf das Festspiel „Olympische Jugend“ zur Eröffnung der Olympischen Spiele 1936 sowie das Festspiel zum 700-Jahre-Jubiläum Berlins. Letzteres wurde 1937 von rund 1 Million Zuschauer^innen in 10 ausverkauften Aufführungen gesehen und war für den damaligen Reichssportminister ein Grund, bei Niedecken-Gebhard ein weiteres Festspiel für das „Deutsche Turn- und Sportfest“ in Auftrag zu geben, das im Mai 1938 in Breslau aufgeführt wurde. Im Sinne einer kritischen Geschichtswissenschaft müssen diese Zahlen jedoch quellenkritisch analysiert werden. Die hohen Verkaufszahlen allein erlauben weder zwangsläufig Rückschlüsse auf ein Bedürfnis des Publikums nach einer affirmativen Gefühlspolitik noch auf deren theaterästhetische Zufriedenstellung durch die monumentale Festspielgestaltung. Niedecken-Gebhards Aufzeichnungen geben Aufschluss über die historischen Umstände, in welchen hohe Verkaufszahlen zustande kommen konnten und was geschah, wenn „Kraft durch Freude“ versagte.

Am 6. April 1938 einigten sich der Regiestab Niedecken-Gebhards, Stadtamtmann Stahl, „Gauwart“ Adam und Vertreter von KdF darauf, zwischen dem 18. und 28. August 1938 zehn Aufführungen zu veranstalten. Die KdF-Organisation übernahm für das Festspiel ein Kartenkontingent von 400.000 Eintritten und für das Barock-Musiktheater 90.000 zusammen mit der Aufgabe, „diese Karten an die

220 Vgl. ebd., 2.

221 Vgl. ebd.

222 Vgl. ebd., 3.

223 Vgl. ebd.

224 Vgl. ebd. 
KdF Mitglieder zu verteilen.“225 Der Festspielleiter legte am 1. Juni 1938 seinen Manuskriptentwurf für das Festspiel „Frohes, freies, glückliches Volk“ nach zahlreichen Änderungen Reichspropagandaminister Goebbels zur Beurteilung vor und erhielt die Erlaubnis zur Durchführung. In der Zwischenzeit hatte KdF es versäumt, die Karten an die Zentralstellen weiterzuleiten, weil der Druckauftrag angeblich zu spät eingetroffen war. Aus diesem Grund gelangten die Karten erst vier Wochen vor Aufführungsbeginn in den Umlauf der KdF-Organisation. „Nachdem der organisatorische Vorverkauf bei KDF restlos und katastrophal versagt hatte“, fiel der übrige Vorverkauf aufgrund schlechter Wetterbedingungen ebenfalls unter den Erwartungen aus. ${ }^{226}$ Hinzu kamen mehrere Konkurrenzveranstaltungen, die den Besuch des Festspiels minderten. Der „Gau Berlin“ veranstalte am 18. und 19. August eine Vorführung des Propagandafilms „Europa erwache“. Vom 24. bis 26. August zogen der ungarische Staatsbesuch und vom 26. bis 28 August die Festbeleuchtung Unter den Linden „ungeheure Zuschauermassen“ an. Der „Völkische Beobachter“ berichtete in jenen Tagen mit großen Fotoreportagen über das Treffen zwischen Hitler und dem ungarischen Staatspräsidenten Miklós Horthy (1868-1944). Das Festspiel wurde hingegen nur mit einer Fotografie des 4. Bilds über das „Volk in Leibesübungen“ dokumentiert. ${ }^{227}$ Weiter wirkte sich das „KdF-Fest der Millionen“ im Rahmen des Stralauer Fischzugs „katastrophal“ auf die Besucherzahlen des Festspiels aus. ${ }^{228}$

Unter dem Strich konnte die KdF-Organisation für das Festspiel knapp 20\% ihres Kartenkontingents und knapp 40\% für das „Orfeo“-Musiktheater verkaufen. „Dass der Verkauf des Volkswagens und des Volksempfängers während der Zeit des Vorverkaufs des Festspiels besonders stark propagiert wurde, war eine weitere Beeinträchtigung unserer Veranstaltung“, rechtfertigte sich der Festspielleiter gegenüber seinen Auftragsgebern. ${ }^{229}$ Es ist gut möglich, dass Niedecken-Gebhard mit seiner Einschätzung richtig lag. „Aus Publikumskreisen“ habe er vernommen, dass die Festspielleitung mit der hohen finanziellen Abhängigkeit gegenüber der Kdf-Vorverkaufsorganisation eine „falsche Preispolitik“ betrieben hätte:

„Die von uns festgesetzten Preise mussten so hoch sein, damit der Wunsch von KDF, die ja selbst noch eine Erhöhung des niedrigsten Preises verlangten, erfüllt worden ist. Hätten wir ohne KDF die Veranstaltung durchgeführt, so hätten wir die Preise von RM -.50 bis 2.festsetzen können, ohne die im Etat vorgesehenen Einnahmesummen herabsetzen zu

225 Vgl. Niedecken-Gebhard, Bericht über die Durchführung, 2.

226 Vgl. ebd., 5.

227 Vgl. „Berliner Schuljugend beim Festspiel im Olympia Stadion“. In: Tägliches Beiblatt zum „Völkischen Beobachter“, Ausg. 236, 24.08.1938, [Titelblatt].

228 Vgl. Niedecken-Gebhard, Bericht über die Durchführung, 5.

229 Vgl. ebd., 5. 
müssen, was natürlich zur Erfassung weiterer Volkskreise unbedingt erforderlich gewesen wäre.“230

Aufschlussreich an dieser Passage ist, dass einerseits die vorgegebene KdFPreispolitik die Frage nach der wirtschaftlichen Rentabilität einer Festspielaufführung rhetorisch wirken ließ. Andererseits wird deutlich, dass bei der Frage, wie das Festspiel auf das Publikum gewirkt haben mag, in Betracht gezogen werden muss, dass ein Festspiel, das im Vorverkauf mehrheitlich von KdF-Organisationen betrieben wurde, ein entsprechend selektives Publikum rekrutierte, welches sich eventuell emotionspolitisch leichter von der leistungsorientierten Selbstdarstellung einer affirmativen NS-Gefühlspolitik ergriffen ließ als ein Zufälliges.

Auch ohne das Mitwirken von KdF besuchten mehr als 300.000 Zuschauer^innen das Festspiel und rund „100 000 Volksgenossen“ die „Orfeo“-Aufführung. Der „spontane und herzliche Beifall“ gebe seinem Festspielkonzept grundsätzlich recht, schrieb der Regisseur selbstbewusst in seinem Bericht. Und auch „die Ausländer“ hätten sich im Rahmen der Aufführungen vom „künstlerischen Aufbauwillen im dritten Reich" beeindruckt gezeigt, wie der Generalsekretär des Internationalen Kongresses für Bildungswesen in seinem Dankesschreiben an die Festspielleitung versichert hätte. ${ }^{231}$

Die rigorose Drosselung des Ausgaben-Etats wenige Tage vor der Aufführung hätte, laut Niedecken-Gebhard, ein finanzielles Debakel verhindert. Darüber hinaus habe auch die Stadt Berlin Einnahmen aus der Nutzung der öffentlichen Verkehrsmittel, der umliegenden Gaststätten, den Verkäufen im Stadion, der Kostümfirmen und der Lieferanten generiert. Zudem betonte Niedecken-Gerhard die arbeitspolitische Bedeutung, welche die Berliner Sommerfestspiele als Arbeitsgeber während 3,5 Monaten für ein Personal hatten, welches ansonsten „grösstenteils“ auf „Arbeitslosenunterstützung“ angewiesen gewesen wäre „oder der Wohlfahrt der Stadt Berlin zur Last gefallen wäre.“"232 Darüber hinaus hätte das Sommerfestspiel während der Theatersommerpause rund 160 Tänzer`innen, 70 Ankleider*innen, 48 Bühnenarbeiter`innen und 300 erwerbslosen Schauspieler*innen, Artistinnen und Bürokräften ein Auskommen gesichert. ${ }^{233}$

Für die Zukunft zog Niedecken-Gebhard Bilanz und wünschte sich 1. ein Festspielthema, welches zwar „spielerisch“ angelegt sei, dennoch einen „heroischen Charakter" miteinbringe und 2. ein Festspielprogramm, in welchem die

230 Ebd., 5.

231 Vgl. ebd., 6.

232 Vgl. ebd., $6 \mathrm{f}$.

233 Vgl. ebd., $6 \mathrm{f}$. 
Aufführung im Stadion als Mittelpunkt einer gesamten Berliner Festspielwoche oder einer großen Rahmenveranstaltung stünde, wie es bei den Olympischen Spielen oder bei der Jubiläumsfeier 1937 der Fall gewesen war. Wenn diese Voraussetzungen gegeben seien, dann könne das Festspiel eine „weithinreichende Fremdenverkehrliche Werbung bedeuten, die Erfüllung einer kulturpolitischen Mission im Rahmen der Gesamtaufgabe der Reichshauptstadt erbringen.“234

\begin{abstract}
„Warum aber kann ein Volk so schöne Feste feiern? Weil es vor sich und vor der Welt ein reines Gewissen hat, weil es Werke des Friedens zu verrichten gewillt ist, weil es die einigende Kraft seines Volkstums, die Unlösbarkeit und Unverletzlichkeit allen Fühlens und Denkens auch in seiner Feierabendgestaltung bestätigt findet. Und das ist der tiefere Sinn auch dieser festlichen, unterhaltsamen BERLINER SOMMERFESTSPIELE IM OLYMPIA STADION.“235
\end{abstract}

Wie diese „kulturpolitische Mission“ des Festspiels „des Friedens“ bei der Bevölkerung ambivalent rezipiert werden konnte, zeigt der folgende Witz über die Politik der nationalsozialistischen Gefühlskultur angesichts des Ausbruchs des Zweiten Weltkriegs und der damit einhergehenden wirtschaftlichen Not des „glücklichen Volk[s]“ im „Dritten Reich“:

„Ein Schwede kommt in Berlin in einen Kolonialwarenladen.

Haben Sie Butter? - Nein. - Eier? - Nein. - Kaffee. Tee,

Südfrüchte? - Nein. - Ja, was haben Sie denn überhaupt?

- Karten für die Vorstellung ,Glückliches Volk‘ 1938،“236

\title{
16.6 Das ,Landi-Glück': Leistungsschau an der Schweizer Landesausstellung 1939 und ihr offizielles Festspiel „Das eidgenössische Wettspiel“ von Edwin Arnet
}

Im vorliegenden Kapitel wird die Schweizerische Landesausstellung 1939 (LA oder „Landi“) in Zürich und deren offizielles Festspiel, „Das eidgenössische Wettspiel“ von Edwin Arnet (1901-1962), im Zentrum stehen. Für die Untersuchung wird auf Bild-, Film- und Textquellen zurückgegriffen, welche sich in den Beständen des Bundesarchivs in Bern, im Online-Archiv des Schweizer Fernsehens, im Stadtar-

234 Vgl. ebd., 7.

235 „Glückliches Volk“, Programmheft, [5].

236 Brandt 2013. 
chiv Zürich und im Nachlass von Oskar Eberle der SAPA in Bern befinden. ${ }^{237}$ Die folgende Analyse erhebt keinen Anspruch auf Vollständigkeit. Vielmehr will die historische Untersuchung an den bisherigen Forschungsstand zur Landesausstellung und $\mathrm{zu}$ dessen offiziellem Festspiel anknüpfen und diesen um eine transnationale Perspektive ergänzen. Das Erkenntnisinteresse liegt auf der Erforschung einer Wissensgeschichte über kulturelle Nationalismen und deren affirmativer Gefühlspolitik. ${ }^{238}$

Bundespräsident Philipp Etter veröffentlichte im April 1939 in der ersten Nummer der offiziellen Ausstellungszeitung der LA ein propagandistisches Schreiben, in welchem er die Landesausstellung als eine „geistige Mobilmachung“ definierte:

„Was heißt das: ,geistige Mobilmachung‘?

Das heißt: Aufbruch der geistigen Kräfte zur Besinnung auf das geistige Antlitz unseres Landes, auf den Sinn unseres Staates, auf das Wesen unseres schweizerischen Volkstums. Aufbruch zur Besinnung auf die Quellen unserer Kraft und auf das Recht unserer Eigenart.

Die Landesausstellung 1939 wird sich nicht darauf beschränken, die wirtschaftlichen und technischen Leistungen unseres Landes zur Schau zu stellen. Sie wird ausholen zu einer lebendigen Kundgebung schweizerischer Geistesgemeinschaft und schweizerischen Kulturwillens. [...]

Ich hoffe, es werde gelingen, der schweizerischen Kunst und Wissenschaft, dem schweizerischen Schrifttum und allen Äußerungen schöpferischen Schweizer Willens an der Landesausstellung einen würdigen und weiten Platz einzuräumen. Dann werden wir sehen, wie organisch, wie selbstverständlich und ungezwungen die Verschiedenartigkeit und Mannigfaltigkeit des schweizerischen Kulturschaffens sich zu einer kraft- und eindrucksvollen Einheit zusammenfügt.

237 Materialien zur „Schweizerischen Landesausstellung 1939“ (Bestand J1.153) und zum offiziellen Festspiel (Bestand J.2.144) im Bundesarchiv Bern; Archiv des Schweizer Fernsehens (SRF), https://www.srf.ch/sendungen/archiv, 10.11.2020; Bestand zur „Schweizerischen Landesausstellung 1939“, (Bestand V.80: Entstehungskontext der LA und des Festspiels: Konzepte, Pläne, Entwürfe, Etat, Korrespondenzen, Festspielunterlagen [Konzepte, Manuskripte, Etat, Korrespondenzen, Regiebuch, 1925-1940 (V.80.23)], Pressematerial, Plakate, Fotografien), Stadtarchiv Zürich; Druckmaterialien zur LA, Nachlass Oskar Eberle (Signatur 110: „Dr. Eberle, Sonderschriften, Pläne, Protokolle, Nicht Theatralia nur Allgemeines über LA“; Eberle PA [Presseartikel] Schweiz Zürich-Diverse: Zürich: Schweizerische Landesausstellung: Festspiel, Ausstellungstheater, Diverses; Eberle 129 PA Landi 1939: Eidgenössisches Wettspiel) SAPA Bern; Forschungsliteratur zum Festspiel der Landesausstellung, Bibliothek der SAPA Bern.

238 Zur Landesausstellung vgl. u. a. Tschudi 2000, Kohler und Moos 2002, Kreis 2010, Baumann 2012, Debluë 2015. Zum Festspiel „Das eidgenössische Wettspiel“ vgl. Kreis 1988, Naef 1988, Tschudi 1993, Tschudi 2000, Das Festspiel, 126-157. In: Stern 2000, 137-140. 
Die Landesausstellung wird uns aufrufen zu geistigem Aufbruch, zu geistiger Selbstbesinnung und Selbstbehauptung. Sie wird uns zusammenführen zu einem großen gemeinsamen Erlebnis und zu freudiger Bejahung dessen, was uns zu gemeinsamer Verteidigung anvertraut ist: des großen schweizerischen Geistesleben, das es zu erhalten und zu mehren gilt!“‘239

Mit diesen Worten beschrieb der Bundespräsident den Sinn und Zweck der LA, die im Dienst einer „geistigen Mobilmachung“ stand und einen „geistigen Aufbruch“, eine nationale „Selbstbestimmung“ und eine „Selbstbehauptung“ propagierte. Eine besondere Funktion sah Etter in der emotionspolitischen Selbstdarstellung einer „schweizerische[n] Geistesgemeinschaft“ und eines „schweizerischen Kulturwillens“, welche sich insbesondere im Bereich der „schweizerische[n] Kunst und Wissenschaft" präsentieren sollten. ${ }^{240}$

Die vorliegende Untersuchung geht von der These aus, dass die LA ein arbeitsund massenpsychologisches Propagandainstrument einer leistungsorientierten, selbstdisziplinarischen und kulturnationalistischen Festkultur war und als solche zur Untersuchung einer Politik von,Glückskulturen' wissenshistorisch analysiert werden kann. Die Funktion der LA als eine „geistige Mobilmachung“ der Schweizer Bevölkerung war Teil der affirmativen Gefühlspolitik der „geistigen Landesverteidigung“. Die LA gilt es historisch als emotionspolitische Reaktion auf das faschistische und nationalsozialistische Bedrohungs- und Krisenszenario vor dem Ausbruch des Zweiten Weltkriegs zu kontextualisieren. ${ }^{241}$

Folgende Forschungsfragen liegen der Untersuchung zugrunde:

1. Welche Propagandainstrumente standen dem LA-Ausstellungskomitee zur Verfügung, um die emotionspolitische Wirkungsmacht ihres Schauplatzes einer Schweizer Arbeitsmoral im Kontext der „geistigen Landesverteidigung“ und des Ausbruchs des Zweiten Weltkriegs am 1. September 1939 entfalten zu können?

2. An welche Nationalgefühle appellierte die affirmative Gefühlspolitik der LA am Beispiel des offiziellen Festspiels und welches emotionspolitische Ziel verfolgten die Theaterschaffenden im Kontext einer Schweizer Theaterpolitik der „geistigen Landesverteidigung“ und einer theaterwissenschaftlichen Debatte über ein Schweizer Nationaltheater?

239 Philipp Etter, „Die Landesausstellung - eine geistige Mobilmachung. Philipp Etter. Bundespräsident“. In: Offizielle Ausstellungs-Zeitung. Die Schweizerische Landesausstellung 1939 in Zürich, 28. April 1939, Nr. 1., 2, Signatur: Fc 204, StArZH.

240 Vgl. ebd.

241 Vgl. Etter 1939, 2. 
Der Aufbau des Kapitels orientiert sich an den oben genannten Forschungsfragen. Folglich ist im ersten Teil das Augenmerk auf die Ausstellung und im zweiten Teil auf das Festspiel gerichtet. Der Fokus der historischen Untersuchung liegt 1. auf dem emotionspolitischen Ausstellungskonzept, 2. auf der Festspieldramatik Edwin Arnets und 3. auf der theaterwissenschaftlichen Festspieltheorie und theaterhistorischen Festspielgestaltung des Theaterwissenschaftlers und Regisseurs Oskar Eberle. Die Problemstellung der Untersuchung fokussiert im transnationalen Vergleich zur NS-Arbeitsmoral und Festkultur „Kraft durch Freude“ auf die leistungsorientierte Selbstdarstellung der Schweiz als ein demokratischer Nationalstaat und zugleich als eine biologistisch-kulturnationalistisch konstruierte „Schweizer Geistesgemeinschaft“.242

Die LA wurde vom 6. Mai bis 29. Oktober 1939 am Zürcher Seebecken veranstaltet. Auf der rechten Seite wurde die „traditionelle“, auf der linken Seite die „moderne“ Schweiz dargestellt. ${ }^{243}$ Für die Planung formierte sich bereits im Februar 1936 eine Ausstellungskommission, deren Präsidentschaft Bundesrat Hermann Obrecht (1882-1940) ${ }^{244}$ übernahm. Das Organisationskomitee bildete den rechtlichen Träger der LA, an deren Spitze ihr Direktor, der Architekt Armin Meili $(1892-1981)^{245}$, für die Verwaltung zuständig war. Die einzelnen Fachgebiete wurden in verschiedenen Komitees durch Vertreter^innen der jeweiligen Berufsbereiche repräsentiert. ${ }^{246}$

Drei Monate nach der Eröffnung der LA zählte die Ausstellung bereits 6 Millionen Eintritte. Die Einwohnerzahl der Schweiz lag damals bei 4 Millionen. Trotz Ausbruchs des Zweiten Weltkriegs am 1. September 1939 bilanzierte der Abschlussbericht Ende Oktober 1939 eine Gesamtzahl von 10,5 Millionen Eintritten bei einem Tagesdurchschnitt von 60.000 Personen. Das Organisationskomitee hatte insgesamt mit nur 3 bis 4 Millionen Besucher*innen gerechnet. ${ }^{247}$

Das Ausstellungskonzept sah vor, dass die LA innerhalb von 14 Themenschwerpunkten eine „möglichst lückenlose Wiedergabe aller Zweige schweizerischen Schaffens“ präsentierte, wie Direktor Meili im Ausstellungskatalog fest-

242 Vgl. Etter 1939, 2.

243 Vgl. „Das war die Landi - Ein Erinnerungsfilm an die Schweizerische Landesausstellung 1939 in Zürich“, 3:45-3:51, ausgestrahlt am 18. Juni 1989, SRF Archiv, https://www.srf.ch/play/ tv/archivperlen/video/landi-39-in-zuerich?id=bc00b7a7-7c7c-4638-ad0b-00a60cb44412, 10.10. 2020. Dieser Dokumentarfilm zeigt historisches Foto- und Filmmaterial.

244 Zur Person vgl. Lätt 2009.

245 Zur Person vgl. Hürlimann 2015.

246 Vgl. Stalder 2000, 87.

247 Vgl. E.G. Graf, Schlussbericht der Schweizerischen Landesausstellung 1939 Zürich an die Grosse Ausstellungskommission erstattet im Namen und Auftrag des Organisationskomitees, [1940], [Verlag nicht ermittelbar], 82, Signatur: Fc 202, StArZH. 


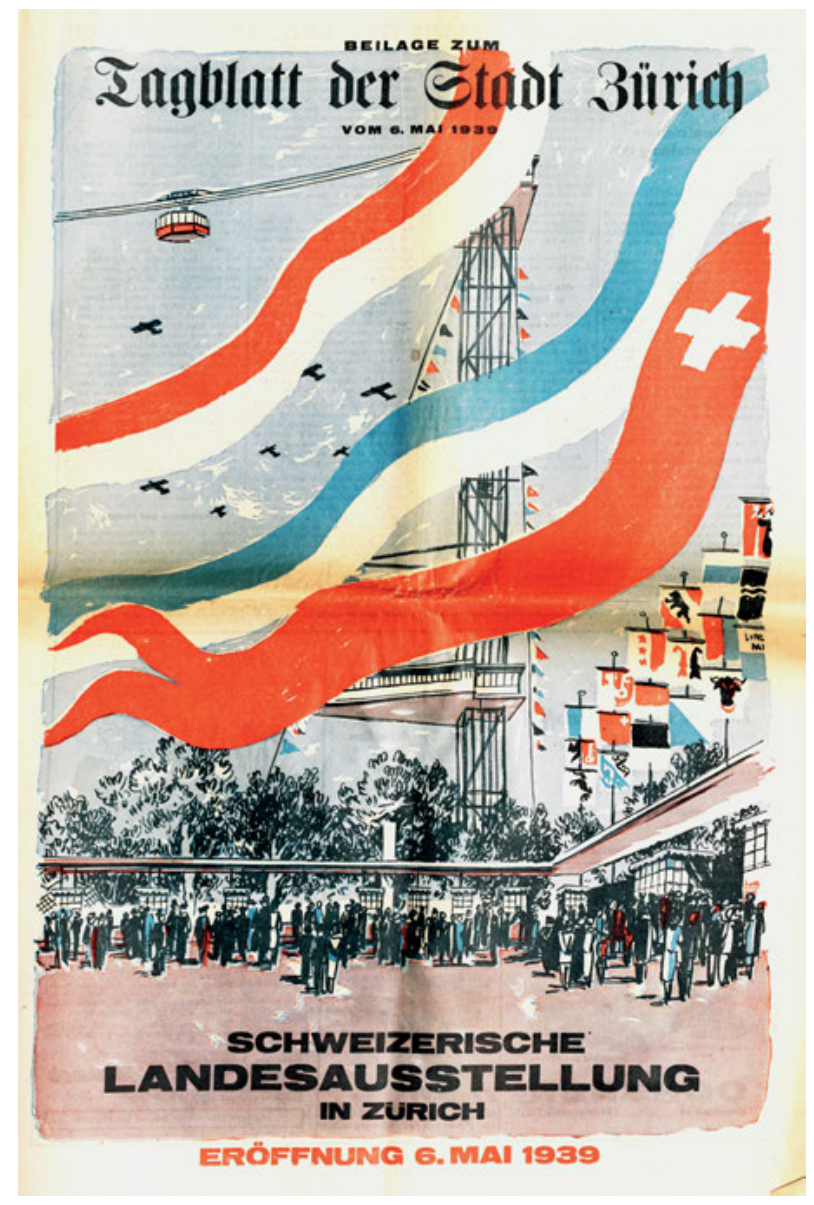

Abb. 26: „Schweizerische Landesausstellung in Zürich. Eröffnung 6. Mai 1939“, Beilage zum Tagblatt der Stadt Zürich, 6. Mai 1939

hielt. $^{248}$ Im Unterschied $\mathrm{zu}$ den vorangegangen Landesausstellungen (1883 in Zürich, 1896 in Genf, 1914 in Bern) ${ }^{249}$ wurde die LA 1939 als emotionspolitischer Schauplatz eines „großen gemeinsamen Erlebnis[ses]“ entworfen. ${ }^{250}$ Die Ausstellung sollte nicht nur eine Rückschau auf die bisher geleisteten Erfolge der

248 Vgl. Meili 1939, 14.

249 Vgl. Kreis 2010.

250 Vgl. Philipp Etter, „Die Landesausstellung - eine geistige Mobilmachung. Philipp Etter. Bundespräsident“. In: Offizielle Ausstellungs-Zeitung. Die Schweizerische Landesausstellung 1939 in Zürich, 28. April 1939, Nr. 1., 2, Signatur: Fc 204, StArZ. 
Schweizer Kantone in den Bereichen Politik, (Land-)Wirtschaft, Wissenschaft, Technik, Literatur, Theater, Musik, Tanz und Kunst in den vier Landessprachen (Deutsch, Französisch, Italienisch, Rätoromanisch) darstellen. Das Ziel war, die Schweizer Bevölkerung aus allen vier Sprachregionen „zur freudigen Bejahung“ gemeinsamer Werte- und Moralvorstellungen zusammenzuführen und durch deren Proklamation, Rezeption und Verbreitung eine kulturnationalistische Funktion zu erfüllen. ${ }^{251}$ Die 14 Abteilungen der Hauptausstellung ${ }^{252}$ sowie die Gesamtarchitektur der LA-Anlage wurden im Sinn einer affirmativen Gefühlspolitik konzipiert. Die LA sei eine „Dokumentation schweizerischer Zusammenarbeit und Zusammengehörigkeit“, bei der die ausstellenden Firmen in den Hintergrund träten, schrieb der Wirtschaftsjournalist und Verleger Eugen Theodor Rimli (1909-1973) begeistert. ${ }^{253}$ Es sollte der Eindruck entstehen, dass die „schweizerische[...] Arbeit“ eine „Gemeinsamkeitsleistung“ darstelle und dabei politische, soziale und konfessionelle Unterschiede und Ambivalenzen im imaginierten Konsens überwunden würden. In der hegemonialen Dominanzhaltung der christlichen, autoritär-rechtskonservativen und männlich-stereotypisierten Gefühlspolitik einer „geistigen Mobilmachung“, welche Bundespräsident Philipp Etter prominent vertrat, wurden gesellschaftspolitische Ambivalenzen der massenpsychologisch motivierten Schweizer Arbeitsmoral zugunsten einer emotionspolitischen Wahrung des ,schönen Scheins“ in der LA bevorzugt verdrängt, wie die Analyse zeigen wird. ${ }^{254}$

251 Vgl. Philipp Etter, „Die Landesausstellung - eine geistige Mobilmachung. Philipp Etter. Bundespräsident“. In: Offizielle Ausstellungs-Zeitung. Die Schweizerische Landesausstellung 1939 in Zürich, 28. April 1939, Nr. 1., 2, Signatur: Fc 204, StArZ.

252 Die Ausstellung wurde in 14 Abteilungen aufgeteilt: Abt. 1 „Heimat und Volk“ widmete sich den Themen „Gegebenheiten der Natur“ und „Das Ideengut unserer Volksgemeinschaft“, das Thema „Rohstoffe“ wurde in der Abt. 2 „Elektrizität“, Abt. 3 „Holz“, Abt. 4 „Die Schweiz, das Ferienland der Völker“, Abt. 5 „Landwirtschaft“ und Abt. 6 „Jagd, Fischerei, Vogelschutz“ behandelt. Auf „Verarbeitung und Verbrauch“ legten die Abt. 7 „Zubereiten und Essen“, Abt. 8 „Fabrik und Werkstatt“, Abt. 9 „Bauen und Wohnen“ und Abt. 10 „Kleider machen Leute“ ihren Fokus. Für die Darstellung der „Verteilung u. Vermittlung - Kultur des Geistes und des Körpers“ waren die Abt. 11 „Soll und Haben“, Abt. 12 „Verkehr und Transport“, Abt. 13 „Kraft und Gesundheit“ und Abt. 14 „Lernen und Wissen, Denken und Dichten“ zuständig.

253 „Die Namen der ausstellenden Firmen traten weit zurück und konnten meist nur auf kleinen Täfelchen gefunden werden; dadurch wurde der früher übliche messeartige Charakter schweizerischer Ausstellungen zum ersten Mal konsequent verlassen und dafür die gemeinsamen Hauptzüge der landeseigenen Produktion hervorgehoben." Rimli 1939a, 5.

254 Vgl. Rimli 1939a, 5. 
„A happy nation“ is the leitmotiv of the whole Exibition“, hieß es in der englischen Ausstellungsbroschüre des LA-Pressediensts. ${ }^{255}$ Die ausländische Berichterstattung war voll des Lobes. „The Efficency Magazine“ schrieb:

„Surely the Swiss people deserve a word of congratulation. At a time when all Europe is in a turmoil, they have gone ahead and organized one of the finest Business Exibitions that Europe has ever seen. If every other democratic nation would do as much, we would soon pass out of the Trepidation Period into a Period or Progress and Prosperity.“256

Die transnational rezipierte Gefühlspolitik einer leistungsorientierten Schweizer Gefühlskultur schien ihre Wirkung bei der demokratisch-liberalen Presse Großbritanniens nicht verfehlt $\mathrm{zu}$ haben.

Der Schweizer Volksmund sprach ebenfalls vom ,Landi-Glück‘, welches die Bevölkerung beim erlebnis- und emotionsreichen Besuch der Landesausstellung empfunden hätte, sei es bei der Zurschaustellung einer kollektiven Schweizer Arbeitsleistung in den verschiedenen Ausstellungsbereichen und Attraktionen ${ }^{257}$ oder während einer der zahlreichen kulturellen Veranstaltungen ${ }^{258}$, wie dem offiziellen Festspiel. Mag man den vielfältigen Zeitzeugenberichten ${ }^{259}$, die nicht nur gezielt vom LA-Pressedienst zur Beeinflussung der öffentlichen Meinung publiziert, sondern auch in verschiedenen, insbesondere bürgerlichen Zeitungen und Zeitschriften ${ }^{260}$ abgedruckt wurden, Glauben schenken, erlebte derjenige Bevöl-

255 Vgl. R.A. Langford, „British appreciation of the Swiss National Exhibition“. In: Swiss National Exhibition Zurich 1939, 1939, Zürich: Freiz Bros., [7] [Ausstellungbroschüre], Nachlass Eberle, 110 Landi, SAPA.

256 Pressestimme zit. nach A. Langford, „British appreciation of the Swiss National Exhibition“. In: Swiss National Exhibition Zurich 1939, 1939, Zürich: Freiz Bros. [2], [Ausstellungsbroschüre], Nachlass Eberle, 110 Landi, SAPA. „The Observer“ schrieb: „The Exhibition shows that the country is much more than the playground of Europe and a producer of cheese and condensed milk. Visitors to Zurich will realise the cultural and industrial importance of Switzerland, and also the unity of the people, in spite of their four different languages.“ Der britische Pressespiegel umfasste „The Observer“, „Daily Mail“, „Womens’ Wear News“, „Birmingham Mail“, „The Efficency. Magazine“, „News Chronicle“, „Glasgow Herald“ und „Yorkshire Post“.

257 Festumzug zur Eröffnung, Schwebebahn von 900 Metern, Wasserbahnfahrt („Schifflibach“), „Landi-Dörfli“, „Lueg ins Land“-Krahn, „Landi-Schwinget“, Seenachtfest am 23. August 1939.

258 Theateraufführungen im „Landi-Theater“, Festspiele, Konzerte, Figurentheater, Trachtenfest, Modeschauen im „Modetheater“ mit musikalischer, tänzerischer und gesanglicher Darbietung.

$259 \mathrm{Zu}$ einer akustischen Geschichtsschreibung der LA vgl. Baumann 2012.

260 U.a. „Schweizer Illustrierte“ (z.B. Nr. 19., 10.05.1939 [Sondernummer]; Nr. 24, 14.06.1939; Nr. 30, 16.07.1939; Nr. 34, 24.08.1939) und die sechs Sondernummern der „Zürcher Illustrierte“ über den Ausstellungsbau (Nr. 19, 12.05.1939), die Mode (Nr. 23, 09.06.1939), die Ausstellung und 
kerungsteil, der sich eine Fahrt nach Zürich und den Tageseintritt leisten konnte und wollte ${ }^{261}$, einen erlebnisreichen Tag voller Glücksgefühle. Die Bäuerin S. B. aus Dürrenast bei Thun äußerte mit Bedauern:

„Warum ich nicht an die Landi gehe? - Nun, das ist schnell gesagt, eine Schar Kinder, ein Haus und ein Garten, die bestellt sein müssen. Jetzt kommt die Beerenzeit, da gibt es doppelt Arbeit. Mein Mann und die beiden älteren Kinder werden diese Ferien dazu benützen, um an die Landi zu fahren mit dem Fahrrad. Dann werde ich an den Berichten der drei meine helle Freude haben können und die Landi so miterleben, als ob ich selbst dort gewesen wäre. Ich weiß das schon zum voraus und freu mich so auf die Landi.“262

Nach dem Grund dieser emotionalen Wirkungsmacht, welche der ,Landi-Geist bei vielen Schweizer*innen entfalten konnte, fragte schon der Wirtschaftsjournalist Rimli:

„LLandi` - wie rasch ist das ein Begriff geworden! Viele konnten es kaum fassen, daß ihre Tore wieder geschlossen wurden und wenn es auf die regelrechte Liebe, die überall für sie empfunden wurde, angekommen wäre, so hätte die Landi noch ein zweites und drittes Jahr weitergeführt und immer wieder mit Millionenbesuch rechnen können. Wenn man aber jemanden fragte, warum er denn der Landesausstellung 1939 eine solche Zuneigung entgegenbringe, so bekam man eigentlich nirgends eine richtige Antwort. Das Volk fühlte sich einfach rein gefühlsmäßig zur Landi hingezogen, so wie die erwachende Liebe zweier junger Menschen nicht äußerlicher Schönheit oder verstandesmäßiger Ueberlegungen, sondern der Ahnung einer glückhaften großen Unbekannten entspringt. Dieses Glücksgefühl zaubert dann die Wunschträume und Ideale hervor, als deren Symbol der andere Teil erscheint.“263

Die folgende Untersuchung wird sich unter dem Aspekt einer Politik der ,Glückskulturen' mit folgender Frage befassen: Welche autosuggestiven „Wunschträume und Ideale“ sorgten beim Publikum für Glückgefühle, die als symbolträchtige „Ahnung einer glückhaften großen Unbekannten“ durch die

das „Landi Dörfli“ (Nr. 27, 07.07.1939), Trachtenfest (Nr. 38, 22.09. 1939), Jugend (Nr. 34, 04.08. 1939) und Technologie (Nr. 41, 13.10.1939).

261 Die Zürcher Illustrierte veröffentlichte eine kritische Fotoreportage mit Blick auf diejenigen Schweizer^innen, welche sich der „allgemein[n] Landesausstellungs-Begeisterung“ in erster Linie aus finanziellen Gründen nicht anschließen konnten, zum Beispiele Bäuer^innen, ausgerechnet jener symbolträchtige Berufszweig, der an der Landi idealisiert wurde. Vgl. „,Was heet er gseet, Landesustellung?` Bilder und Worte von solchen, die nicht kommen dürfen, können oder wollen!“ In: Zürcher Illustrierte, Nr. 28, 1939, S. 1196f., VII.80.50a, StArZ.

262 ",Was heet er gseet, Landesustellung?‘ Bilder und Worte von solchen, die nicht kommen dürfen, können oder wollen!“. In: Zürcher Illustrierte, Nr. 28, 1939, S. 1196f., VII.80.50a, StArZ. 263 Rimli 1939a, 5. 
Selbstdarstellung der LA eine emotionspolitische Wiedererkennung im Publikum auslösen konnten?

Die erste Abteilung des Ausstellungteils an der Schweizerischen Landesausstellung von 1939 trug den Titel „Heimat und Volk“ und führte entlang der sogenannten „Höhenstrasse“ (Abb. 27). Das erziehungspolitisch-propagandistische Ausstellungskonzept sah vor, dass im ersten Ausstellungsteil den Besucher`innen als Auftakt zur „Höhenstrasse“ das „Ideengut unserer Volksgemeinschaft“ erklärt werde. Dieser Bereich war unter Leitung des Präsidenten des Ausstellungskomitees, Meinard Lienert, Direktor der Schweizerischen Zentrale für Handelsförderung, in acht Themengebiete unterteilt worden: „Unser Land“, „Unser Volk“, „Soziale Arbeit“, „Lebendiger Bund“, „Wehrwille“, „Arbeit und Wirtschaft“, „Ehrung“ und „Gelöbnis“ (Abb. 27). ${ }^{264}$

Bevor die Besucher`innen den Ausstellungsbereich betreten konnten, führte ihr Weg durch ein hohes Eingangstor mit der Aufschrift „Ewiger Bund“. Oberhalb des Tors schwebte eine überlebensgroße weibliche Plastik im Stil der Neuen Sachlichkeit, die - in Anlehnung an die Allegorie der Glücksgöttin Fortuna - den programmatischen Werktitel „Glückliche Zukunft“ (Abb. 28) ${ }^{265}$ trug.

Im Interesse Etters emotionspolitischer Propagandabotschaft („Die Landesausstellung - eine geistige Mobilmachung“) sollten die Besucher`innen den „Geist der Landi“ nicht nur auf schriftlichen Texttafeln erfahren. ${ }^{266}$ Das Ausstellungskomitee setzte auf eine audiovisuelle Wissensvermittlung, die möglichst alle Sinne ansprach. Auffallende Typografien (von Handschriften über erste Druckschriften bis zum zeitgenössischen Stil der Neuen Sachlichkeit) auf Bannern, Plakaten und Stoffstücken gedruckt, soziologische, geografische und wirtschaftliche Statistiken und Grafiken in Verbindung mit leicht verständlichen Ikonografien und illustrativen Wandbildern verkleideten die Innen- und Außenfassaden der Ausstellungsgebäude. Hörstationen, historische Museumsobjekte und dreidimensionale Großraumplastiken als geschichtsträchtige Ikonografien ergänzten das multimediale Ausstellungserlebnis. Indem die Kurator^innen verstärkt auf den Einsatz von Bild- und Tonvermittlung setzten, konnte die erzie-

264 Vgl. Aufbau Abt. I „Heimat und Volk“. In: Schweizerische Landesausstellung 1939 Zürich. Katalog: Offizieller Führer mit Ausstellerverzeichnis und Orientierungsplan, Zofingen: Ringier, 29. 265 Vgl. Schweizerische Landesausstellung 1939 Zürich, Hrsg. 1940. Die Schweiz im Spiegel der Landesausstellung 1939, Bd.1, Zürich: Atlantis, 60, Signatur: FS 201:1, StArZ. Werkangaben: „Glückliche Zukunft“, Walter Knecht, Eingang Höhenweg. Vgl. ebd., 9.

266 Vgl. Philipp Etter, „Die Landesausstellung - eine geistige Mobilmachung. Philipp Etter. Bundespräsident“. In: Offizielle Ausstellungs-Zeitung. Die Schweizerische Landesausstellung 1939 in Zürich, 28. April 1939, Nr. 1., 2, Signatur: Fc 204, StArZH. 


\section{HEIMAT UND VOLK}

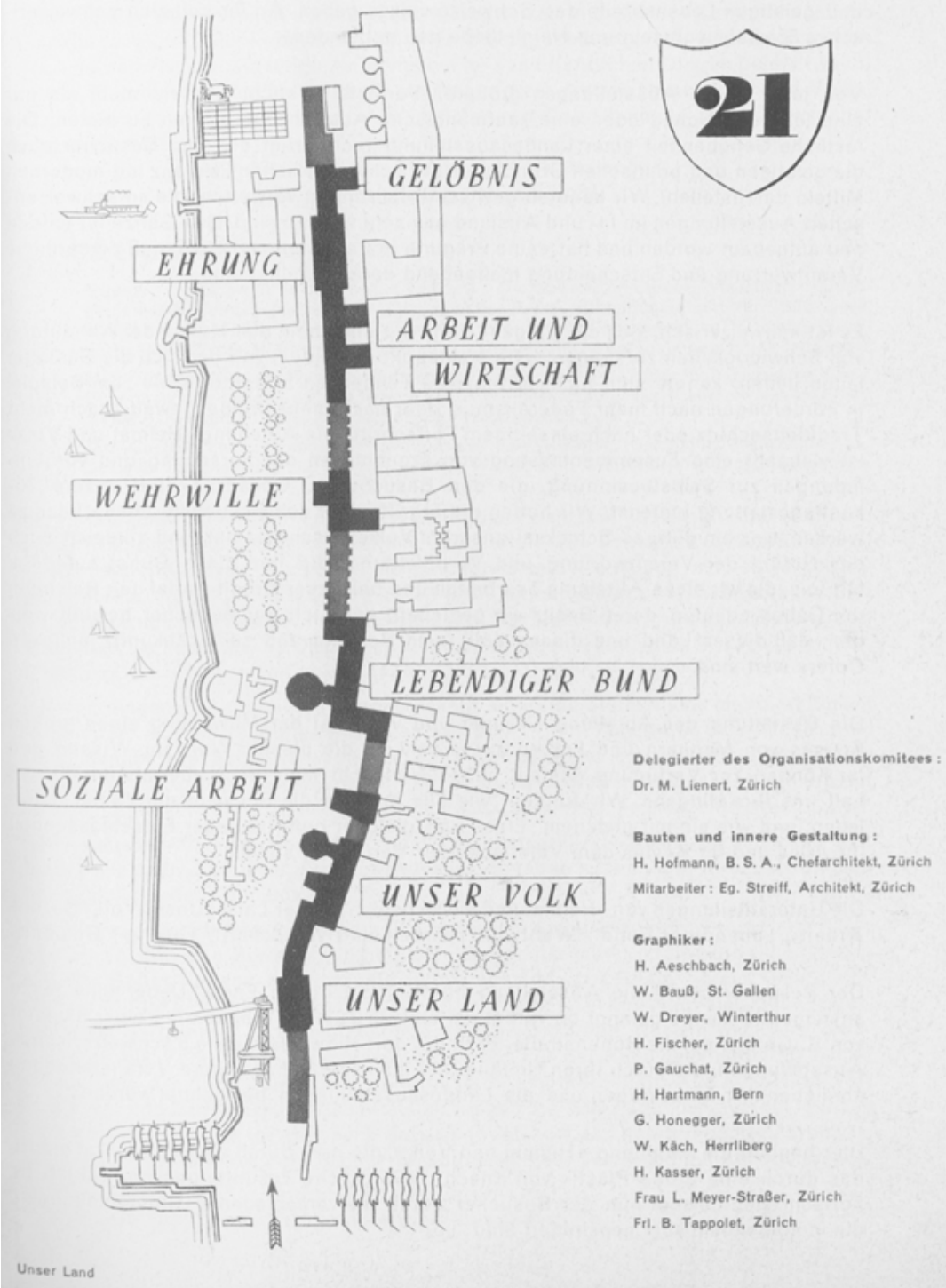

Abb. 27: Übersichtsplan des ersten Ausstellungsteils „Heimat und Volk“, Schweizerische Landesausstellung (LA), Zürich, 1939 


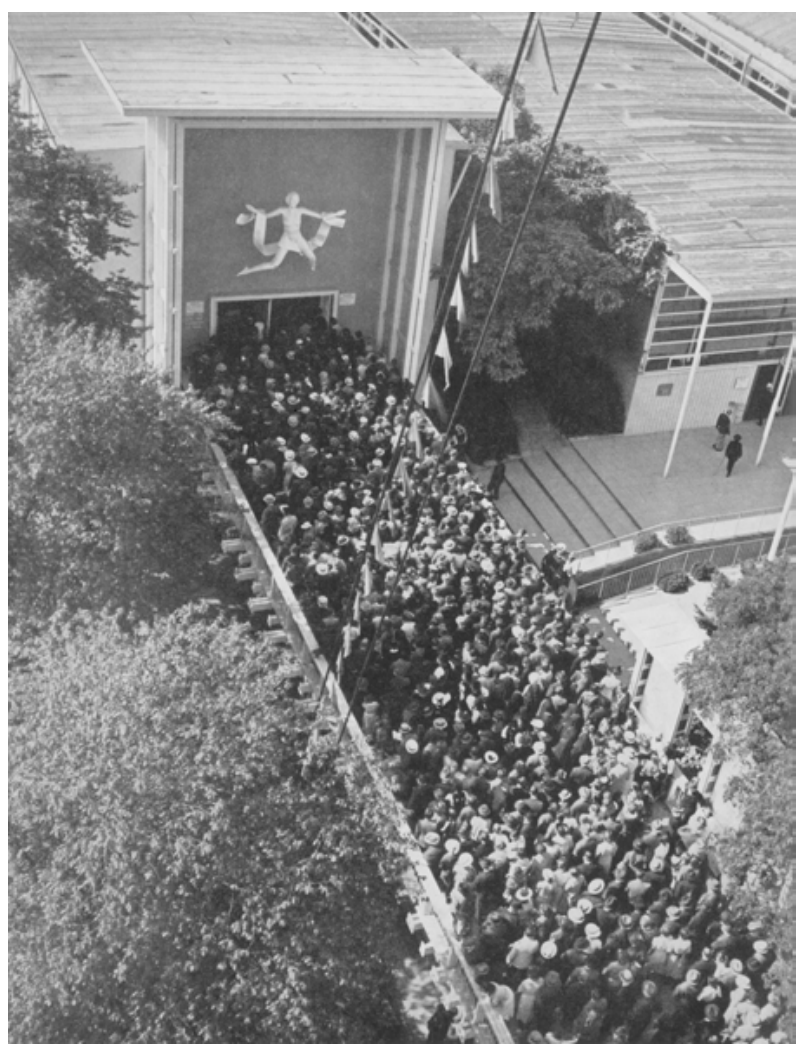

Abb. 28: „Das Schweizervolk drängt sich zum Höhenweg seiner Landesausstellung“, [Originaler Fototext], [Eingangstor der „Höhenstrasse“ mit schwebender Figur „Glückliche Zukunft“ von Walter Knecht], LA, Zürich, 1939

hungspolitische Sendung des ,Landi-Geists' die gewünschte emotionspolitische Wirkungsmacht bei den Besucher`innen entfalten.

Im Ausstellungsbereich „Unser Volk“ wurden biologistische, charakterologische und „völkerpsychologische“ Eigenschaften der „schweizerische[n] Menschen“ dargestellt, welche, gemäß dem Ausstellungstext, trotz unterschiedlicher Herkunft, Sprache und christlicher (!) Konfessionen eine Nation bilden würden: „Sie sind nicht aus einem Holz geschnitzt, aber vom gleichen Geiste beseelt“ (Abb. 29). ${ }^{267}$ Die gesellschaftspolitischen Auswirkungen des „Ideenguts unserer Volksgemeinschaft“ wurden am Beispiel verschiedener Lebensgebiete („Schwei-

267 Vgl. Mojonnier 1939a, 39. 


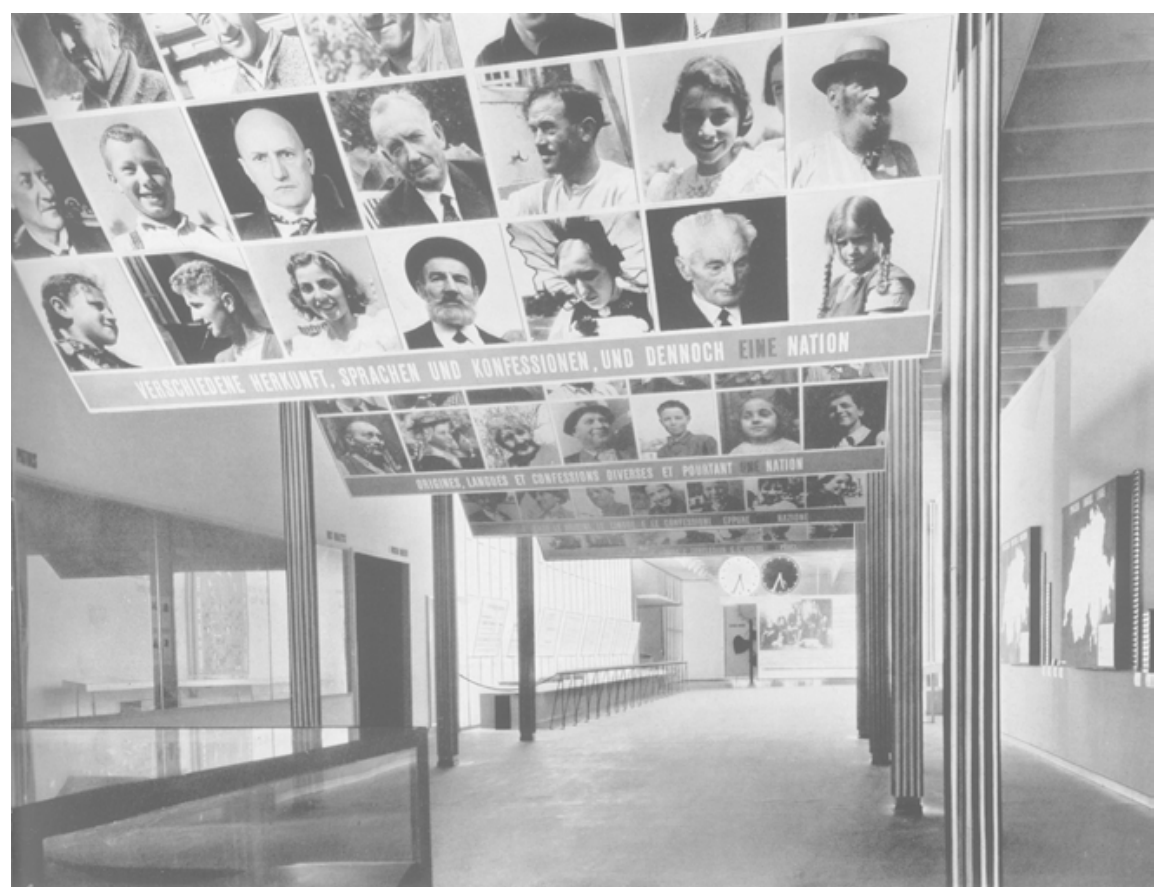

Abb. 29: „Sie [Schweizer] sind nicht aus dem gleichen Holz geschnitzt, aber vom gleichen Geiste beseelt“, Abt. I „Heimat und Volk“, LA, Zürich, 1939

zer Familie“, Verbände, Vereine, Sport, Soziale Arbeit, Kirche) illustriert. ${ }^{268}$ Von den biologistischen Ansätzen abgesehen, unterschied sich das LA-Ausstellungskonzept über eine „glückliche Zukunft“ des stereotypisierten Schweizer Volkes vom „rassenhygienisch“ konzipierten Ausstellungskonzept einer homogenen, gleichsprachigen, „arischen Volksgemeinschaft“, wie sie zur selben Zeit in NSDeutschland propagiert wurde (Kap. 14.2).

Im transnationalen Vergleich stellte die LA dennoch ein ähnlich leistungsorientiertes Glückswissen zur Schau, das - wie in NS-Deutschland - auf den Erkenntnissen der Arbeitspsychologie basierte. Beispiele dafür sind die arbeitspsychologische Selbstdarstellung einer selbstdisziplinarischen Persönlichkeitsund leistungsorientierten Körperkultur im Sport, im biopolitischen Kult um eine

268 Vgl. E.G. Graf, Schlussbericht der Schweizerischen Landesausstellung 1939 Zürich an die Grosse Ausstellungskommission erstattet im Namen und Auftrag des Organisationskomitees, [1940], [Verlag nicht ermittelbar], 20, Signatur: Fc 202, StArZH. 
idealisierte Schweizer Jugend („Gesunde Jugend - Gesundes Volk“) und im geschlechterstereotypisierten, moralisierenden Schweizer Mütterglück („Gute Hausfrauen - Reiches Volk!“ $){ }^{269}$

Auf die stereotypisierte Schweizerfrau und ihren Beitrag zur Gemeinschaftsleistung ging die Ausstellung in einer Sondersektion ein. Die rechtliche und folglich berufliche Emanzipation der Frau, beispielweise im Bereich „Wissenschaft und Kunst“, wurde in der Ausstellung zwar benannt, aber im Sinne der christlich-rechtskonservativen Familienpolitik der „geistigen Landesverteidigung“ erst zögerlich befürwortet. ${ }^{270}$ So wird der Schweizer Frauentypus und ihr gesellschaftliches Wirken im offiziellen Ausstellungsführer nach wie vor im Sinne einer kontinuitätstreuen, christlich-geschlechterstereotypisierten Schweizer Familienhierarchie beschrieben, wie schon in Hoppelers Frauenratgeber gesehen (Kap. 14.5):

„Das Wirken der Frauen wird im Leben des Volkes oft zu wenig gewürdigt. [...] Als Mitarbeiterin ihres Mannes, als Hüterin des Herdes, als Erzieherin der Kinder, opfert sie sich auf für ihre Angehörigen und leistet damit im Verborgenen wertvollste Arbeit für die Gesamtheit." 271

Diese exemplarischen Ausstellungsbeiträge zeigen eine transnationale Kontinuität einer ambivalenten Wissenszirkulation von arbeitspsychologischem und biologistischem Glückswissen zwischen der Schweiz und NS-Deutschland auf, wie sie beispielsweise auch in der Ausstellung „Gesundes Leben. Frohes Schaffen“ thematisiert wurde, die vom 24. September bis 6. November 1938 im Berliner Funkturm präsentiert worden war (Kap. 14.2). ${ }^{272}$ Die LA zeigte in diesem Ausstellungsbereich ihre nationalistisch-biologistische Vorstellung einer geschlechterstereotypisierten Schweizer Heirats- und Geburtenpolitik (Abb. 30) ${ }^{273}$, die wiederum - im Unterschied zu NS-Deutschland - eine ausländische Eheschließung mit einer Angehörigen des „Dritten Reiches“ aus einer hegemonial-männ-

269 Vgl. Mojonnier 1939a, 44, 46.

270 Auf die Forderung nach dem Schweizer Frauenstimmrecht wurde in der Ausstellung mit einem wirtschaftspolitischen Argument Bezug genommen: Mit einer eigenen Wählerstimme könnten sich die Schweizer`innen als Folge verstärkt in die Arbeitswelt einbringen, was wiederum für den Staat mehr Steuereinnahmen bedeuten könnte. Vgl. Mojonnier 1939a, 43.

271 Schweizerische Landesausstellung 1939 Zürich. Katalog: Offizieller Führer mit Ausstellerverzeichnis und Orientierungsplan, Zofingen: Ringier, 35.

272 Vgl. Ausstellungsführer zur Ausstellung „Gesundes Leben - Frohes Schaffen“. Hg. v. „Gemeinnützige Berliner Ausstellungs-, Messe- und Fremdenverkehrs GmbH, Berlin 1938, Signatur: Do2 96/3852, Deutsches Historisches Museum, Berlin.

273 Vgl. Mojonnier 1939a, 40. 
lichen Perspektive nicht ausschloss. Zur Erklärung verwendete Arthur Mojonnier in der Publikation „Das goldene Bruch der LA 1939“ ein problematisch rassistisches Vokabular, welches die „Verbreitung der neuen Blutzufuhr“ als geburtenpolitischen Nebeneffekt befürwortete:

„Jeder achte Schweizer heiratet eine Ausländerin! So unerfreulich das für die ,achte Schweizerin“ sein mag, so zeugt die stete vollständige Verarbeitung der neuen Blutzufuhr mit unseren hergebrachten Wesen doch für die Gesundheit und Gegenwartskraft des Schweizerischen Geistes.“274

Im Dokumentarfilm des Schweizer Fernsehens „Das war die Landi - Ein Erinnerungsfilm an die Schweizerische Landesausstellung 1939 in Zürich“, der am 18. Juni 1989 ausgestrahlt wurde, kommentiert die Erzählerstimme mit pathetischpatriotistischem Unterton die historischen Film-, Bild- und Tonaufnahmen der LA. Der letzte Raum mit dem prosaischen Titel „Gelöbnis“ wird den Fernsehzuschauer^innen im historischen Kontext der „geistigen Landesverteidigung“ erklärt:

„Der Patriotismus schlug hohe Wellen. Doch man hüte sich darüber zu lächeln. Dieser Patriotismus war damals von staatserhaltender Notwendigkeit. Hier in diesem Raum stand das berühmte Denkmal vom Wehrmann, der seinen Waffenrock anzieht. Was der einfache Soldat beim Betrachten dieser Skulptur wohl dachte? In dieser Halle ging es besonders feierlich zu. Ohne Geheiss, ganz spontan, zogen die Männer ihre Hüte, vor der Skulptur der vier Landesteile über denen ein Genius schwebte.“275

Der Raum „Gelöbnis“ verwies auf den am Eingangstor bekundeten ewigen Bund, der die Grundlage des Ideenguts der ,Schweizer Volksgemeinschaft“ symbolisierte und diese imaginierte „Geistesgemeinschaft“ (Etter) in eine „glückliche“ Zukunft führen würde. Das „Gelöbnis“ war im Kontext der „geistigen Landesverteidigung“ nicht allein dem mythenumwobenen Schwur der drei Eidgenossen von 1291 gewidmet, sondern es wurde als ein militärisches Treuegelöbnis gegenüber der Schweizer Armee und deren Oberbefehlshaber, General Henri Guisan (18741960), verstanden.

274 Mojonnier 1939a, 40.

275 „Das war die Landi - Ein Erinnerungsfilm an die Schweizerische Landesausstellung 1939 in Zürich“ ausgestrahlt am 18. Juni 1989, 20:00 - 21:50, SRF Archiv, https://www.srf.ch/play/tv/archiv perlen/video/landi-39-in-zuerich?id=bc00b7a7-7c7c-4638-ad0b-00a60cb44412, 10.10.2020. 


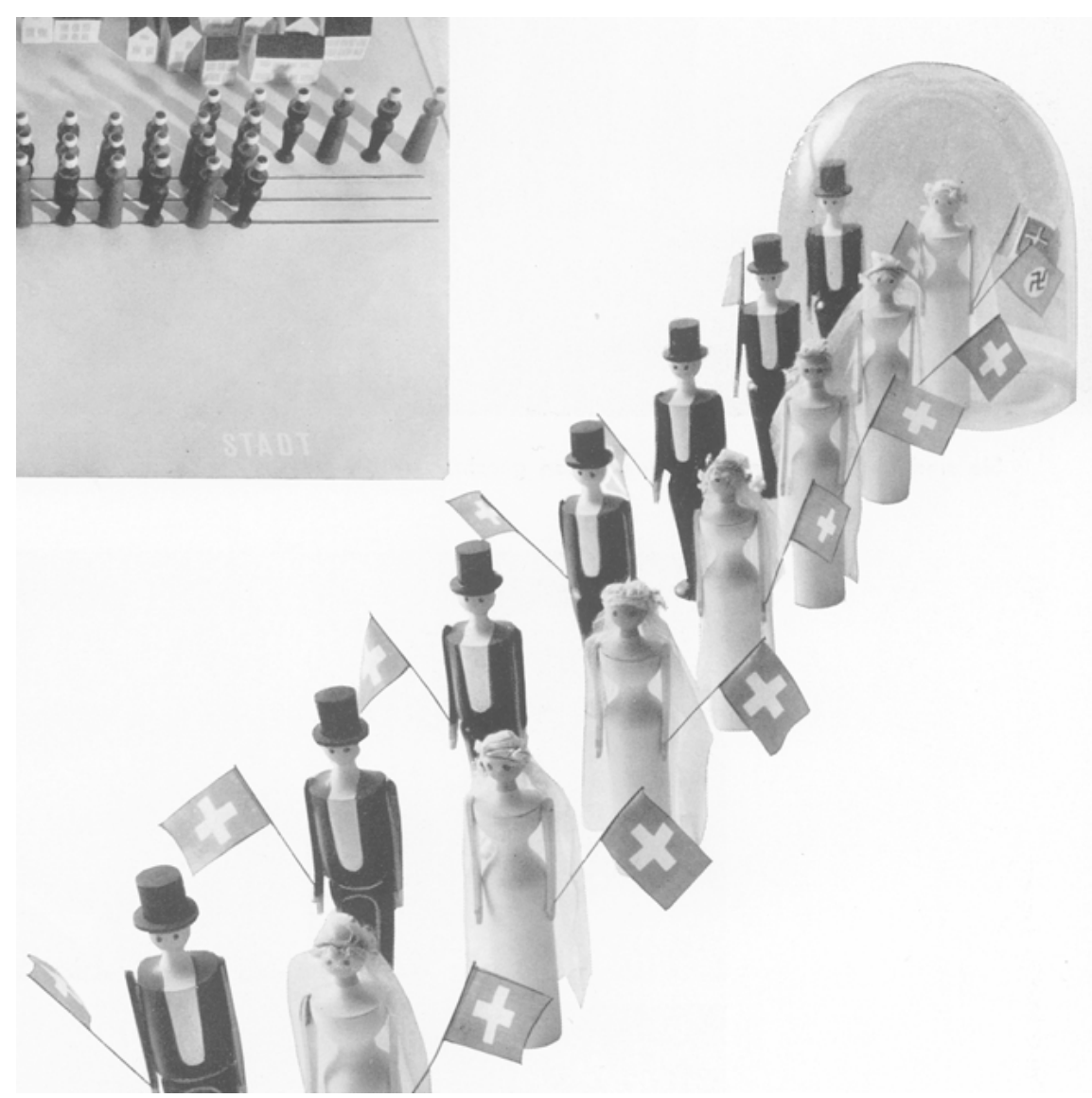

Abb. 30: „Verbreitung der neuen Blutzufuhr“: [Schweizer Heiratspolitik an der LA: Eine Braut hält die Hakenkreuz-Flagge des NS-Regimes], [Auszug aus originalem Fototext], Abt. I „Heimat und Volk“, LA 1939 Zürich

Die Skulptur der Schweizer „Wehrbereitschaft“ von Hans Brandenberger (Abb. 31$)^{276}$ symbolisiert die selbstdisziplinarische Opferbereitschaft eines

276 Die Bildunterschrift zu dieser Illustration in „Das goldene Buch der LA 1939“ lautet: „Hätte dieser Geist und diese Bereitschaft nicht seit jeher in unserem Volke bestanden, so wäre die Eidgenossenschaft weder entstanden noch erhalten geblieben. Die Wehrpflicht jedes Bürgers ist in der Schweiz keine Erfindung der Neuzeit, sondern 650jährige Tradition, so dass die Pflicht fast mehr als ein selbstverständliches Recht aufgefasst wird. Wenn das Vaterland ruft, legt der Schweizer das bürgerliche Kleid weg und zieht den Waffenrock an. Hans Brandbergers ,Wehrbereitschaft‘ gibt diese Wandlung vom friedlichen zum kampfbereiten Bürger plastisch wieder. 


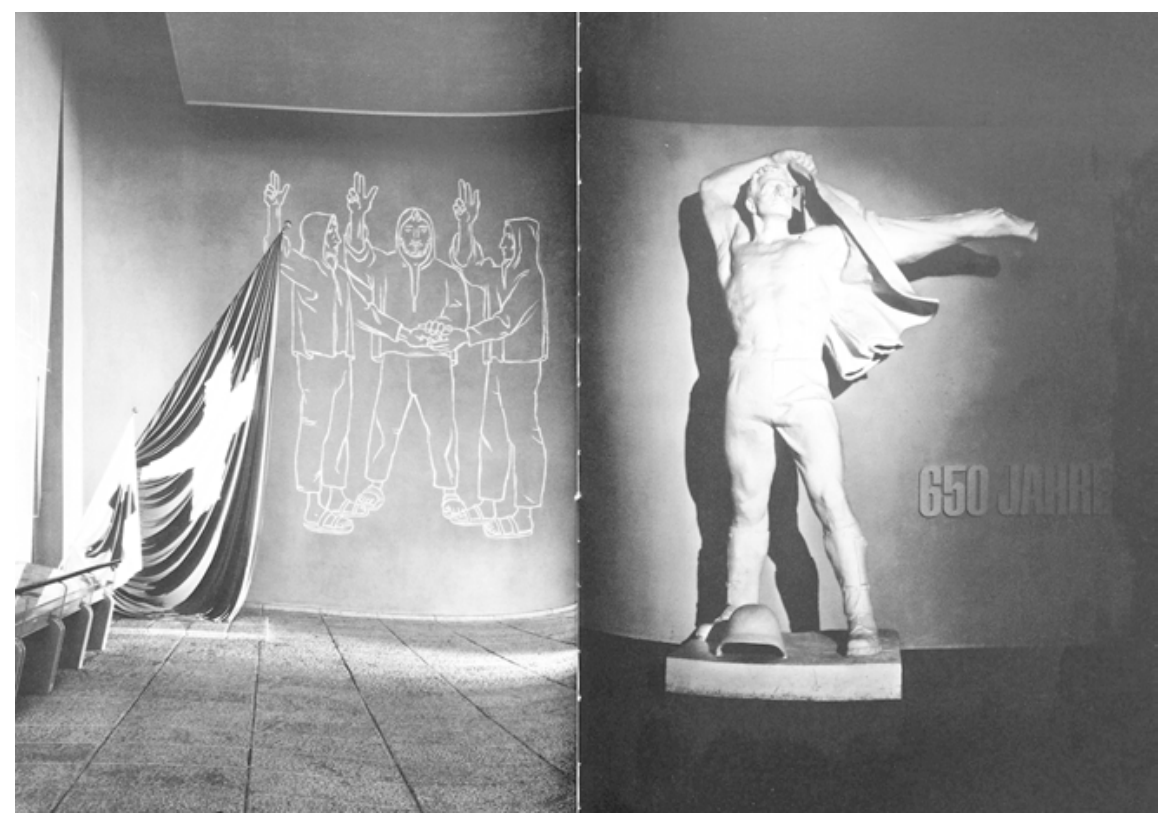

Abb. 31: [lkone der Schweizer „Wehrbereitschaft“]: Hans Brandenberger (Bildhauer): „Wehrbereitschaft“, 1939. [Im Hintergrund: Der „Rütli Schwur“, die Gründungslegende der Alten Eidgenossenschaft symbolisiert durch den Schwur der drei Eidgenossen (Uri, Schwyz und Unterwalden) 1291, sich gegen die Habsburgische Fremdherrschaft zur Wehr zu setzen], Halle „Gelöbnis“, Abt. I „Heimat und Volk“, LA, Zürich, 1939

Schweizer Bürgers, der im Kriegsfall seine Zivilbekleidung ablegen und den „Waffenrock“ anziehen würde. Als Soldat würde er die Schweizer Werte des ewigen Bunds der Schweizer „Geistesgemeinschaft“ beschützen und damit nicht nur die nationale Freiheit seines Landes, sondern auch seine eigene Freiheit als demokratischer Bürger verteidigen. In diesem Sinne lautete das „Gelöbnis“ der Politik einer Schweizer Gefühlskultur, das im letzten Ausstellungsraum „Heimat und Volk“ von einer pseudoreligiösen Schweizer Glaubensgemeinschaft beschworen wurde, wie folgt:

„Rufst du mein Vaterland?

Sieh' Uns mit Herz und Hand

Die Wappen der drei Urkantone mahnen stolz an das kostbarste Erbe der Vergangenheit: unsere Freiheit. Und jeder fühlt, dass Rütli, Morgarten und Sempach sich tief in unsere Herzen eingegraben haben und in der Stunde der Gefahr ebenso opferfreudig Nachfahren finden werden. Wir sind bereit!“ Vgl. Mojonnier 1939b, 66. 


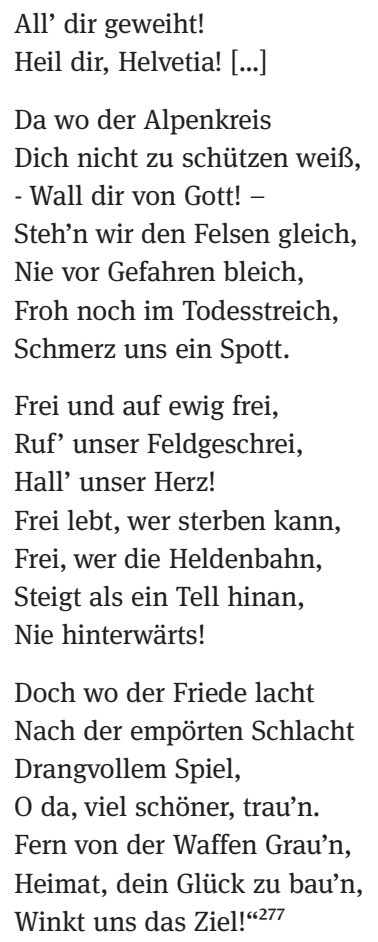

„Froh noch im Todesstreich“ sollte die autosuggestive Emotionalisierung und „opferfreudige“ Bejahung des Schweizer Werte- und Machtsystems die leistungsorientierte Mobilisierung als selbstdisziplinarischen Dienst am „Vaterland“ legitimieren. „Tell“, die transnationale Mythenfigur eines Freiheitskämpfers, war das emotionspolitische Sinnbild der LA für einen männlich-stereotypisierten Schweizer „Wehrmann“ im Sinne einer affirmativen Gefühlspolitik im Kontext der „geistigen Mobilmachung“. ${ }^{278}$ Zukunftsweisend für diese affirmative Gefühlspolitik war ein ideologisch, biologistisch und kulturnationalistisch konstruiertes Zusammengehörigkeitsgefühl einer „,öllkerpsychologischen“ Einheit in der kulturellen Vielfalt. In christlicher Analogie beruft sich diese imaginierte „Geistesgemeinschaft“ in Krisen-, Kriegs- und Friedenszeiten auf einen „ewigen Bund“, der die Nation auf der Grundlage ihrer arbeitsmoralischen Lebensführung in

277 „Gelöbnis“ neben gleichnamiger Plastik im letzten Raum der Abt. 1 „Heimat und Volk“, beim Ausgang aus der Höhenstrasse. Vgl. Mojonnier 1939b, 96.

$278 \mathrm{Zu}$ Tell s. Kap. 16.2. 
selbstbestimmter „Freiheit“ zusammenhalten würde und in eine utopische, „glückliche“ Zukunft führen könne.

Vor diesem Hintergrund machte Bundespräsident Etter nach Ausbruch des Zweiten Weltkriegs eine gewagte Zeitdiagnose: Die Schweiz befände sich gegenwärtig „mitten im Kraftfeld der großen europäischen Entscheidung“, die er als eine „,Glückliche Gefahr““279 bezeichnete. ${ }^{280}$ „Glücklich deshalb, weil sie uns wieder zur Besinnung auf die Werte unseres Landes zwang und die Flamme der Opferbereitschaft für das Vaterland in einem an die besten Zeiten unserer Geschichte erinnernden Maße entfachte. “281 Etter deutete die Krisen- und Kriegssituation als „glückliche Gefahr“ für die Schweiz, in der sich der demokratische Nationalstaat und dessen Bevölkerung auf ihre historisch gemeinsam imaginierten Werte- und Moralvorstellungen und auf ein biologistisches Zusammengehörigkeitsgefühl besinnen müsse, um während und nach der Krise als „Geistesgemeinschaft“ emotionspolitisch vereint auftreten und den „glücklichen“ Wiederaufbau leistungsorientiert tätigen zu können. In einer Publikation über die emotionspolitische Bedeutung der „Höhenstraße“ im Kontext der internationalen Kriegsbedrohung hieß es im Rückblick:

„Eine solche Zeit verlangte geradezu, daß man dem Volke seine Höhenstraße erschloß, auf der es zusammenfassend all das sehen, erleben und schätzen konnte, was ihm als Einzelerscheinung bereits als ein besonderer Vorzug seiner Heimat zum Bewußtsein gekommen war.“282

Das „Gelöbnis“ einer Schweizer Gefühlspolitik im „ewigen Bund“ war eine historische Referenz auf den mythischen Bund der alten Eidgenossenschaft, die sich gegen ideologische und militärische „Eindringlinge“ aus dem Ausland zur Wehr gesetzt hätte. Das „Gelöbnis“ stand im Rahmen der LA, wie schon 1291, in einem transnationalen Spannungsfeld: innenpolitisch gegenüber Sympathisant`innen der Gefühlspolitik der NS-Arbeitsmoral, außenpolitisch gegenüber der militärischen Überlegenheit der „deutschen Wehrmacht“. Umso mehr war es Etter im Sinn einer ,geistigen Mobilmachung“ ein Anliegen, im Rahmen einer affirmativen Gefühlspolitik der Bevölkerung die Hoffnung zu vermitteln, dass die Schweizer Heimat nach dem Krieg (eine Invasion war zu diesem Zeitpunkt nicht auszuschließen) gemeinsam auf der Grundlage schweizerischer Werte wiederaufgebaut

279 Etter zit. nach Rimli 1939b, 5.

280 Vgl. Rimli 1939b, 5.

281 Vgl. ebd.

282 Ebd. 
werden könne und die „Geistesgemeinschaft“ nach aller Entbehrung (wieder) ein kollektives „Glück“ finden würde. Dieses „Gelöbnis“ ist in der gleichnamigen

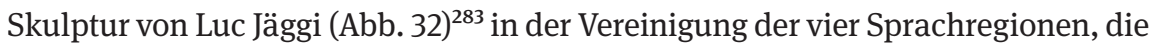
von einem übernatürlichen Schutzgeist begleitet werden, symbolisiert.

Viele Besucher`innen der LA verstanden die emotionspolitische, nationale Sendung der Skulptur. Dies dokumentieren auch die historischen Filmaufnahmen jener Männer, die vor der Skulptur ehrfürchtig ihren Hut zogen. Diese Schweizer erkannten sich in der Darstellung des „ewigen Bundes“ und dessen „Gelöbnisses“

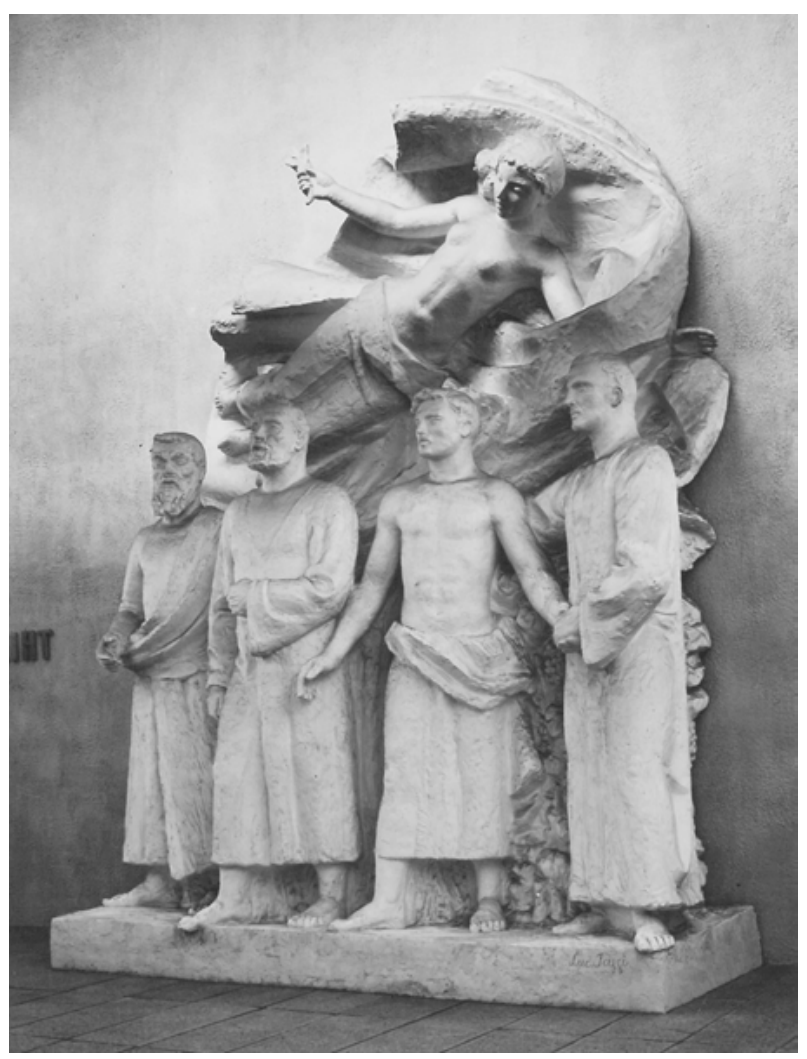

Abb. 32: [„,Gelöbnis“ zur Wehrbereitschaft]: Luc Jaggi (Bildhauer): „Gelöbnis“, 1939, Inschrift: „Rufst Du, mein Vaterland“ in allen vier Landessprachen, Halle „Gelöbnis“, Abt. I „Heimat und Volk“, am Ende der Höhenstrasse, LA, Zürich, 1939

283 Bilder aus der Schweizerischen Landesausstellung Zürich 1939. Sonderdruck der Zeitschrift „Werk“. Schweiz. Monatsschrift für Architektur, Freie Kunst, Angewandte Kunst. In: Das Werk, Jg. 26, H. 5-6, 1939, Zürich: Gebr. Fretz, 41. 
wieder. Ihre Zustimmung zum propagierten Schweizer Moral- und Wertesystem im Rahmen der affirmativen Gefühlspolitik der ,geistigen Landesverteidigung“ (top down) demonstrierten die emotional mobilisierten Besucher spontan in ihrer Geste einer emotionspolitischen Körperpraktik (bottom up). Der ästhetische Erlebnisraum der Landesausstellung bot den angemessenen Schauplatz für die aktive Selbstdarstellung eines propagierten Glückswissens.

Der Ausstellungsbereich der Abt. I „Heimat und Volk“ mit seiner „Höhenstrasse“ und seinen Ausstellungsräumen zu Themen wie „Volk“ und „Gelöbnis“ wurde als eine multimediale Wissensvermittlung konzipiert und als erziehungsund emotionspolitisches Propagandamittel massenpsychologisch eingesetzt. Das Ziel war, eine gemeinschaftsstiftende Gefühlspolitik bei den Besucher^innen auszulösen und sie im Sinne einer „geistigen Mobilmachung“ zwar für einen (militärisch eher aussichtslosen) Kriegseinsatz zu aktivieren, jedoch mit dem emotionspolitischen Versprechen zu vertrösten, dass die Schweiz am Ende zumindest die moralischen ,Sieger‘ einer „glücklicheren“ Zukunft werden würden, wie es sie die Geschichte der Eidgenossenschaft in der Propagandaausstellung „Heimat und Volk“ lehrte.

Folgende Erkenntnisse lassen sich an dieser Stelle zusammenfassen: Das Ziel der LA war es, die Selbstdarstellung einer „glücklichen“ Schweizer Arbeitswelt im Kontext der antifaschistischen und antinationalsozialistischen Abgrenzungs- und Distinktionsstrategie der „geistigen Landesverteidigung“ $\mathrm{zu}$ demonstrieren. Das Ausstellungskonzept der „Höhenstraße“ der Abt. I „Heimat und Volk“ zielte 1. auf eine leistungsorientierte Selbstdarstellung, 2. auf eine ideologische Anweisung zur autosuggestiven Emotionalisierung und Wiedererkennung in wissenshistorischer Kontinuität zur individualisierten Selbstoptimierungskultur der transnational rezipierten Erfolgs- und Glücksratgeber, 3. zur selbstdisziplinarischen Erziehung und 4. zur gemeinschaftsstiftenden Mobilisierung der Bevölkerung.

Die konstruierte Erlebniswelt der „Landi“, wie die Ausstellung verniedlichend im Volksmund genannt wurde, sollte, in wissenshistorischer Kontinuität zu Eberles theaterwissenschaftlicher Festspieltheorie einer Schweizer VolkstheaterKultur, in der architektonischen Form einer kultischen Feierstätte die Besucher`innen emotionspolitisch mobilisieren. ${ }^{284}$ Auf welche Weise? Die interaktiv gestaltete Ausstellung der LA als Propagandainstrument einer affirmativen Gefühlspolitik sollte die Besucher^innen, im Unterschied zu einer passiven Hörerschaft einer politischen Festrede, emotionalisieren.

Die Fotoreportage in der „Schweizer Illustrierten“ „Jeder genießt die Landesausstellung auf seine Weise“ vom 24. Juni 1939 veranschaulicht (Abb. 33), mit

284 Mehr dazu im Verlauf dieses Kapitels. 
welchen emotionspolitischen Propagandamitteln das Ausstellungskomitee darauf abzielte, dass möglichst alle Altersgruppen gesellschafts-, sprachen- und geschlechterübergreifend im Sinne eines imaginierten Zusammengehörigkeitsgefühls und als Symbol einer kollektiven Schweizer Arbeits-, Leistungs- und „Geistesgesellschaft“ an den unterschiedlichen Partizipationsmöglichkeiten der LA teilnehmen konnten. Die Reportage zählt spielerische Aktivitäten auf, wie zum Beispiel die Wissensvermittlung für Fachleute ${ }^{285}$ und solche, die es einmal werden wollten. ${ }^{286}$

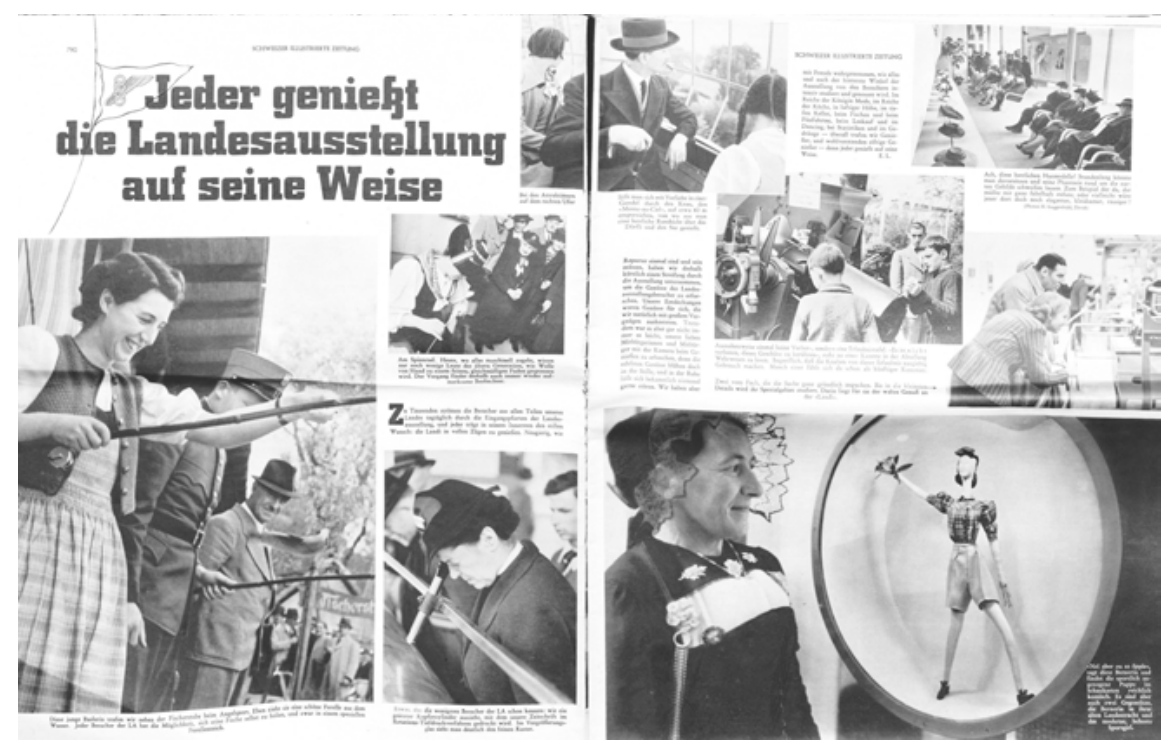

Abb. 33: [Emotionspolitische Aktivierung der LA-Besucher*innen]: „Jeder genießt die Landesausstellung auf seine Weise“, Fotoreportage in der „Schweizer Illustrierten“, 1939

285 Abb. 33: Wissenschaftler^innen begutachten die Ausstellungspräsentation ihres Fachgebiets, rechts: „Zwei vom Fach, die die Sache ganz gründlich anpacken. Bis in die kleinsten Details wird ihr Spezialgebiet studiert. Darin liegt für sie der wahre Genuß der ,Landi““. Vgl. N.N. „Jeder genießt die Landesausstellung auf seine Weise“. Schweizer Illustrierte Zeitung, Sonderausgabe, 24.06.1939, Nr. 14, 790 f., 791, VII.80.52, StArZ.

286 Abb. 33: Knaben betätigen ein Kanonengeschoss: „Ausnahmsweise einmal keine Verbot-, sondern eine Erlaubnistafel. ,Es ist nicht verboten, dieses Geschütz zu berühren', steht an einer Kanone in der Abteilung Wehrwesen zu lesen. Begreiflich, daß die Knaben von dieser Erlaubnis ausgiebig Gebrauch machen. Manch einer fühlt sich da schon als künftiger Kanonier.“ Vgl. ebd., 791. 
Ein weiteres Beispiel einer emotionspolitischen Aktivierung der Besucher`innen waren die zahlreichen Kulturveranstaltungen (neben Theateraufführungen, Festspielen, Konzerten, Modeschauen etc.), die im Rahmenprogramm der LA stattfanden. Exemplarisch sei hier das Eidgenössische Trachtenfest genannt. Nationalgefühle wie „Glück“, Freude und Heimatliebe sowie eine tiefe, emotionale Verbundenheit und Solidarität mit dem Schweizer Bauernstand schien dieses Fest bei einigen Zuschauer*innen wachzurufen. Vom Anblick des Umzugs emotional ergriffen, schrieb ein Besucher:

„Die Trachtenbewegung wuchs an jenen beiden Augusttagen über sich selber hinaus. Sie sprengte den Kreis ihrer selbstgesetzten Ziele und wurde zur machtvollen Verkörperung unseres Nationalgefühls überhaupt. War es ihr vor dem bewusst gewesen, dass sie in Wirklichkeit Träger und Werkzeug einer Erneuerungsbewegung war, die das ganze Volk zu durchsäuern begonnen hatte und nun das Trachtenfest zum willkommenen Anlass nahm, sich im jubelnden Glück einer wahren Selbstfindung zu sonnen? [...] aus der Sache des Bauernstandes wurde durch die begeisterte Zustimmung Hunderttausender eine wahrhaft nationale Bewegung.

Denn in diesem Trachtenvolk, das in seiner Herrlichkeit vor uns Städtern vorüberzog, erkannten wir uns plötzlich selber in den besten Zügen unseres eigenen Wesens. Die Tränen herzbeklemmender Freude, die über tausend Wangen rannen, galten dem Heimatboden, zu dem wir alle uns in unserem tiefen Unbewusstsein heimlich zurücksehnen, dem Glück der Bestellung des Ackers [...].

[...] wir spürten alle leise in uns das Bauernblut rollen, das immer wieder die Bevölkerung der Städte mit neuen Säften durchsetzt und so zum Quell fortwährender Erneuerung der Volkskraft wird, die sich ohne solche Zufuhr neuer Energien in der Welt der Städte verzehren müsste. Und wer von uns beglückten Zuschauern irgendwo auf dem Lande draussen Verwandte wusste oder Angehörige seines Geschlechtes gar im Zuge sah, der wurde dieser Verbundenheit plötzlich mit einer Innigkeit froh, und Tausende mag der Wunsch angekommen sein, aus dem Spalier der Zuschauer hinauszutreten und in den Reihen des Trachtenvolkes mitzuschreiten.“287

Dieses Beispiel eines Augenzeugenberichts zeigt in erstaunlicher sprachlicher Nähe zur „Blut-und-Boden“-Ideologie des NS-Regimes und der NS-Theaterwissenschaft, welche emotionspolitische Wirkungsmacht das Trachtenfest als Propagandainstrument bei den Zuschauer*innen auslösen konnte und welche Nationalgefühle in diesem Zusammenhang genannt wurden. Der Städter fühlte sich „beglückt“ beim Anblick der romantizistisch-kulturnationalistischen Idealisierung des Schweizer Bauerntums im Kontext der Leistungsschau einer Schweizer Arbeitsmoral. Der Zuschauer fühlte sich biologistisch („organisch“ in den Worten Etters) mit dieser antimodernistischen Illusion einer bäuerlichen Lebensführung verbunden. In wissenshistorischer Kontinuität zum leistungsorientierten Per-

287 Thommen 1939, 90. 
sönlichkeits- und Selbstoptimierungsdiskurs der Ratgeberliteratur beschreibt der LA-Besucher ein Gefühlserlebnis „im jubelnden Glück einer wahren Selbstfindung“. Er begriff die „Trachtenbewegung“ als „nationale Bewegung“ einer affirmativen Gefühlspolitik. In der Wiedererkennung des Individuums im kulturnationalistischen Spiegel eines imaginierten Kollektivs erkannte der Zuschauer die „Verkörperung unseres Nationalgefühls“ im idealisierten Symbol des Bauernstands und in dessen Arbeitsglück, dem „Glück der Bestellung des Ackers“. Diese gefühlspolitische Erkenntnis, die über eine intellektuelle Reflexion hinaus in einer körperlichen Gefühlsregung als Glücksempfindung massenpsychologisch erfahrbar wurde, bewirkte beim Zuschauer ein selbstdisziplinarisches Bestreben, selber aktiv zu werden. Der LA-Besucher verspürte den Wunsch, an dieser politischen Feier der kulturnationalistischen Schweizer Gefühlskultur mitzuwirken. Im Dienst an dieser emotionspolitischen Selbstdarstellung eines ewigen Bundes wollte er „in den Reihen des Trachtenvolkes“ mitschreiten, in der Hoffnung, in dieser kollektivistischen Körperpraktik ein biologistisch gedeutetes Zusammengehörigkeitsgefühl (oder „Verschmelzung“ nach Kindermann) zwischen Städter`innen und Bauern/Bäuerinnen als Schweizer Volks- und Arbeitsgemeinschaft erleben zu können.

Diese emotionspolitische Identifikation mit einem imaginierten Wir erinnert im transnationalen Vergleich an die Beobachtungen des Auslandschweizers Denis de Rougemont, der aus einer Außenperspektive das befremdliche Erlebnis eines emotionspolitischen Gemeinschaftsgefühls der „deutschen Volksgenossen“ bei einer kultisch anmutenden NS-Massenveranstaltung in Frankfurt beschrieb: „Ich bin allein und sie sind eine Gemeinschaft." ${ }^{288}$ Vor diesem Hintergrund müsste, aus einer transnationalen Vergleichsperspektive, Hendrik de Mans Warnung vor populistisch-emotionspolitischen Glücksversprechen, die auf arbeitspsychologisches Glückswissen zurückgriffen, insoweit recht gegeben werden, als eine affirmative Gefühlspolitik in ihrer jeweiligen länderspezifischen Ausprägung historisch nicht nur in NS-Deutschland, sondern auch in einem demokratisch regierten Nationalstaat wie der Schweiz in Erscheinung treten konnte. ${ }^{289}$

Dem Eidgenössischen Trachtenfest der LA lag, wie schon in den vorangegangen Fallbeispielen erwähnt, eine janusköpfige Eigenschaft als affirmative Gefühlspolitik zugrunde: In Wahrheit hatten viele Landwirte aufgrund ihrer beruflichen Sorgen, ihrer betrieblichen Verpflichtungen und mangels finanzieller Mittel keine Möglichkeit, die LA zu besuchen. Ein Milchbauer aus dem Appenzell äußerte gegenüber einem Journalisten auf die Frage, warum er nicht zur LA ginge:

288 Rougemont 2004, 112 (Kap. 16.4).

289 Vgl. Man 1933b (Kap. 16.3). 
„Nää, i vermag’s nomme, d' Süüch isch nütz Rentables.“290 Vom durchschnittlichen Milchertrag von 50 Litern pro Tag erhalte er aufgrund der Viehseuche noch 7 Liter pro Tag. Wenn die LA in St. Gallen stattfände, würde er einen Besuch vielleicht riskieren, „aber Zöri isch för miin Göldseckel ond zom Laufe e chli z’wiit-eweg. “291 Ausgerechnet der Berufsstand der Schweizer Bäuerinnen, welchen die LA propagandistisch und emotionspolitisch wirkungsmächtig für das LA-Publikum idealisierte, konnte oftmals nicht am ,Landi-Glück' teilhaben. Dasselbe galt für viele Angestellte, welche sich die Reise nach Zürich und den Eintritt zur LA nicht leisten konnten. Ein Dienstmann, der am Basler Bahnhof arbeitete, erläutert pointiert: „[...] dann können die einfachen Arbeiter eben nicht an die Landi kommen. Und in dem Fall kann es mit diesem Unternehmen am Ende nicht gut herauskommen, denn der Arbeiter ist derjenige, der das Geld bringt.“292

Mit dem Ausbruch des Zweiten Weltkriegs wurde Etters Appell zur „geistigen Mobilmachung، über Nacht Realität und die Landesausstellung wurde zum emotionspolitischen Sinnbild der Schweizer Wehrhaftigkeit gegenüber Hitlers „Blitzkrieg“-Strategie. Die per Gesetz angeordnete „Mobilmachung“ der Schweizer Armee galt für alle Schweizer Bürger, ob sie sich emotionspolitisch der „Glaubensgemeinschaft“ im Sinne der „geistigen Landesverteidigung“ zugehörig und dem „Gelöbnis“ des ewigen Schweizer Bundes aus patriotischen Nationalgefühlen verpflichtet fühlten oder nicht.

Nachdem im ersten Teil des Kapitels der Fokus auf dem Ausstellungskonzept der Abt. I „Heimat und Volk“ lag, soll im zweiten Teil das Augenmerk auf das emotionspolitische Konzept des offiziellen Festspiels der LA gerichtet werden.

290 “,Nein, ich kann es mir nicht leisten, die Seuche (Viehseuche) ist nichts Rentables.“” [Übersetzung von der Autorin], vgl. „,Was heet er gseet, Landesustellung?‘ Bilder und Worte von solchen, die nicht kommen dürfen, können oder wollen!“. In: Zürcher Illustrierte, Nr. 28, 1939, S. 1197., VII.80.50a, StArZ.

291 „Aber Zürich ist für meinen Geldbeutel und für einen Fussmarsch zu weit weg.“ [Übersetzung von der Autorin], Ebd.

292 „Es ist dieses Jahr wirklich wenig los. Es kommen fast keine Fremden mehr. Aus Deutschland zum Beispiel kommt überhaupt kein Bein mehr. Ja und wie soll man dann in diesen Verhältnissen noch an eine Ausstellung reisen können? Wenn das so weitergeht, dann können die einfachen Arbeiter eben nicht an die Landi kommen. Und in dem Fall kann es mit diesem Unternehmen am Ende nicht gut herauskommen, denn der Arbeiter ist derjenige, der das Geld bringt.“ [Übersetzung von der Autorin]. Orginaltext im Basler Dialekt: „Es isch das Johr hailles wenig los. Es kemme fascht kaini Fremde meh. Us em Diitsche zum Bischspiel kunnt iberhaupt kai Bai meh. Ja und wie soll me derno in däne Verheltnis no kenne an d'Usstellig reise? Wenn das däwäg wyter goht, derno kenn halt die aifache Arbeiter nit an d'Landi. Und in däm Fall kas mit däm Unterähme nit geut useko, denn der Arbeiter isch däjenig, wo’s Gäld bringt.!“ „,Was heet er gseet, Landesustellung?‘ Bilder und Worte von solchen, die nicht kommen dürfen, können oder wollen!“. In: Zürcher Illustrierte, Nr. 28, 1939, S. 1196 f., VII.80.50a, StArZ. 
Aus einer transnationalen Perspektive wird „Das eidgenössische Wettspiel“ in seinem historischen Entstehungs- und Aufführungskontext mit Bezug auf Arnets Festspieldramatik und Eberles theaterwissenschaftliche Festspieltheorie und -gestaltung vor dem Hintergrund der Schweizer Nationaltheater ${ }^{293}$-Debatte wissenshistorisch untersucht.

Für den transnationalen Vergleich orientiert sich die Untersuchung methodisch an Martin Sterns theaterhistorischen Kriterien zum Schweizer Festspiel, welche für den Zeitraum der 1930er bis 1950 Jahre herausgearbeitet wurden: „enkomiastisch-verklärend“, „utopisch-verheißend“ und „satirisch-realitätsbezogen“. ${ }^{294}$ Diese Analysekriterien werden in Bezug auf das LA-Festspielkonzept kritisch angewendet und um die Perspektive einer affirmativen Gefühlspolitik erweitert. Im transnationalen Vergleich zum Festspiel „Glückliches Volk“ (Kap. 16.5) geht die Untersuchung von folgenden Forschungsfragen aus:

293 Ansätze einer Schweizer Nationaltheater-Debatte sind bereits bei Jean-Jacques Rousseau (1712-1778), dem Genfer Moralphilosophen und aufklärerischen Vordenker der Französischen Revolution, und dessen Favorisierung eines nationalen, ,patriotischen` Festspiels gegenüber dem städtischen, als mondän und ,unsittlich` empfundenen Schauspiel zu erkennen. Vgl. u.a. Brief an d'Alembert (1758, z.T. dt. 1761) und „Julie oder Die neue Héloise“ (1761, dt. 1761/1776), „Emile oder Von der Erziehung“ (1762, dt. 1762), „Vom Gesellschaftsvertrag“ (1762 dt. 1782). Vgl. Jacob 2012. Weiter ist der im Übrigen schon damals transnational geführte Schweizer Nationaltheater-Diskurs beim Schweizer Schriftsteller Gottfried Keller („Am Mythenstein“ 1861) zu erwähnen. Keller verfasste anlässlich einer Feier zu Schillers 100. Geburtstag eine Abhandlung zu Schillers „Wilhelm Tell“ und zur Schweizer Festspielkultur und ergänzte diese mit dem Entwurf eines nationalen Festspiels. Vgl. Amrein 2016, 197. Auf Kellers „Mythenstein“ bezog sich wiederum Eberle u.a. im Rahmen des LA-Festspiels. Vgl. Eberle 1939a, 17-32. Ferner sind Diskursansätze bei dem von Schiller für die theaterästhetische Theorie der „Schaubühne als moralische Anstalt betrachtet“ rezipierten Schweizer Philosophen und Theologen Johann Georg Sulzer (1720 - 1779) („Allgemeine Theorie der schönen Künste“ [1771-1774]) zu finden. Vgl. Sulzer 1994. Für die wissenshistorische Kontinuität der Debatte seit 1900, die bis in die 1940er und 1950er Jahre von politisch rechten (Gonzague de Reynold) bis linken (Jacob Bührer) Vertreter^innen bereits während der Weimarer Republik und später in der NS-Zeit heftig gegen ,ausländische Einflüsse“ geführt wurde (z.B. durch den Schweizerischen Schriftstellerverein, SGTK), vgl. u.a. Max Zollinger 1909. Eine schweizerische Nationaltheaterbühne. Eine Studie zur schweizerischen Theatergeschichte, Aarau: Sauerländer \& Co; Jacob Bührer. 1912. Die Schweizerische Theaterfrage und ein Vorschlag zu ihrer Lösung, Bern: A. Francke; Carl Friedrich Wiegand. 1909-1910. Eine schweizerische Nationalbühne? In: Wissen und Leben, 5: 401-403; Paul Lang. 1924. Bühne und Drama der deutschen Schweiz im XIX. und beginnenden XX. Jahrhundert. Zürich: Orell Füssli; Otto von Greyerz. 19241945. Zur schweizerischen Theaterfrage. In: Schweizerische Monatshefte für Politik und Kultur, 4: 406-411. Zur historischen Forschung, vgl. u.a Mattioli 1995, Rosenberger 2001, Amrein 2004, Amstutz 2000, Schulz 2012.

294 Vgl. Das Festspiel, 126-157. In: Stern 2000, 157. 
1. Welcher Entstehungskontext, welche Handlung, Dramaturgie und Theaterästhetik lagen dem offiziellen LA-Festspiel zugrunde?

2. An welche Nationalgefühle appellierte die affirmative Gefühlspolitik des LAFestspiels? Welches emotionspolitische Ziel verfolgten die Theaterschaffenden im Kontext einer „geistigen Mobilmachung“ und einer theaterwissenschaftlichen und theaterpolitischen Debatte über ein Schweizer Nationaltheater und eine Schweizer Volkstheaterkultur?

3. Wie wurde das Festspiel rezipiert?

Ausgehend vom Forschungsstand der theaterhistorischen Untersuchung bei Alain Tschudi über „Das eidgenössische Wettspiel“295 wird zunächst der Entstehungskontext und die Festspielhandlung kurz erläutert. Anschließend liegt der Schwerpunkt auf einer Analyse des Festspiels mit Fokus auf das emotionspolitische Konzept von Arnets Festspieldramatik und Eberles theaterwissenschaftlicher Festspieltheorie. Die praktische Anwendung Eberles Festspiel- und Laienspieltheorie wird einerseits im Kontext der LA-Gefühlspolitik einer Schweizer Nationaltheater-Debatte, andererseits im transnationalen Vergleich zu de Mans sozialistischem Massenspiel und der NS-Theaterwissenschaft (Kindermann, Niessen) sowie der NS-Theaterpraktik (Niedecken-Gebhard) analysiert.

Edwin Arnet, Inlandredakteur der „Neuen Zürcher Zeitung“, ging als Gewinner eines Wettbewerbs hervor, welchen das LA-Organisationskomitee im Vorfeld lanciert hatte. Dramatiker unterschiedlicher politischer Ausrichtungen nahmen an diesem Wettbewerb teil. Zu den Kandidaten zählten der Kabarettist Walter Lesch (1898-1958) vom „Cabaret Cornichons“ („Die kleine große Schweiz“), der Schriftsteller und Nationalrat Felix Moeschlin (1882-1969) („Festspiel 1939“) sowie der Dramatiker und Literaturprofessor Robert Faesi mit einem Entwurf für ein „Weihespiel“.${ }^{296}$ Entsprechend der politischen Haltung der Festspielautoren enthielten die Festspielentwürfe, welche von sozialistischen Massenspielen bis zu kultischen Festspielen reichten, jeweils kritische Aussagen über das NS-Regime und/oder die Schweizer Politik. Folglich waren sie aus Sicht des LA-Komitees mehr oder weniger mit der emotionspolitischen Ambivalenz aus Schweizer Neutralität und „geistiger Mobilmachung“ vereinbar.

Das Festspiel von Arnet konnte nach intensiver Überarbeitung durch den Regisseur Oskar Eberle am Eröffnungstag der LA, am 6. Mai 1939, Premiere feiern

295 Vgl. Tschudi 1993, Tschudi 2000.

296 Zum Wettbewerbsverfahren und der Entstehung der Festspielleitung vgl. Eberle 1939c, Eberle 1940. Vgl. Tschudi 1993. 


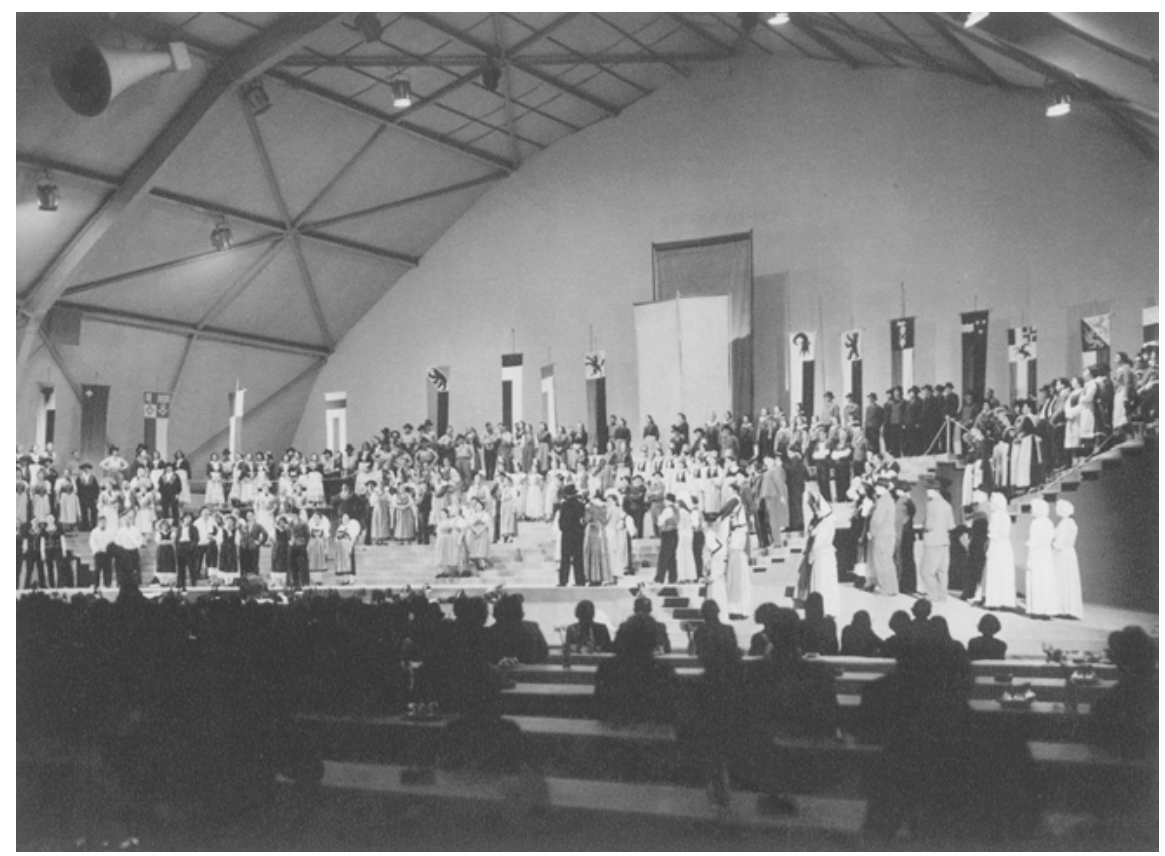

Abb. 34: „,Das eidgenössische Wettspiel‘ von Edwin Arnet, Musik von Paul Müller, Regie: Oskar Eberle. Das Spiel zeigte die Gefahren, die der Schweiz von aussen und innen drohen und wie sie überwunden werden können. Fast 150000 Menschen haben es in 34 Aufführungen gesehen: das war der bisher grösste Festspielerfolg in der Schweiz.“ [Originaler Fototext], Offizielles LA-Festspiel, Festhalle, Zürich, 1939

und wurde anschließend wöchentlich in der Festhalle aufgeführt (Abb. 34). ${ }^{297}$ Es fanden 34 Abendvorstellungen statt, die von rund 150.000 Menschen gesehen wurden. ${ }^{298}$ Die Begeisterung im Publikum widerspiegelte das überwältigende Lob, die das Festspiel durch die Presse erfuhr. Die 100 Meter lange und 43 Meter

297 Zur Festspielproduktion: „Das eidgenössische Wettspiel“ von Edwin Arnet, Paul Müller (Musik), Oskar Eberle (Regie), Max Hengartner (Musikalische Leitung), Herta Bamert und Rösli Möschlin (Tanzleitung), Hedwig Giger-Eberle (Kostüm), 1000 Mitwirkende, Schweizer Berufsschauspieler*innen und Mitglieder der „Freien Bühne“ Zürich, sowie Berufsmusiker^innen des Tonhalle-Orchesters Zürich, UA: 6. Mai 1939, anlässlich der Eröffnung der LA, 20:30-22:30 Uhr, Festhalle der LA in Zürichhorn, Wiederholungen jeweils donnerstags, Preise Fr. 1.50.-, 3.-, 4.-, 5.(inkl. Steuer und Programm). Vgl. Eberle 1939a, 32 [Liste der Mitwirkenden, vor der ersten Programmseite].

298 Vgl. Eberle 1939c, 71. 
breite Festspielhalle konnte 5.000 Besucher`innen empfangen und hatte eine nach hinten gestuft ansteigende Festspielbühne. ${ }^{299}$

Wie der Titel des Festspiels bereits andeutet, stand im Zentrum der Handlung eine Wette zwischen „den „zeitlosen Grundkräfte[n] des Guten und des Bösen“. ${ }^{300}$ Damit bediente sich die Festspielleitung einer für die 1920er bis 1940er Jahre typischen Handlungsform, die in Kontinuität zu den Wetten der biblischen HiobsFigur oder Goethes „Faust“ standen. Bei einer Festspiel-Wette wurde in der Regel ein dramaturgisch dreistufiger Ablauf gewählt, aus dem sich die Dialektik einer These - Antithese - Synthese ergab. Im „eidgenössischen Wettspiel“ fiel die Wahl auf ein vierstufiges Verfahren. Auf Prolog und „Vorspiel“ folgten vier „Hauptspiele“ mit jeweils einem „Zwischenspiel“. Die in einer Wette oftmals in einem zweiten Schritt auftretende Helfer- oder Ratgeberfigur wurde im LA-Festspiel von der Figur des „Schweizermannes“ dargestellt, der als moralischer Wegweiser des fehlgeleiteten „Schweizer Volks“ fungierte. ${ }^{301}$

Der „Wächter der Schweiz“, der „Genius“, tritt in der Wette gegen eine geschlechterstereotypisierte weibliche „Verführerin“ und einen männlichen „Verführer“ auf. Derjenigen Figur, welcher es gelingt, das „Schweizervolk“ bzw. dessen Stellvertreter, den charakterologischen Prototyp eines impulsiv handelnden „Schweizergesells“, auf ihre Seite zu ziehen, gewinnt die Schweiz. ${ }^{302}$ Die Seele des „Schweizergesells“ steht im Zentrum der Wette, welche die höheren Mächte umwerben und für ihre amoralischen Absichten $\mathrm{zu}$ instrumentalisieren versuchen. Der Genius erklärt die Spielregeln: Beide „Höllenengel“ suchen sich ihre „Trabanten“ aus. ${ }^{303}$ Die „Verführerin“ wählt den „Bürger“ und den „Bauherrn“ und möchte durch sie die Schweiz zu weiblich-stereotypisierter „Verweichlichung und Gottlosigkeit“ verleiten. ${ }^{304}$ Der „Verführer“ wählt den „Krieger“ und den „Regenten“, um die Schweiz zu männlich-stereotypisiertem/r „Krieg und Macht“ zu verlocken. ${ }^{305}$ Der Genius stellt dem „wankelmütigen“ „Schweizergesell“ einen im Sinne der „geistigen Landesverteidigung“ moralisch gefestigten „Schweizermann“ gegenüber, der das „Volk“ jedesmal kurz vor dessen moralischem Abgrund, entsprechend dem dramaturgischen Spannungsbogen, viermal retten wird.

299 Zur Bühnenarchitektur vgl. Eberle 1939c, 58-62.

300 Vgl. Eberle 1939d, 37.

301 Zur „Wette“ im Schweizer Festspiel vgl. Das Festspiel, 126-157. In: Stern 2000, 129.

302 Vgl. Eberle 1939a, 35.

303 Vgl. ebd.

304 Vgl. Eberle 1939d, 37.

305 Vgl. ebd. 
Im „Schlussspiel“ verkündet der Genius den Sieg des Schweizermannes „des Wahrers der reinen Menschenwürde“.306 Auf Geheiß des Genius nimmt der Schweizermann im Landsgemeindering dem „Schweizervolk“ sein Gelöbnis des ewigen Bundes ab (Abb. 35). Diese Handlung steht in emotionspolitischer Referenz zum dramaturgischen Endpunkt der „Höhenstrasse“ des LA-Ausstellungskonzepts „Heimat und Volk“ und mag als solchen vom Publikum erkannt worden sein. Gemäß dem Regisseur waren Sinn und Zweck des Festspiels, dass „das Schweizer Volk“ die Moral des Festspiels, die im Gelöbnis des ewigen Bundes durch den Landsgemeindering symbolisiert wurde, begriff:

„Aufgabe des Schweizer Wehrmanns ist es, das freie Menschentum zu schützen; Aufgabe der Stände ist es, sich brüderlich zu verständigen; Aufgabe unserer Politik ist es, die Vielfalt zu bewahren; Aufgabe des ganzes Volkes ist, im Angesicht Gottes, das durch Natur und Geist vorgezeichnete Schicksal treu zu erfüllen. Das zu beschwören, treten die Eid-Genossen zum Ring zusammen." ${ }^{307}$

Der Regieeinfall des Landsgemeinderings kam von Eberle (Abb. 35), der den „Ring des Volkes“ bei Arnet zum Landsgemeindering als ein „sakral-politisches Urerlebnis der Eidgenossen“ umdeutete. ${ }^{308}$

Eberles Regieanweisung war, gemäß seiner nationalistischen Festspieltheorie, ein theaterästhetisches Zusammenspiel aus einem kultischen Weihespiel und einem „vaterländischen Festspiel“ ${ }^{\text {“309 }} \mathrm{zu}$ schaffen. Seiner Ansicht nach stellte das Festspiel die theaterhistorisch und „völkerpsychologisch“ „urtümlichste Theaterform der Eidgenossenschaft“ dar. ${ }^{310}$ Gemeinsam mit anderen Ausprägungen der Volksfeste und Volksspiele würde das Festspiel der einzig ,wahren“ Schweizer Nationaltheaterform entsprechen. Unter „Festspiel“ verstand Eberle „Theateraufführungen des Volkes für das Volk anlässlich eines vaterländischen, jahreszeitlichen oder kirchlichen Festes. “311 Eberle erläutert seine Festspieltheorie wie folgt:

„[Die] Bedeutung [des Festspiels] beruht darauf, dass das Volk, ohne an materielle Gewinne zu denken, mit dem Einsatz seiner Leistung und Spielfreude selber die Bühne betritt, in ein höheres Wesen sich verwandelt, und sich als gläubig, als kämpfend, als heroisch erlebt. Das Volk erfährt damit leibhaftig jene Kräfte, die in siebenhundertjähriger Geschichte die Eid-

306 Vgl. Eberle 1939a, 38.

307 Eberle 1939d, 37.

308 Vgl. Arnet 1939, 46.

309 Dem „vaterländischen Festspiel“ widmete Eberle bereits 1928 eine Ausgabe der SGTK-Jahrbuchreihe, vgl. Eberle 1928b.

310 Vgl. Eberle 1943, 144.

311 Vgl. ebd., 142. 


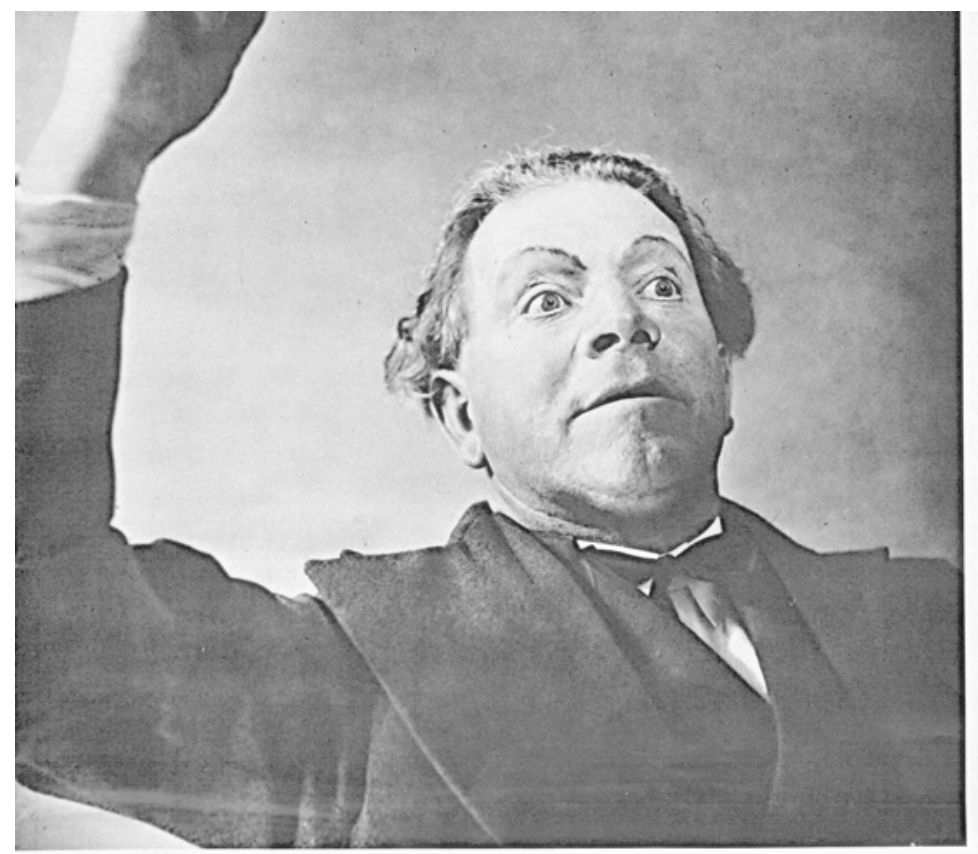

\section{"Das \\ Eidgenössische}

Wettspiel»

Le festival

de l'Exposition
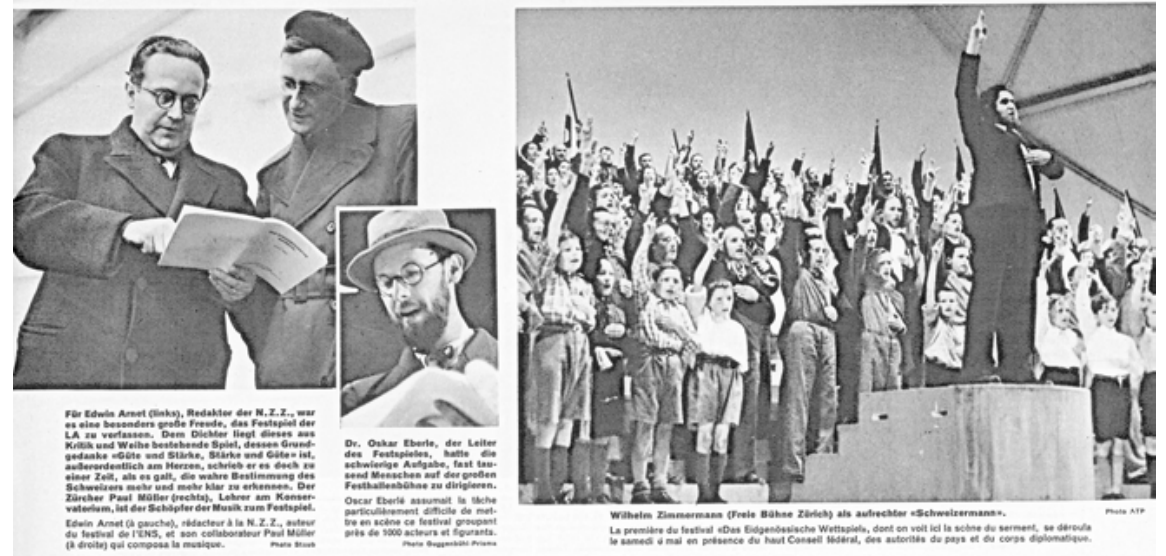

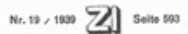

Abb. 35: [Emotionspolitisches Gemeinschaftserlebnis der Laiendarsteller*innen]: Foto oben: „Emil Gyr (Freie Bühne Zürich) stellt den ,Schweizer-Gesellen“ mit innerem Feuer und lebendigster Beweglichkeit dar“. Foto unten, links: Edwin Arnet (links) und Paul Müller (rechts). Foto unten, Mitte: „Dr. Oskar Eberle, der Leiter des Festspiels, hatte die schwierige Aufgabe, fast tausend Menschen auf der großen Festhallenbühne zu dirigieren“. Foto unten, rechts: „Wilhelm Zimmermann (Freie Bühne Zürich) als aufrechter ,Schweizermann““. Fotoreportage in der „Zürcher Illustrierten“, 1939 
genossenschaft schufen und erhielten. In der Verwandlungsfähigkeit und im Verwandlungswillen des einfachen Volksspielers in den heroischen Ahnen offenbart sich eine staatserhaltende Kraft, die jenseits aller intellektuellen ,Beweise‘ für die Staatserhaltung liegt. Volksfeste und Volksspiele [...] sind eine Funktion der Volksseele und liegen der Sphäre des Unbewussten näher als der Verstandeshelle des Bewussten. [...] Die spielfreudige Urschweiz hat sich gegen den Einbruch fremder Heere zur Wehr gesetzt, als es galt, aus dem ,Spiel` Ernst zu machen, nicht weil Theaterspieler bessere Kämpfer wären, sondern weil im Spiel seelische Kräfte zur Entladung kommen können, die sich im Ernstfall im Staatsleben auswirken [...]. “312

Die transnationale Wissenszirkulation einer arbeitspsychologischen „Kraft durch Freude“, die einer theaterästhetischen Wirkungsmacht zugrunde läge, instrumentalisierte zeitgleich die NS-Theaterwissenschaft und -politik (Kap 15.6). In Eberles Festspieltheorie kam eine theaterästhetische „Kraft durch Freude“, auf der Suche nach einem Schweizer Nationaltheater, im Kontext der nationalen Theaterpolitik einer „geistigen Landesverteidigung“ als leistungsorientierte „Urkraft des Schweizertums“313 zum Ausdruck. Der Theaterwissenschaftler konstruierte eine metaphysisch-verklärte „Verwandlungsfähigkeit“ und einen „Verwandlungswillen“ der Laiendarsteller`in zur stereotypisierten Heldenfigur (z. B. Tell) auf der Volkstheaterbühne (Kap. 15.7, 16.2). ${ }^{314}$ Die esoterisch-energetische Kraftfreisetzung der leistungsorientierten und heroisch überhöhten Selbstdarstellung würde die Laienspieler`in, in wissenshistorischer Analogie zum arbeitspsychologischen Glückswissen der Ratgeberliteratur, wiederum in leistungsorientierte Handlungen im Alltag umsetzen können. Im Unterschied zu „rassenhygienischen“ Auslegungen (wie bei Kindermann) argumentiert Eberle mit der „staatserhaltenden Kraft“ der Volksspiele. ${ }^{315}$ Die Laiendarsteller`innen würden sich im Ernstfall aufgrund ihres „,völkerpsychologischen“ Leistungswillens und ihrer Spielfreudigkeit autosuggestiv und emotionspolitisch zu wehrhaften Freiheitskämpfer^innen mobilisieren können, in anachronistischer Analogie zum Gründungmythos der Schweizer Eidgenossenschaft. Eberle fährt fort:

„So ist das Festspiel in seiner reinsten Ausprägung kultisches Spiel und steht damit im Gegensatz zum mimischen Drama. Es wächst aus der Staatsidee, aus dem Glauben, aus der Natur und wird damit zum vaterländischen Festspiel, zum religiösen Festspiel, zum Jahreszeiten- Festspiel. [...] Festspiele sind nur die mit Festen, also gelegentlich wiederkehrenden dramatischen Aufführungen des Volkes. [...] Fast alle Befürworter für ein schweize-

312 Ebd., 144.

313 Ebd.

314 Vgl. Eberle 1943, 144.

315 Vgl. ebd. 
risches ,Nationaltheater ' gehen von Festspielerfahrungen aus, fordern aber als ständige Einrichtungen in Wirklichkeit Volksspielbühnen.“316

Mit welchen Mitteln Eberles Festspieltheorie in seiner Regiearbeit Anwendung fand, wird im Folgenden untersucht.

Die dramaturgische Ergänzung des Landsgemeinderings kann exemplarisch für Arnets Zusammenarbeit mit Eberle stehen, durch welche der Dramatiker Arnet, eigenen Aussagen zufolge, einen theaterästhetischen „Entstädterungsprozess“ erlebte. ${ }^{317}$ In seiner Doppelrolle als Theaterwissenschaftler und erfahrener Festspielregisseur gab Eberle sein theaterhistorisches Wissen über das Mysterienspiel, Fastnachtsspiel und Barocktheater an Arnet weiter. Dabei betonte er die Wichtigkeit einer theaterästhetischen Unterscheidung zwischen der massenpsychologischen Wirkungsmacht des Volkstheaters und der einer "Stadtbühne“. ${ }^{318}$ Diese subjektive, christlich geprägte Wissenszirkulation in theaterhistorischer Volkstheaterkunde, die nicht frei von einer hegemonialen Blickperspektive auf einen stereotypisierten Volkstypus war, sei nach Ansicht Arnets nötig gewesen, um in einer „Riesenhalle, wo das Volk weder auf Wurst noch Tranksame verzichten will“ ${ }^{319}$ ein emotionspolitisch wirkungsmächtiges Festspiel aufführen zu können:

„Der bewusste Verzicht auf Kulisse und Vorhang, das Bestreben, die Orchestra nicht zu einem trennenden Graben zwischen Zuschauervolk und Spielervolk auswachsen zu lassen, die gesunde Abneigung gegen alle Effekte der städtischen Illusions- und Guckkastenbühne... das kennzeichnet Eberles Tätigkeit, und das tat mir eine Welt auf, in der es mir, wie einem Stadtgast auf dem Lande zunehmend wohler wurde.““320

Wie bereits in Kapitel 15.7 gesehen, war Eberle von der autosuggestiven Wirkungsmacht des Laienspiels überzeugt, der eine transnationale, „völkerpsychologische“ Freude am Spiel der Nachahmung zugrunde lag. Eine besondere Suggestionskraft besäße, laut Eberle, die authentisch anmutende Selbstdarstellung des Volkstypus im Laienspiel. Diese könne laut Arnet beim Publikum eine theaterästhetische Wiedererkennung bewirken, die sich wiederum in einer emoti-

316 Ebd., $144 \mathrm{f}$.

317 Vgl. Arnet 1939, 45f. „Wo mein Stadtkopf ein paar eigenwillige Figuren, Symbole und Schauplätze erfand, die wage Erfindungen meiner Phantasie waren, und ganz vom ehrlichen Wege der Tradition ablagen, stupfte mich Eberle beim Ellenbogen und riet mir zu bestimmteren und realeren Dingen.“ Vgl. Arnet 1939, 46.

318 Vgl. Arnet 1939, 46.

319 Vgl. ebd., 45.

320 Ebd., 46f. 
onspolitischen Mobilisierung manifestiere, wie Eberle es am Beispiel einer Aufführung der Urner Tell-Spiele beschrieb (Kap. 16.2). Eberles „völkerpsychologische“ Laienspieltheorie sah folglich eine theaterästhetische Funktion in der Aktivierung der Zuschauerinnen zur Schaffung eines Gemeinschaftsgefühls zwischen „Zuschauervolk und Spielervolk“321 (Kap. 15.7). Darüber hinaus stellte Eberle seine Festspielästhetik auf der Grundlage seiner theaterhistorischen Forschung in eine überzeitliche „völkerpsychologisch“-metaphysische Kontinuität mit mittelalterlichen Volksspielarten der ,alten Eidgenossenschaft“ (Mysterienspiel, Fastnachtspiel, Staatsspiel) und konstruierte daraus ihre Legitimität:

„Festzuhalten ist ein für allemal, dass das Festspiel in seiner reinsten Ausprägung aus metaphysischem Grund wächst und dass es gilt seine eigenen Gesetze zu erkennen und seine eigene Form zu entwickeln. [...] $]^{\text {‘322 }}$

In seiner überhöhten Selbstdarstellung, als Erbe einer theaterästhetischen Erneuerung des „nationalen Staatsspiels“, sah sich Eberle als Teil einer Reformtheaterbewegung, die auf Jean-Jacques Rousseau, Gottfried Keller und Johann Georg Sulzer im Rahmen einer Schweizer Nationaltheater-Debatte zurückgehe. ${ }^{323}$ Zeitgenössische Bestätigung für seine Ansichten über ein Schweizer Volkstheater als Idealform eines Schweizer Nationaltheaters fand Eberle bei seinem ehemaligen Doktorvater Josef Nadler. ${ }^{324}$ Dieser hatte mehrere theaterhistorische $\mathrm{Ab}$ handlungen zur Schweizer Nationaltheater-Debatte geschrieben (u.a. im III. Jahrbuch der SGTK) ${ }^{325}$ und dabei „stammeskundlich-völkische“ Eigenschaften einer Schweizer Dichtung zu erkennen geglaubt, welche Einfluss auf die Entwicklung des Schweizer Volkstheaters genommen hätten und im Zusammenhang mit einer angeblich problematischen Schaffung einer Schweizer Nationaltheaterkultur an Schweizer Berufstheaterbühnen ständen. ${ }^{326}$

Weitere wissenshistorische Kontinuitäten in Eberles Festspieltheorie eines massenpsychologischen „Urtheaters“ (Kap. 15.7) sind auch in der sozialistischen Festspielästhetik zu finden, wie sie Le Bons Theorie einer sozialen Masse zugrunde lag und bei Piscator und de Man praktische Anwendung fand (Kap. 15.6, 16.3). Wissenshistorische Referenzpersonen waren für Eberle auch die NS-Theaterwissenschaftler Kutscher und Niessen in Bezug auf ihre methodisch interdis-

321 Vgl. ebd.

322 Eberle 1943, 145.

323 Vgl. Eberle 1939b.

324 Vgl. Eberle 1943, 25.

325 Vgl. Nadler 1930.

326 Vgl. Neuber 2002. Vgl. Ranzmaier 2008. 
ziplinären Ansätze einer „,völkerkundlichen“ Theaterwissenschaft (Kap. 15.6, 15.7). Kindermanns Vorstellung eines kulturnationalistischen Sendungsauftrags und einer biologistisch-metaphysisch-,,völkisch“ verklärten Verwandlung des „IchZuschauers“ in eine homogene Einheit aus Zuschauer^innen und Darsteller^innen kommen Eberles Konzept einer metaphysisch überhöhten „Spielgemeinschaft“ nahe, wobei er in folgender Passage von einer explizit „rassenhygienischen" Argumentation absieht:

\begin{abstract}
„Das offizielle Festspiel der LA fasst alle Elemente des Volksspiels wieder straff zusammen: Früher wagten oftmals nur Fastnachtsspiele aktuell zu sein - hier ist es einmal ein Staatsspiel. Die Bühne verzichtet auf jede Art von Theatermalerei. An Stelle von toten Kulissen steht, nach altem Brauch, das lebendige Spielrequisit. Alle Elemente des Volksspiels sind vereint: Aufzug und Requisit, belebte Gruppen und Einzelsprecher, instrumentale Musik und singende Chöre. Die Klammer aber, die alle Szenen fest zusammenhält, ist die Wette überzeitlicher Mächte um die Seele und Existenz der Eidgenossenschaft. Damit ist ein Staatsspiel über die aktuelle Problemstellung hinaus wieder in den Bereich ewiger Kräfte gestellt.“'327
\end{abstract}

Im transnationalen Vergleich zu Niedecken-Gebhards monumentaler Festspielästhetik (Kap. 16.5) fallen bei Eberle ähnliche theaterästhetische Mittel auf: 1 . hinsichtlich eines religiös verankerten kultischen Weihespiels mit musikalischen Einlagen und 2. hinsichtlich eines zunächst anachronistisch anmutenden Aktualitätsanspruchs im Zitationsgestus wissenshistorischer Gründungsmythen und Figuren (u.a. Jahn, Kallenberg vs. Tell, Pestalozzi) als vermeintlich unverzichtbares theaterästhetisches Element eines „vaterländischen Festspiels“.

Carl Niessens Einladung an die SGTK mit der Bitte, die Schweizer Landessektion an der internationalen Ausstellung „Theater im Freien“"328 zu gestalten, die vom 1. Juli bis 31. August 1937 in Frankfurt a. Main stattfand, ist in diesem Zusammenhang aufschlussreich. Niessens Schreiben zeigt, dass Eberle in seiner Doppelrolle als Theaterwissenschaftler und Theaterschaffender nicht nur transnational rezipiert wurde, sondern auch im Rahmen einer internationalen Ausstellung über historische und zeitgenössische Festspielformen von der NS-Theaterwissenschaft und NS-Theaterpolitik als regimekonform erachtet und rezipiert wurde. Das Schreiben Niessens an Bundesrat Philipp Etter vom 22. Februar 1937

327 Eberle 1941, 72.

328 Niessen, Carl, Ausstellung „Das Theater im Freien“ veranstaltet von der Stadt Frankfurt a. Main mit dem „Reichsbund der Deutschen Freilicht- und Volksschauspiele e.V.“ anlässlich der Römbergfestspiele vom 1. Juli bis 31. August 1937, Frankfurt a. Main, Sonderdruck aus der „Frankfurter Wochenschau“, Heft 4/1937, verantwortlich Hauptschriftleiter Dr. Franz Lerner, Frankfurt: Franz Zof. Henrich, V.2.10.44, Bestand E3001 A, Papier: 1000/727_17, BAR. [Abk. Niessen, Theaterausstellung, Sonderdruck, 1937]. 
unterstreicht, dass Eberles theaterwissenschaftliche Forschungstätigkeit, die er seit 1927 im Rahmen der SGTK betrieb, auch nach 1933 transnational von einem bestimmten Kreis von „völkischen“ Theaterwissenschaftler*innen in NSDeutschland wahrgenommen und geschätzt wurde:

\begin{abstract}
„[...] Die Schweiz hat für den Gedanken des Theaters unter freiem Himmel in Vergangenheit und Gegenwart so Beispielhaftes geleistet, dass wir die Verdienste ausgedehnt zur Anschauung bringen möchten. Bereits bei den früheren Vorbereitungen haben wir mit der Gesellschaft für schweizerische Theaterkultur durch Herrn Dr. Oskar Eberle (Luzern, Kapuzinerweg 15a) Fühlung genommen. Ferner baten wir Herrn Dr. Eberle, in den wissenschaftlichen Beitrat einzutreten. Deshalb würden wir sehr dankbar sein, wenn die Beschickung in Verbindung mit Herrn Dr. Eberle, als dem massgebenden Kenner erfolgen könnte. $[\ldots]^{\text {*329 }}$
\end{abstract}

Der wissenschaftliche Beirat war von „maßgeblichen Fachleuten aus allen beteiligten Ländern“ zusammengestellt worden und ergänzte Niessens Mitarbeiterstab, welcher ihm bereits für die Ausstellungen „Faust auf der Bühne“ in Braunschweig und „Faust in der bildenden Kunst“ zur Verfügung gestanden war. ${ }^{330}$ Das propagandistische Konzept der Theaterausstellung verfolgte ein kulturnationalistisches Ziel, nämlich die Darstellung des „mimischen Urtrieb[s], der als unzerstörbarer Kern in allen seinen vielfältigen Erscheinungsformen lebt“, sich im „festlichen Spiele[...] der Völker“ präsentiere und „das Ringen des neuen Deutschlands um kultische Vertiefung des Lebens der Nation“ darstelle, wie es „in architektonische[n] Feierstätten großen Ausmaßes“ in Erscheinung trete. ${ }^{331}$ An dieser propagandistisch, hegemonial konzipierten Selbstdarstellung der NSFestspielkultur in Vergangenheit und Gegenwart gegenüber dem „festlichen Spiele[...] der Völker“ nahm die SGTK bereitwillig teil. ${ }^{332}$

329 Brief von Prof. Dr. Carl Niessen an Bundesrat Philipp Etter, Vorsteher des eidgenössischen Departements des Innern, Frankfurt a. Main, 22.02.1937, vgl. Dossier. „Beteiligung an Ausstellung ,Das Theater im Freien““, Frankfurt a. Main 1937, V.2.10.44, Bestand E3001 A, Papier: 1000/727_17, BAR. [Abk. Brief, Niessen an Etter, 1937].

330 Vgl. Brief, Niessen an Etter, 1937. Zudem standen Niessen in einem Arbeitsauschuss sowohl Generalintendant Hans Meißner, ,der Anreger und tätige Förderer dieser Ausstellung, Universitätsprofessor Dr. Artur Kutscher, der wertvolle Arbeiten über die Geschichte des Theaters im Freien anregte, Universitätsprofessor Dr. Ernst Beutler, Direktor des Frankfurter Goethe-Museums und Intendant Dr. Rudolf Meyer, der Geschichtsschreiber des Freilufttheaters im Barock und Rokoko“ zur Seite. Niessen, Theaterausstellung, Sonderdruck, 1937, $4 \mathrm{f}$.

331 Vgl. Niessen, Theaterausstellung, Sonderdruck, 1937, 7.

332 Weiterführende Forschungen könnten Erkenntnisse über die Finanzierung und die Ausgestaltung der Schweizer Sektion geben. 
Um die transnationale Wissenszirkulation der kulturnationalistischen Festund Laienspieltheorie Eberles näher zu veranschaulichen, soll dessen Regiearbeit in der Schwurszene des Schlussteils des LA-Festspiels untersucht werden. Eberles theaterästhetische Regieanweisung lautet zu Beginn der Schlussszene: „Volles Licht flutet über das Podium des Landsgemeinderings, in dessen Mitte nun der Schweizermann steht“. ${ }^{333}$ Kinder „strömen in jubelnden Scharen von allen Seiten herbei und umringen in engem Kreis das Podium mit dem Schweizermann.“334 Der Schweizermann fordert die Kinder zum Schwur auf, ihre „Heimat zu lieben“: Die Kinder schwören es (Abb. 36).

Das „Trachtenvolk“ aller Schweizer Gemeinden aus vier Sprachregionen schließt zu ihnen auf und bildet einen zweiten Kreis und schwört: „Der Heimat Vielfalt wollen wir bewahren! Wir schwören es! ${ }^{‘ 335}$ Darauf erwidert der Schweiz-

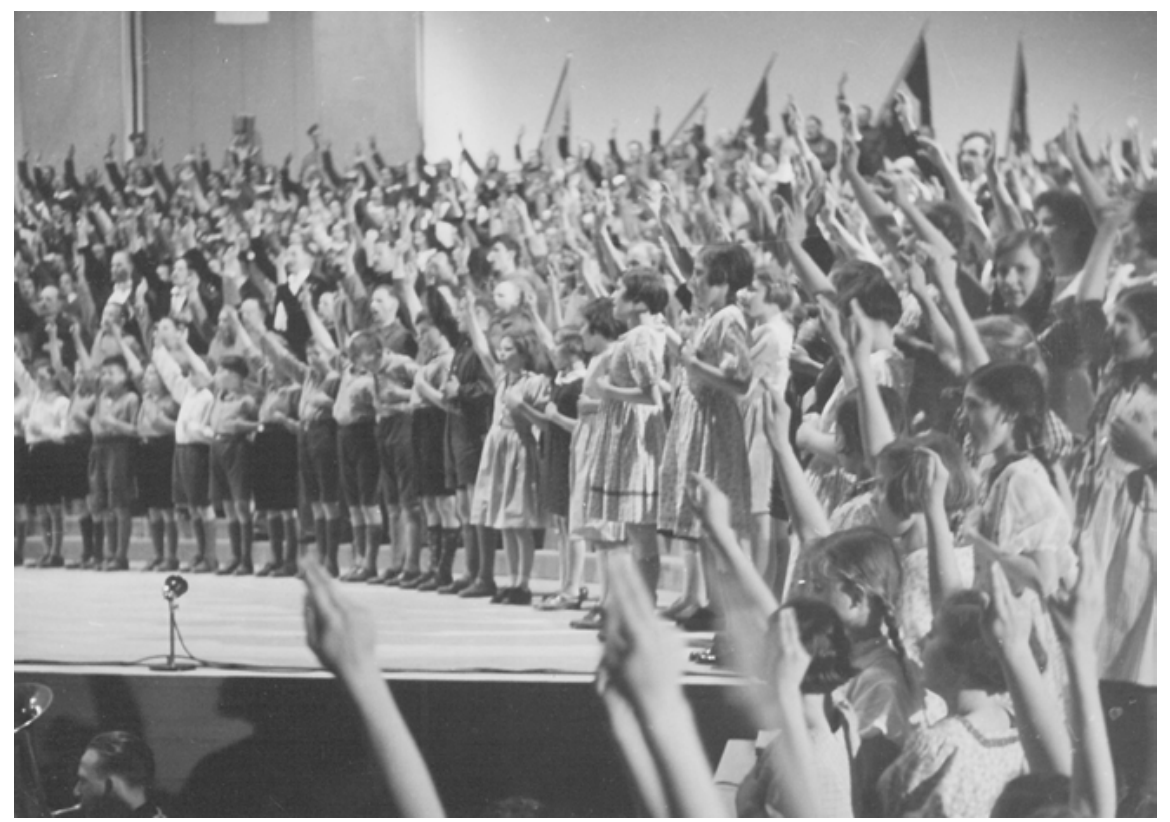

Abb. 36: [Emotionspolitische Festspielästhetik: Schwurszene mit Gesang der Schweizer Hymne von Arnet und Müller ,Eidgenoss' entroll die Fahne‘]. „Das eidgenössische Wettspiel“ von Edwin Arnet, Regie: Oskar Eberle, Offizielles Festspiel der Schweizerische Landesausstellung, Festhalle, Zürich, 1939

333 Vgl. Eberle 1939e, 47.

334 Vgl. ebd., 37.

335 Vgl. ebd., 48. 
ermann: „Naht jetzt, durch Glück und Not getrennte Brüder / Eint euch im neuen Schwure wieder.“336 „Bürger“ und „Arbeitslose“ folgen dem Ruf und schließen einen dritten Kreis, um den Schweizermann: „Wir wollen Brüder sein! Wir schwören es!“337 Als letzte werden die „Soldaten“ vom Schweizermann aufgefordert, den „Ring“ zu schließen, ihn zu bewachen und zu beschützen. Eberles Regieanweisung lautet:

„Zuletzt marschieren von allen Seiten die Wehrmänner in Feldgrau und Helm herbei. Sie schließen um die drei Kreise der Kinder, des Trachtenvolkes, der Bürger und Arbeitslosen den vierten Kreis, den machtvollen Schutzring.“338

Der Schweizermann fordert nun die Soldaten zum Schwur auf: „Unser Schwert beschütze den Menschen. Wir schwören es!“339

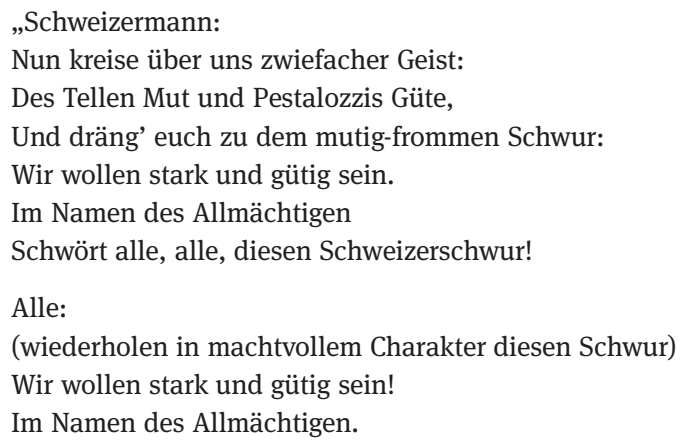

Zum Schluss singen die Spieler auf der Bühne und das ganze zuschauende Volk die Schweizer Hymne.“340

Der Schwur auf den ewig währenden Bund der Schweizer Eidgenossenschaft wurde vom gemeinsamen Anstimmen der Schweizer Nationalhymne als theaterästhetische Durchbrechung der ,Vierten Wand“ abgelöst. Die theaterästhetische Wirkungsmacht entfaltete sich beim Festspielpublikum, das bereitwillig in den Gemeinschaftsgesang miteinstimmte. Laut Pressemitteilungen war es ein massenpsychologischer Erfolg. Die Zuschauer`innen konnten als mitspielende Akteur^innen mobilisiert werden. Sie empfanden sich offenbar als Teil des thea-

336 Vgl. ebd., 48.

337 Vgl. ebd.

338 Eberle 1939e, 49.

339 Vgl. ebd.

340 Ebd. 
terästhetischen Zusammengehörigkeitsgefühls aus Spieler- und Zuschauervolk, einer emotionspolitischen Selbstdarstellung der imaginierten Schweizer „Geistesgemeinschaft".

„Das eidgenössische Wettspiel“, in Zusammenarbeit Arnets und Eberles, entwirft eine leistungsorientierte und zugleich moralisierende Schweizer Lebensführung auf der Festspielbühne, die als Schauplatz einer kulturnationalistischen Gefühlspolitik einer Schweizer Arbeitsmoral und zugleich einer ,geistigen Mobilmachung“ eine propagandistische Wirkungsmacht entfaltete. „Das eidgenössische Wettspiel“ stellte gemäß Eberles Festspieltheorie eine theaterästhetische Überschneidung aus einem kultischen Weihespiel und einem „vaterländischen Festspiel“ dar.

Im Folgenden soll aufgezeigt werden, wie Arnets Festspieldramatik und Eberles Regiearbeit mit der kulturnationalistischen Botschaft der LA als eine „geistige Mobilmachung“ in Einklang gebracht wurden. Dazu muss nochmals das emotionspolitische Ausstellungskonzept der LA vor Augen geführt werden. Eine Leitfrage für das Ausstellungskonzept der Landesausstellung lautete: „Wie zeigen wir dem Schweizervolk und den Ausländern, eindrucksvoll und leichtverständlich, was wir können und wollen?“341 Die LA sollte vordergründig keinen „Rechenschaftsbericht“ über die Leistungen der Schweizer Nation erbringen (was die Landesausstellung, dem leistungsorientierten Selbstdarstellungskonzept geschuldet, dennoch tat), sondern einen expliziten Blick nach vorne richten, auf die „Sendung der LA als Wegbegleiter und Plan für unser schweizerisches Schaffen in der Zukunft“. ${ }^{342}$ Im Bewusstsein um die „Not der Zeit“ und der „Bedrohung unserer nationalen Existenz“ sah Direktor Meili die LA als ein bedeutsames ideologisches Propagandainstrument der „geistigen Landesverteidigung“: „[...] in Zeiten weltanschaulicher Umwälzungen“ müsse das „Ringen um die Seele“ mitberücksichtigt werden. Zwischen Meilis moralischem Erziehungskonzept der LA, in Anbetracht der ideologischen Bedrohung durch die faschistischen bzw. nationalsozialistischen Nachbarländer Italien und Deutschland, und der moralischen Festspielwette um die Seele des wankelmütigen „Schweizergesells“ bestand ein direkter Zusammenhang. ${ }^{343}$

Eine Hauptaufgabe der Ausstellung sah Meili folglich in der moralischen Überzeugungs- und Erziehungsaufgabe der ideologischen Gesinnungsgestaltung seiner Besucher*innen und der damit verbundenen emotionspolitischen Erwe-

341 Meili 1939, 13.

342 „Es handelt sich nicht nur um einen ,Rechenschaftsbericht“ über das Geleistete. Viel bedeutungsvoller ist die Sendung der LA als Wegleitung und Plan für unser schweizerisches Schaffen in der Zukunft.“ Meili 1939, 14.

343 Vgl. ebd. 
ckung von Schweizer Nationalgefühlen: „Gäbe es ein stärkeres Mittel zur Formung eines Glaubens, als das Ueberzeugen? Das Schweizervolk von seinem moralischen Wert und seiner Tüchtigkeit zu überzeugen, ist eine der Hauptaufgaben dieser nationalen Kundgebung. “344 Mit welchen emotionspolitischen Propagandainstrumenten sollte diese Überzeugungsleistung in die Wege geleitet werden? Im Folgesatz betont Meili die Wichtigkeit der Künste und deren „Haltung“ als Teil der geistigen Überzeugungsleistung zur Erweckung emotionspolitischer Nationalgefühle, welche dem Ziel der „Landesausstellung - als geistige Mobilmachung“ (Etter) zugrunde läge. ${ }^{345}$

„Kein monumentales Portal bildet den Eintritt: [...] aber die Zeitläufe mahnen ihn [den LABesucher], dass alles menschliche Glück und aller menschliche Friede von Kampf und Vernichtung umwittert sind. Die Spannung macht die Seele bereit für Grösse und Verantwortung." 346

Vor diesem Hintergrund stellte sich der Dramatiker Arnet beim Entwurf seines Festspiels für die LA dieselbe Frage wie schon der LA-Direktor vor ihm: Was macht das wahrhaft Schweizerische eigentlich aus und wie kann die propagierte Schweizer Eigenart eines Schweizer Kulturwillens in der Selbstdarstellung eines Konglomerats aus Schweizer Nationalgefühlen auf die Festspielbühne gebracht werden ${ }^{347}$ Arnets Antwort auf diese Frage lautet im Sinne Eberles kultischer Festspieltheorie wie folgt:

„Ein Staatsfestspiel hat ein Weihespiel zu sein. Ein Spiel, das bloss zu Hass und Polemik gegen einen andern Staat oder gegen einzelne Kreise des eigenen Staates aufriefe oder das ausschliesslich mit Kritik an den Schönheitsfehlern unserer Demokratie ausgefüllt wäre, könnte wohl reizvoll und interessant sein, niemals aber gelänge es ihm die Katharsis, die reinigende Verwandlung des Zuschauers, die der oberste Zweck eines jeden wahren Staatsfestspiels zu bleiben hat. ${ }^{\text {(348 }}$

Arnet deutet Aristoteles' wissenshistorischen Katharsis-Begriff von der reinigenden Wirkungsästhetik der Tragödie auf das Schweizer Staatsfestspiel um. Die emotionspolitische Wirkungsintention des nationalen Festspiels als ein kultisches Weihespiel könne, nach Arnet, eine „reinigende Verwandlung des Zuschauers“ bezwecken. Arnet zufolge verfing sich diese theaterästhetische Umdeutung der

344 Ebd.

345 Vgl. Meili 1939, 14.

346 Huber 1940, 64.

347 Vgl. Arnet 1939, 42.

348 Ebd., 45. 
aristotelischen Dichtungstheorie, die mit Blick auf die Tragödie entwickelt wurde, nicht in konzeptionellen Widersprüchen. Der Festspielautor benutzte den Katharsis-Begriff, um die massenpsychologische Intention der kulturnationalistischen Festspielästhetik als eine Politik der affirmativen Schweizer Gefühlskultur zu beschreiben. Im Unterschied zu Niedecken-Gebhards monumentaler NS-Festspielästhetik verzichtete Arnet auf ein biologistisches Vokabular. Die Idee einer theaterästhetischen „Reinigung“ bei Arnet kann zwar, mit Blick auf die Zusammenarbeit mit dem Dramatiker Eberle und dessen Laienspieltheorie, in einem „völkerpsychologischen“ Kontext situiert werden. Zentral bei Arnets theaterästhetischer Wirkungstheorie ist jedoch die Verortung im Rahmen einer kultischnationalistischen Gefühlskultur.

Aus kritischer Distanz stellt sich die Frage, wie es den mitwirkenden Laienspieler`innen während der Vorbereitung der Festspielaufführung ergangen war und ob sich die gewünschte „Begeisterungsfähigkeit“ bei der „Spielergemeinschaft“ entfalten konnte. ${ }^{349}$ Aus Sicht des voreingenommenen Dramatikers schilderte Arnet den Entstehungskontext der Aufführung als „beglückende[s] Erlebnis“ wie folgt:

\footnotetext{
„Aber das Packendste war, wie sich die Mitwirkenden, Leute aus allen Ständen, immer mehr zu einem Spielervolk verschmolzen, das wohl gelegentlich demokratisch schimpfte, dann aber trotz den Proben in eiskalter Halle und hundert anderen Strapazen jeden, der an seiner Begeisterungsfähigkeit hätte zweifeln wollen, kurzerhand geprügelt hätte. Wie sich hier eine Spielergemeinschaft für eine Aufgabe einsetzte, die sie als eine vaterländische empfand, wie sich in dieser grossen Familie ein wundervoller Geist der Kameradschaft entfaltete, das ist mir zu einem beglückenden Erlebnis geworden.“350
}

Die Presse war mehrheitlich begeistert vom „eidgenössischen Wettspiel“, welches alle drei Kriterien (nach Stern) eines typischen Schweizer Festspiels jener Zeit erfüllte: Es war sowohl „enkomiastisch-verklärend“, wenn es das Gelöbnis im Landsgemeindering darstellte und „utopisch-verheißend“, wenn es eine „glückliche“ Zukunft beschwor, als auch „satirisch-realitätsbezogen“, wenn es die Wehrhaftigkeit des wankelmütigen „Schweizergesells“ angesichts des drohenden Kriegsausbruchs ironisierend und realitätsnah in Frage stellte. Dennoch gab es vereinzelt kritische Stimmen, beispielsweise seitens der Kommunistischen Partei, welche die affirmative Gefühlspolitik, wie sie in Form des „vaterländischen Festspiels“ als ein verklärendes „Ideal der Wirklichkeit“ dargestellt wurde, an-

349 Vgl. Arnet 1939, 47.

350 Ebd. 
gesichts der sozialpolitischen Missstände im Land und der weltpolitischen Krisenlage problematisierte:

„In den Dutzend Aufführungen, die bisher stattfanden, haben über 80000 Personen dieses Festspiel der Landesausstellung gesehen. [...] Warum klatschen die 80000 ? - Weil es schön farbig ist, weil die Fragen wohl tiefgreifend sind, aber ihre Behandlung nicht. Weil das glückliche Ende mit der Losung, die Schweiz sei gütig und stark, ein richtiges Filmende ist. Ja, wir alle möchten die Schweiz gütig und stark. Aber sie ist in der sozialen Frage weder gütig, noch in der Außenpolitik stark. Sondern umgekehrt! Aber es tut den 80000 wohl, sich das Ideal als Wirklichkeit vorlügen zu lassen, es beruhigt ihr Gewissen, speziell wenn sie 5 Fr. für den Eintritt bezahlt haben.“351

Der rechtspopulistischen „Nationalen Front“, die mit NS-Deutschland sympathisierte, ging die Festspielgestaltung als emotionspolitische „Herzerquickung“ und „Gesinnungsbestärkung“ noch zu wenig weit:

„[...] Schließen wir ab: Der Dichter gehört zu jenen Leuten, die gemerkt haben, daß in der Welt etwas nicht in Ordnung ist. Insofern ist dieses Festspiel anders, als Festspiele gewöhnlich sind. Es wächst aus den Nöten und Aengsten der Gegenwart heraus. Es ist handgreiflich und hat Fleisch und Blut. Der Zuschauer fühlt, dass da um ihn gewettet wird und daß die Wette im Grunde genommen verdammt ernst ist. Aber wenn der Dichter gemerkt hat, daß etwas los ist, hat er wie die meisten Schweizer nicht gemerkt, was los ist. Aber was da über Ursache und Natur der Not und Gefahr gesagt wird, [...] ist genau das, was man tagtäglich am Biertisch zu hören bekommt. Daß es zieht ist klar: denn so mit Musik und Bögge und Versli ${ }^{352}$ auf der Bühne zu hören, was man sonst selber am Biertisch verzapft und ins Käsblättlii53 schreibt, ist eine Herzerquickung und eine Gesinnungsbestärkung sondergleichen. Aber haben wir das wirklich nötig?‘354

Der Theaterwissenschaftler Kachler sah sich das Festspiel bei der Premiere an und musste neben viel Lob auch theaterästhetische Mängel benennen: Das Festspiel stehe in seiner „künstlerischen Form“ in einer Kontinuität zu den „schweizerischen Mysterienspielen“, was ihm „Substanz“ verleihe. ${ }^{355}$ Dem „Wesen des Festspiels“ nach sei die Handlung „leicht begreifbar“ und in der „Abfolge der Szenen gut überschaubar. Zugleich hat es mit Darsteller-Massen zu rechnen, um Wir-

351 Arnold Tobler, „Zum Festspiel der Landesausstellung. Das eidgenössische Wettspiel“. In: Freiheit. Schweizerische Volkszeitschrift. Organ der Kommunistischen Partei der Schweiz, 28.07. 1939, 2, Signatur: MFB 2, Schweizerisches Sozialarchiv, Zürich.

352 „Versli“, ein kleiner Vers.

353 „Käsblättli“ (Käseblatt), Lokalzeitung.

354 Ulrich Osterwalder, „Das eidgenössische Festspiel des Edwin Arnet“. In: Die Front. Nationales Kampfblatt der Schweiz, 17.06.1939, o.S. Faksimile, vgl. Anhang: Dokumente, Nr. 20, Tschudi 1993.

355 Vgl. Kachler 1939, 209. 
kungen in die weite Zuschauermenge zu erzielen.“ Die „eingehenden Melodien“ seien ein theaterästhetisch wirksames Mittel, um die Zuschauer^innen, trotz der großen Distanz zur Bühne, „zu beleben“. Jedoch:

„Nicht ganz glücklich in der Anlage scheint uns neben der Bühne auch der ungefähr fünftausend Menschen fassende Zuschauerraum zu sein. Wohl steigen die hintersten Plätze des imposanten mehr als hundert Meter langen, 43 Meter breiten und 13 Meter hohen Zeltes tribünenartig empor, aber schon im zweiten Block [...] ist [eine] einigermaßen gute Sicht auf die unteren Teile der Bühne nur noch für große Leute möglich.“356

Kachler kommt zum Schluss, dass der „ideale Aufführungsort für solche Festspiele“ das „ansteigende Amphitheater“ sei. Doch würden diese benannten „Einschränkungen die Gesamtwirkung des Festspiels keineswegs“ beeinträchtigen, „zumal das akustische Problem sehr befriedigend gelöst ist. Uns als Hauptsache bleiben die künstlerische Gesamtleistung und der Geist, von dem die Aufführung getragen wird.“357

Die historische Untersuchung des offiziellen LA-Festspiels „Das eidgenössische Wettspiel“ von Edwin Arnet in der Regie von Oskar Eberle konnte aufzeigen, wie das nationale Festspiel im Kontext von Etters Appell als emotionspolitisches Propagandamittel für die Schweizer Bevölkerung eingesetzt wurde, um über die Rezeption der theaterästhetischen Wirkungsmacht zur selbstdisziplinarischen Mobilisierung im Kontext der Annexionsgefahr durch das „Dritte Reich“ aufzurufen.

Das Festspiel sollte 1. eine moralisierende Selbstdarstellung in der theaterästhetischen Gattung eines nach Arnet und Etter konzipierten kultischen Weihespiels und „vaterländischen Festspiels“ demonstrieren, 2. eine autosuggestive Emotionalisierung, Selbsterkennung und gemeinschaftsstiftende Bejahung einer Schweizer Lebensführung, entsprechend Etters Wertesystems einer „Landesausstellung, als eine geistige Mobilmachung“, sowohl bei den Laienspieler`innen als auch beim Publikum der Landesausstellung bewirken und dadurch 3. eine leistungsorientierte Mobilisierung aufgrund der theaterästhetischen Festspielerfahrung auslösen.

Im Sinn einer Politik der Schweizer ,Glückskultur' stellte das Festspiel eine schweizerische Lebensführung in der charakterologisch moralisierenden Ratgeberfigur des Schweizermannes dar. Dieser setzte sich, stellvertretend für den Freiheitskämpfer „Tell“ und den moralisch gefestigten Erziehungspädagogen „Pestalozzi“, für ein rechtschaffenes Schweizer Volk ein. Mit dieser „nationalen 
Sendung“ (Kindermann/Kolbenheyer) wurde ein utopischer Wegweiser in eine „glückliche“ Zukunft in Aussicht gestellt, die als eine arbeitspsychologische Glücksmoral im Kontext der LA durch Laienspieler^innen selbst dargestellt wurde. Das Festspiel entwarf in der dramaturgischen Handlung eines Wettspiels ein dichotomes Weltbild aus einem imaginierten Wir, den moralisch ,Guten', welche, in einem Abgrenzungs- und Distinktionsgestus zum Konstrukt der Anderen, den ,Bösen', als Gewinner der Wette hervorgingen. Diese emotionspolitische Dichotomie kann im transnationalen Vergleich als wesentliches Merkmal einer Politik der ,Glückskultur‘ bezeichnet werden.

\section{7 „An die Freude“: Musikästhetische Glückserfahrungen zu Hitlers 53. Geburtstag in der Berliner Philharmonie während des Zweiten Weltkriegs}

In der „Feierstunde“ der NSDAP am Spätnachmittag des 19. April 1942, dem Vorabend des 53. Geburtstags von Diktator Adolf Hitler, spielten die Berliner Philharmoniker die 9. Sinfonie in d-Moll op. 125 von Ludwig van Beethoven (1770 1827) in der Berliner Philharmonie. Im Konzertsaal saßen Vertreter*innen der Staats-, Partei- und „Wehrmacht“-Eliten sowie „Soldaten, Verwundete und Rüstungsarbeiter. Es herrscht eine sehr würdige und weihevolle Stimmung. “358 Unter dem Dirigat von Wilhelm Furtwängler (1886-1954) (559 $^{3}$ gelang eine „vollendete Wiedergabe“, wie Reichspropagandaminister Joseph Goebbels in sein Tagebuch notierte. ${ }^{360}$ Ein Rezensent des „Völkischen Beobachters“ schrieb:

„Das erhabenste Werk des größten Genius im Reiche der deutschen Musik brachte dem Führer symbolhaft zum Ausdruck, daß die Nation, seinem Beispiel folgend, sich über die Not

358 Goebbels, Josef, Tagebucheintrag vom 20. April 1942. (Vgl. Goebbels 1942). Rundfunkübertragung des Konzerts vom 19.04.1942: Beethoven, van Ludwig, Symphony, No. 9, D Minor, Op. 125, UA 1824, Wilhelm Furtwängler, Berlin 19.04.1942, Bruno-Kittel Chor, Berliner Philharmoniker, P/C Archipel Desert Island Collection, 2004, Youtube: https://www.youtube.com/watch?v=F54_ nb2dc6w, 12.03.2020. Bericht über die „Feierstunde“ in der Philharmonie, „Deutsche Wochenschau“, 22. April 1936, Nr. 306, https://www.dailymotion.com/video/x341vew, 12.03.2020

359 Furtwängler, der eine ,unpolitische‘ Kunstauffassung vertrat, gilt in der musikhistorischen Forschung angesichts der historischen Umstände im „Dritten Reich“, in welchem „die Kunst“ propagandistisch als emotionspolitische und moralische „Erzieherin“ der „Volksgemeinschaft“ instrumentalisiert wurde, bis heute als einer der prominentesten Vorzeigedirigenten im Dienst des NS-Regimes. Vgl. Gregor 2011, $860 \mathrm{f}$.

360 Vgl. Goebbels 1942. Zu den Berliner Philharmonikern im „Dritten Reich“ mit Fokus auf Krieg, Musik und Emotionen vgl. Müller 2012. Vgl. auch Aster 2007, Trümpi 2011. 
der Zeit über das Schicksal, so hart es auch treffen mag, erheben will. Beethovens hinreißendes, titanenhaftes Werk erhob in dieser Feierstunde die Herzen der Millionen, die sich an diesem Tage mit heißen Wünschen dem Führer nahten, sich ihm und seinem Werk von neuem [sic] weihten.“361

Die finale Sinfoniekantate nach Schillers Gedicht „An die Freude“ (1785), für welche neben dem „Bruno-Kittel Chor“ Erna Berger (Sopran), Gertrude Pitzinger (Alt), Helge Rosvaege (Tenor) und Rudolf Waatzke (Bass) engagiert worden waren ${ }^{362}$, entfaltete eine „hinreißende Wirkung“: „Niemals habe ich sie [die Philharmoniker] mit einer solchen Inbrunst zur Darstellung bringen hören wie hier. Das Publikum war auf das tiefste [sic] ergriffen“, so Goebbels. ${ }^{363}$ Die seit 1801 bekannte Volksweise „An die Freude“ schien einzelne Zuhörerinnen sehr bewegt zu haben: „Neben mir sitzen Soldaten und Arbeiter, denen die Tränen in den Augen stehen. Die Übertragung ging über alle europäischen Sender; sie wurde auch im Führerhauptquartier abgehört und hat dort einen tiefen Eindruck hinterlassen. “364 Wie können die von Goebbels beschrieben „Tränen in den Augen“ der Arbeiter*innen und verwundeten Kriegssoldaten emotionshistorisch quellenkritisch untersucht und kontextualisiert werden? ${ }^{365}$

Im vorliegenden letzten Kapitel wendet sich die Untersuchung unter der Perspektive einer Politik der ,Glückskulturen' einem Fallbeispiel aus der zweiten Hälfte des Zweiten Weltkriegs zu, der „Feierstunde der NSDAP am Vorabend von Hitlers 53. Geburtstag““. ${ }^{366}$ An diesem Beispiel werden Aspekte der musikästhetischen Wirkungsmacht der historischen Aufführungspraktik in der Berliner Philharmonie aufgezeigt und emotionshistorisch kontextualisiert. Sie sollen die Un-

361 Sch., „Die Feierstunde in der Berliner Philharmonie“. In: Völkischer Beobachter, 20.04.1942, 110. Ausgabe, 55. Jg., Berliner Ausgabe, 2, Zeitschriftenarchiv, Staatsbibliothek zu Berlin, PreuBischer Kulturbesitz, Berlin.

362 Vgl. Sch., „Die Feierstunde in der Berliner Philharmonie“. In: Völkischer Beobachter, 20.04. 1942, 110. Ausgabe, 55. Jg., Berliner Ausgabe, 2, Zeitschriftenarchiv, Staatsbibliothek zu Berlin, Preußischer Kulturbesitz, Berlin.

363 Vgl. Goebbels 1942. Zur Beethoven-Rezeption im NS-Regime und speziell der 9. Sinfonie DDur Op. 125, vgl. Eichhorn 1993, Budde und Witkowski 2007.

364 Goebbels 1942.

$365 \mathrm{Zu}$ Tränen in der Gefühlsgeschichte vgl. Frevert 2012, „Tränen lügen nicht“, 17 ff, 22f., Plamper 2013b, Dixon 2015.

366 Vgl. Joseph Goebbels, „In Dankbarkeit und Treue. Ansprache von Reichsminister Dr. Goebbels in der Feierstunde der NSDAP am Vorabend des Geburtstages Adolf Hitlers“. In: Völkischer Beobachter, 20.04.1942, 110. Ausgabe, 55. Jg., Berliner Ausgabe, 2, Zeitschriftenarchiv, Staatsbibliothek zu Berlin, Preußischer Kulturbesitz, Berlin. 
tersuchung über „Glück“ als ein zentrales Propagandamittel einer Gefühls- und Wissenspolitik des NS-Regimes abrunden. ${ }^{367}$

Die Untersuchung geht von der These aus, dass die „Feierstunde“ im wissenshistorischen Kontext der selbstdisziplinarischen Arbeitspsychologie und transnationalen Theaterwissenschaft (wie gesehen u.a. bei Kindermann, Kutscher, Perger, Niessen, Niedecken-Gebhard, Eberle)

1. emotionspolitisch eine ,kultische Feierstätte' symbolisierte, an der die Erneuerung des „rassenideologischen“ ,Bunds“ zwischen „Volk“ und NS-Regime als autosuggestives Treuegelöbnis auf den „Führer“ zelebriert wurde,

2. arbeitspsychologisch die „Feierstunde“ eine leistungsorientierte Selbstdarstellung in der Aufwartung der renommierten Berliner Philharmoniker zu ,Ehren' von Hitlers Geburtstag massenwirksam über Film-, Bild-, Ton- und Textmedien ${ }^{368}$ für das In- und Ausland demonstrierte und

3. massenpsychologisch mit der „Feierstunde“ als Teil einer Gefühlspolitik einer totalitären ,Glückskultur‘ eine selbstdisziplinarische Mobilisierung im Kontext der nahenden „totalen Mobilmachung“ in der zweiten Hälfte des Zweiten Weltkriegs bezweckt wurde.

Die musikästhetische Wirkungsmacht der Aufführung von Beethovens 9. Sinfonie sollte beim Publikum eine autosuggestive Emotionalisierung und Bejahung des Werte- und Machtsystems des NS-Regimes, dessen „rassenhygienischer“ Lebensführung und Arbeitsmoral „Kraft durch Freude“ auslösen und eine selbstdisziplinarische Mobilisierung im Hinblick auf die „totale Mobilmachung“ gegen Ende des Zweiten Weltkriegs erzeugen.

Schillers Ode „An die Freude“ wurde vom NS-Regime dahingehend instrumentalisiert, dass die lyrischen Verse in einem multimedialen Zusammenspiel zwischen Goebbels' Rhetorik und der musikalischen und gesanglichen Aufführungsästhetik im Konzertsaal der Philharmonie ein emotionspolitisches Glückserlebnis beim Publikum entfalten sollten. ${ }^{369}$ Der emotionspolitische Auslöser dürfte ein imaginiertes, „rassenideologisch“ und kulturnationalistisch konstru-

367 Zur Musikgeschichte und zu Emotionen vgl. Weber 2009c, 223, Budd 1985. Zu Musikgeschichte, Nationalismus und Emotionen vgl. Bohlman 2004.

368 Z.B. „Wochenschau“, illustrierte Zeitschriften, Rundfunk und Zeitungen.

369 In der Rezeptionsgeschichte besaß Schillers Gedicht, das 1785 kurz vor der Französischen Revolution entstanden war, mit seinem im 18. Jh. beliebten Motiv der Freundschaft einen hohen Stellenwert. Der Dichter selbst bewertete seine Ode jedoch als eher mittelmäßig. Früh gelangte der Text in Liedersammlungen volkstümlicher Gesänge und gilt mit 65 Kompositionen als das meistvertonte seiner Gedichte. Mehr zur Entstehungs- und Wirkungsgeschichte der Ode vgl. Meier, Göpfert und Alt 2004. 
iertes Gemeinschaftsgefühl zwischen Künstler`innen (Sänger^innen, Philharmonikern), Publikum (Arbeiter^innen und Kriegssoldaten) und den Repräsentant*innen des NS-Regimes gewesen sein. Diese scheinbare Einheit aus den Vertreter^innen des „Volks-“ und „Staatskörpers“ vermittelte den „deutschen“ Rundfunkhörer*innen und Zuschauer^innen der „Wochenschau“ eine „rassenideologische“ Inklusion und manifestierte, aus einer transnationalen Perspektive, eine emotionspolitische Außenwirkung der rassistischen Exklusivität. Um sich der intendierten emotionspolitischen Suggestionskraft der 9. Sinfonie gegenüber den „Volksgenossen“ sicher zu sein, sprach Goebbels zur emotionspolitischen Einstimmung in die kultische Feierstunde ein explizites Konglomerat affirmativer Nationalgefühle („Glück“, Freude, ferner Gefühle der Liebe, Einheit, Verbundenheit, Geborgenheit, Gemeinschaft, Treue und des Schutzes) an, wie die Analyse zeigen wird. In den vertrauten Klängen Beethovens 9. Sinfonie und dem allerseits bekannten Volkslied „An die Freude“ sollten die Zuhörer*innen eine emotionspolitische Wiedererkennung erfahren. Die „Feierstunde“ als Teil einer affirmativen Gefühlspolitik der NS-Arbeitsmoral „Kraft durch Freude“ dokumentiert im Kriegsjahr 1942 deren janusköpfige Ambivalenz und tragische Kontinuität im Kontext des verheerenden Kriegstreibens, dem sich die „deutsche“ Bevölkerung zusehends ausgesetzt sah und der katastrophalen Folgen des Holocausts, bei welchem rund 6 Millionen europäische Jüdinnen ums Leben kamen.

War es allein die Musik, die das Publikum zu „Tränen“ rührte oder war es die musikästhetische Wirkungsmacht aus Wort, Klang, Gesang und Orchestrierung? Goebbels betont in seiner Eröffnungsrede der „Feierstunde“ einmal mehr die emotionspolitische Bedeutung der Künste, am Beispiel von Schillers vertontem Gedicht in Beethovens 9. Sinfonie, als ein affirmatives Propagandainstrument einer Politik der nationalsozialistischen ,Glückskultur‘:

\footnotetext{
„Wenn am Ende unserer Feierstunde die Stimmen der Menschen und Instrumente zum großen Schlussakkord der Neunten Symphonie ansetzen, wenn der rauschende Choral der Freude ertönt und ein Gefühl für die Größe und Weite dieser Zeit bis in die letzte deutsche Hütte hineinträgt, wenn seine Hymnen über alle Weiten und Länder erklingen, auf denen deutsche Regimenter auf Wache stehen, dann wollen wir uns alle - ob Mann, ob Frau, ob Kind, ob Soldat, ob Bauer, ob Arbeiter, ob Beamter - zugleich des Ernstes der Stunde bewußt werden und in ihm auch das Glück empfinden, Zeuge und Mitgestalter dieser größten geschichtlichen Epoche unseres Volkes sein zu dürfen!“370
}

Goebbels beschreibt im Verlauf seiner Rede die musikästhetische Dramaturgie von Beethovens 9. Sinfonie im Aufführungskontext der „Feierstunde“ während

370 Goebbels 1991b, 118. 
des Zweiten Weltkriegs. Nach der Überwindung musikästhetisch erwirkter Gefühle von Schmerz, Entzweiung und Chaos in den ersten Sätzen der Sinfonie, werde das Orchester vom Dirigenten in einer kontinuierlichen Steigerung „zum großen Schlussakkord“ hingeführt. Im „rauschenden Choral der Freude“, in welchem alle negativen Gefühle überwunden scheinen, würden die Zuhörerinnen „Glück [darüber] empfinden, Zeuge und Mitgestalter dieser größten geschichtlichen Epoche unseres Volkes sein zu dürfen!“. Goebbels interpretiert Beethovens 9. Sinfonie als ein musikästhetisches Erlebnis im Kontext einer emotionspolitischen Kriegsmetaphorik. In musikästhetischer Analogie zum finalen Glücksgefühl impliziert der Reichspropagandaminister einen Vergleich zum siegreichen Glücksgefühl am Ende eines Krieges. Das musikästhetische Erlebnis der Aufführung Beethovens 9. Sinfonie wird durch Goebbels zum Propagandainstrument einer nationalsozialistischen Glückskultur. Dabei knüpft Goebbels mit seiner Interpretation an eine historische Deutungstradition an, die auf Richard Wagner (1813-1883) zurückgeht, wie Neil Gregor in seiner Untersuchung über die Aufführungskontinuität von Beethovens Werk zeigt. ${ }^{371}$

Goebbels Rede lässt keinen Zweifel daran, dass er das in der Sinfoniekantate besungene „Elysium“372, in welches ausschließlich die von den griechischen Göttern geliebten Helden (wie der Krieger Achill) eintreten durften, für seine Kriegspropaganda instrumentalisierte. Wie schon bei Niedecken-Gebhard (Kap. 16.5) gesehen, vollzog Goebbels in seiner Feierrede einen historischen Brückenschlag von der Gegenwart des „Dritten Reichs“ zur siegreichen Wehrhaftigkeit der Preußischen Armee unter Friedrich II. (1712-1786) in der „kritischen Phase des Siebenjährigen Krieges“. ${ }^{373}$ Anhand des 4,8 Millionen teuren Historienfilms „Der große König“ von Veit Harlan, der am 3. März 1942 uraufgeführt wurde, verglich Goebbels die „harten Proben und geschichtlichen Prüfungen“, mit denen sich der „große Preußenkönig“ mit „mitfühlendem Herzen als ein ringender Titan“ auseinandersetzen musste, mit Hitlers derzeitiger Lage. Wie schon Friedrich II. werde auch Hitler von seinem „Volk“ für sein angeblich vergleichbares „staatsmännische[s] und militärische[s] Genie[...]“ und seine Warmherzigkeit als „Führer“ geliebt und bewundert. ${ }^{374}$ Goebbels’ Lobpreisung von

371 Vgl. Gregor 2011, $861 \mathrm{f}$.

372 „Freude schöner Götterfunken, Tochter aus Elysium, wir betreten feuertrunken, Himmlische,

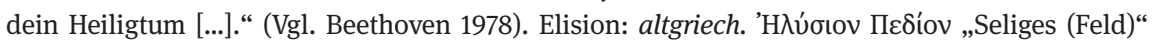
oder „Insel der Seligen“, lat. Elysium. Dichterische Bedeutung für „Zustand des vollkommenen Glücks“, vgl. Duden, http://www.duden.de/rechtschreibung/Elysium, 10.02.2020.

373 Vgl. Goebbels 1991b, 112.

374 Vgl. Goebbels 1991b, 112 ff. Hinweis zum Historienfilm „Der König“ vgl. Goebbels 1991b, 112, Fußnote 1. Zur historischen Gefühlspolitik Friedrichs II. vgl. Frevert 2012. 
Hitlers affirmativer Gefühlspolitik wirkt aus heutiger Sicht zynisch. Dabei war Goebbels nicht der einzige emotionspolitische Propagandist einer affirmativen Gefühlskultur während der Kriegszeit. Auch Göring nahm Hitlers Geburtstag zum Anlass, „das deutsche Volk“ zur Erneuerung ihres Treueschwurs zum „Führer“ aufzurufen und ihm angesichts des Krieges bedingungslose Opferbereitschaft zuzusichern:

„Männer und Frauen des deutschen Volkes! Vereint mit den Soldaten der Front, die
Deutschlands Ehre und Freiheit weit über die Grenzen Europas hinaus tapfer und siegge-
wohnt verteidigen, bringen die Schaffenden der Heimat, die in hartem Tagewerk in Stadt und
Land dem kämpfenden deutschen Millionenheer treu und helfend zur Seite stehen, dem
Führer zu seinem heutigen Geburtstag in heißer Liebe ihre aus dankerfüllten Herzen kom-
menden Glück- und Segenswünsche entgegen. [...]
Wir erneuern am heutige Tage aus dankbarem Herzen unseren Schwur: Tapfer zu sein,
kein Opfer und keine Gefahr zu scheuen, in der Anspannung aller Kräfte nicht müde zu
werden, bis der Endsieg errungen und des Großdeutschen Reiches Macht und Herrlichkeit
für alle Zukunft gewährleistet ist! Den Allmächtigen flehen wir an: Schütze unseren geliebten
Führer und segne weiterhin sein Werk!“375

Auch Goebbels sprach in der Feierrede seine Zuhörerinnen direkt gesellschafts-, geschlechter-, generationen- und berufsübergreifend an („ob Mann, ob Frau, ob Kind, ob Soldat, ob Bauer, ob Arbeiter, ob Beamter“ “) ${ }^{376}$ und beschwor sie auf ihre Funktion als „Zeugen“ und auf ihre Aufgabe als „Mitgestalter“ einer als herausragend gedeuteten Zeitepoche: $:^{377}$

„Ob wir das größere Glück genießen, in seiner [Hitlers] unmittelbaren Umgebung zu wirken
oder direkt unter seinen Augen arbeiten zu dürfen, ob wir nur dazu berufen sind, als un-
bekannte Soldaten, Arbeiter oder Bauern an seinem Werke kämpfend oder schaffend teil-
zunehmen [...] - gleichgültig: Wir sehen immer noch über uns eine Kraft, die uns stützt und
hält, fühlen uns geborgen in der schützenden Hut eines Mannes, der unserem Jahrhundert
wegweisend voranschreitet. Wir brauchen nur zu folgen, er aber muß die Bahn brechen. Er
steht allein seinem und unserem Schicksal gegenüber, um den Titanenkampf, der uns um
das Leben unseres Volkes aufgezwungen wurde, siegreich auszufechten. Wenn wir also
heute, am Vorabend seines 53. Geburtstags, die ganze Nation um die Lautsprecher ver-
sammeln, dann ist das etwas anderes und viel mehr als eine feierliche Zeremonie. Hier soll
nur bestätigt werden, was alle Deutschen fühlen und empfinden, und zwar heute viel tiefer
und verpflichtender als je zuvor. Es ist gewissermaßen die Erneuerung der Treue und des

375 Hermann Göring, „Aufruf Görings an das deutsche Volk“. In: Völkischer Beobachter, 20.04. 1942, 110. Ausgabe, 55. Jg., 1, Berliner Ausgabe, 1, Zeitschriftenarchiv, Staatsbibliothek zu Berlin, Preußischer Kulturbesitz, Berlin.

376 Zur Geschlechter- und Körpergeschichte im Nationalsozialismus vgl. Frietsch und Herkommer 2009.

377 Vgl. Goebbels 1991b, 118. 


\begin{abstract}
Glaubens, die so millionenfach durch Taten und Leistungen, durch Opfer ohne Zahl, durch Einsatz von Blut und Leben und tausendenfältigen bitteren Tod ihre Bewährung gefunden haben, daß sie der Worte nicht mehr bedürften. Wenn jemals die deutsche Nation sich vereint gefühlt hat in einem Gedanken und in einem Willen, dann in dem, ihm zu dienen und seinem Gebote zu folgen. Diesmal sollen die Klänge der heroischsten [...] Titanenmusik, die je einem [...] deutschen Herzen entströmten, dieses Bekenntnis in eine ernste und weihevolle Höhe erheben [...].““378
\end{abstract}

In der Bewusstwerdung dieser ideologischen Deutung der „NS-Volksgemeinschaft“"379 im „Dritten Reich“ mit Hitler als „liebe[m] Vater“ an der hierarchischen Spitze (worauf die Parallele vom „Dritten Reich“ zum „Elysium“, dem Ort vollkommener Glückseligkeit, vermutlich abzielte), sollten die Zuschauer „Glück empfinden“"380.

Der Propagandaminister instrumentalisierte Beethovens Sinfonie und Schillers Verse, um unter den Zuhörerinnen ein überzeitliches, kulturnationalistisches Gefühl kollektivistischer Verbundenheit im pseudoreligiösen Bekenntnis der „rassenhygienischen“ Glaubensgemeinschaft gegenüber Hitlers NS-Staatsideologie erneut zu bekräftigen. Dabei wurde Hitler von Goebbels zum einsamen Helden stilisiert, der jederzeit bereit sei, für sein „Volk“ übermenschliche „Titanenkämpfe“ auszutragen, wie es die „deutsche“ Nationalgeschichte von ihm verlange. Wie schon Etter in seiner Rede beim Ausbruch des Zweiten Weltkriegs betont auch Goebbels am Ende seiner Feierrede die Ambivalenz des „Glücks“ angesichts der schweren Kriegszeit, in der sich das „Volk“ befände:

„Es gibt kein größeres Glück auf Erden, als dem Genius seines Volkes und seinem Werke zu dienen. Machen wir uns dieses Glück täglich teilhaftig. Die Schwere unserer Zeit ist auch Ihre Größe, wir möchten sie mit keiner anderen tauschen.

In Dankbarkeit und Treue senden wir dem Führer unsere Grüße. Wie von einem unzerreißbaren Band fühlen sich Front und Heimat in dieser Stunde umschlungen. Das Deutschtum in aller Welt ist vereint in dem heißen Wunsche, den wir noch jedesmal am Vorabend seines Geburtstages in die Worte zusammenfaßten: Er soll uns bleiben, was er uns war und ist - unser Hitler! [starker Beifall].“381

Es stellt sich die Frage, ob die weihevolle „Feierstunde“ wirklich die von Goebbels beschworenen, emotionspolitischen Nationalgefühle von „Glück“ und Freude, von Liebe, Einheit, Verbundenheit, Geborgenheit, Gemeinschaft, Treue und Schutz hervorrufen konnte und die Menschen deshalb zu Tränen gerührt waren.

378 Goebbels 1991b, 118.

379 Zur „Volksgemeinschaft“ vgl. Wildt 2007a, Reinicke u. a. 2014, Steber und Gotto 2014.

380 Vgl. Goebbels 1991b, 118.

381 Ebd., 119. 
Eine Antwort auf die emotionspolitische Rezeption der „Feierstunde“ mag im über Jahrzehnte eingeübten bürgerlichen Habitus von Wahrnehmungs- und Handlungsmustern der Konzertgänger*innen gelegen haben, in welchem sich die musikästhetische Wirkungsmacht Beethovens 9. Sinfonie, unabhängig von politischen Machtwechseln, bei den Zuhörer*innen entfalten konnte. ${ }^{382}$ Jene Soldaten und Arbeiter*innen, welche mit diesem bürgerlichen Konzerthabitus nicht vertraut waren, empfanden womöglich im Kriegsjahr 1942 Gefühle der Ehre und des Stolzes, zu den Auserwählten zu gehören, die an dieser staatlichen Feierlichkeit teilnehmen durften. Vielleicht war es tatsächlich ihre Liebe zum Vaterland oder zum „Führer“, welche die überwältigende, emotionale Ergriffenheit vieler Zuhörer^innen in der Philharmonie als kultischer Feierstätte angesichts der musikästhetischen Selbstdarstellung der NS-„Feierstunde“ auslösen konnte. Womöglich war es ein Konglomerat affirmativer Nationalgefühle im Spannungsfeld einer ideologischen Zustimmung zum opferbereiten Treuegelöbnis an den „Führer“ und das in ihm verkörpert geglaubte „Glück“ und einer ernüchternden Erkenntnis über das sich als utopisch herausstellende Glücksversprechen angesichts der Kriegsverbrechen und Bombardements, welche sich in den ambivalent zu deutenden Tränen der Zuschauer*innen widerspiegelte.

Abschließende Antworten werden auf diese Fragen keine gegeben werden können. Eine emotionshistorische Kontextualisierung der Konzertaufführung in der Berliner Philharmonie kann aus der Perspektive einer Politik der ,Glückskultur` jedoch Hinweise liefern. Emotionspolitisch war das Publikum bereits im Vorfeld der Aufführung durch die von Goebbels als Geburtstagsgruß getarnte

382 Der Musikhistoriker Sven Oliver Müller sieht einen Grund für den ungebrochenen Erfolg der Berliner Philharmoniker nach 1933 im bürgerlichen Habitus der Konzertgänger, vgl. Müller 2012, 122. Müller kommt in seinem Vergleich zwischen der Weimarer Republik und dem „Dritten Reich“ sowie dem besetzten Frankreich zum „ernüchternden“ Schluss: „Die politische Situation änderte sich, aber der musikalische Kanon nicht. [...] Die Eliten, Künstler, Journalisten und Hörerschaften beider Länder strebten musikalische Ähnlichkeiten an." Musikalische Experimente und emotionaler Widerstand wurden laut Müller nur selten geäußert, vgl. Müller 2012, 117, $127 \mathrm{f}$. Auf die Zuhörer^innen im NS-Regime bezogen, resümiert Müller: „Letztlich scheinen die meisten Hörer, die emotional im Musikleben beteiligt sind, wünschenswerte und fröhliche Emotionen zu erwarten.“ Müller 2012, 124. Ausgehend von diesem Forschungsstand hat die vorliegende Untersuchung mit Fokus auf Theaterpolitik, Theaterwissenschaft und Theatertätigkeit neben Kontinuitäten und Ambivalenzen auch eindeutige Differenzen im transnationalen Vergleich von der Weimarer Republik zum NS-Regime bzw. dem NS-Regime und der Schweiz (1933-1945) aufzeigen können (Kap. 15 u. 16). 
Propaganda-Rede auf die umgedeutete Ode an den „Führer“383 eingestimmt worden.

Ian Kershaw zeigt in seiner einflussreichen Untersuchung zum „Hitler-Mythos“, dem Personenkult um Hitler, wie der Diktator seine Popularität im Laufe der NS-Herrschaft auf Kosten seiner Partei ausbauen konnte und welch wichtige „kompensatorische Funktion“ sein Personenkult dabei erfüllte. ${ }^{384}$ Ergänzend zu Kershaws Forschung soll im Folgenden aufgezeigt werden, welche unterschiedlichen Funktionen Glücksvorstellungen bei der Konstruktion des „Hitler-Mythos“ einnahmen. Grundvoraussetzung für den „Führer“-Kult sei der Umstand, dass Hitler als „nationaler Führer“ im psychologischen Bewusstsein der Bevölkerung „oberhalb und außerhalb der Sorgen des Alltagslebens“ stand und laut Kershaw daher nicht unmittelbar in Beziehung zu den ökonomischen Alltagssorgen der Menschen, den Terror- und Unterdrückungsmechanismen der Partei sowie dem Fehlverhalten der einzelnen in Verbindung gebracht wurde. ${ }^{385}$ Die Kurzformel dafür lautete noch bis zum Kriegsantritt gegen die UdSSR am 22. Juni 1941: „Der Führer, ja! Die Partei, nein!“386 Kershaw erklärt dieses grenzenlose und naive Vertrauen in den „Führer“ während der Friedensjahre 1933-1939 und der ersten Kriegsphase folgendermaßen:

„Die emotionale Zuneigung zu Hitler wurzelte in der Auffassung, er repräsentiere das Ideal der nationalen Gemeinschaft und der nationalen Größe, er führe Deutschland zu größerem Wohlstand, und was auch immer unmittelbar an Opfern verlangt werden möchte, so sei doch knapp jenseits des Horizonts für alle eine Glückssträhne zu erwarten.“387

Welcher Pfad ins Land des kollektiven „Glücks“ führen sollte, darüber wurde seitens der Zivilbevölkerung anscheinend zu wenig reflektiert, so Kershaw. ${ }^{388}$

Neben Goebbels bekräftigte Hitler selber seine mystisch-überhöhte Unfehlbarkeit und seine Funktion als Glücksbringer. In seiner Rede vom 13. September 1936, während des „Parteitag[s] der Ehre“ in Nürnberg, sprach er vor „den Kampforganisationen der Partei“ mit einer Mischung aus semantischer und me-

383 Zur Entstehungs- und Wirkungsgeschichte der Ode vgl. Meier, Göpfert und Alt 2004, LinderBeroud 2009, Escher 2017.

384 Vgl. Kershaw 1999, 108.

385 Kershaw nennt als Gründe für die ablehnende und misstrauische Haltung der Bevölkerung gegenüber der Partei Angriffe auf christliche Kirchen, Arroganz, Rabaukentum, Vulgarität von organisierten Mobs, Korruption und Bestechlichkeit, vgl. Kershaw 1999, 198.

386 Vgl. Picker 1963, 132.

387 Kershaw 1999, 186.

388 Vgl. ebd., 186. 
taphorischer Pseudoreligiosität von sich und seiner Einheit mit dem „deutschen Volk“:

„Das ist das Wunder unserer Zeit, daß ihr mich gefunden habt [hier unterbrach ihn langer Beifall] daß ihr mich gefunden habt unter so vielen Millionen! Und daß ich euch gefunden habe, das ist Deutschlands Glück.“389

In diesem spezifischen emotionshistorischen Kontext ist dann auch Goebbels pathetische Rede vom empfundenen „Glück“ zu verstehen, welches im Anschluss an seine Rede musikalisch und gesanglich in der orchestrierten Volksweise „An die Freude“ gesteigert werden konnte. So heißt es in den Strophen:

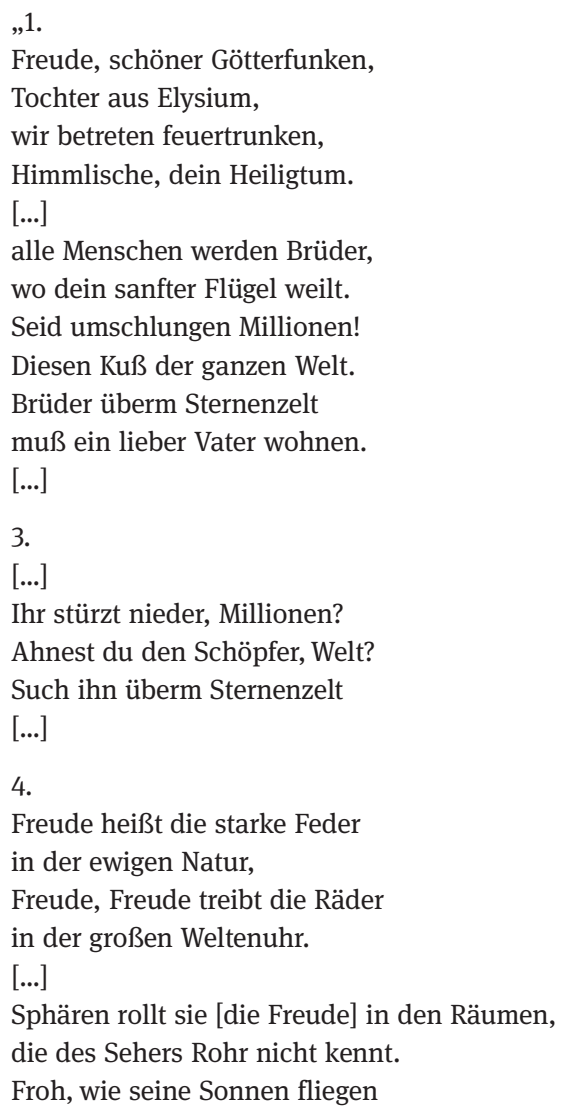

389 Hitler, Adolf, Rede vom 13.09.1936 vor den „Kampfformationen der Partei“ am „Der Parteitag der Ehre“, 08.-14.09.1936, in Nürnberg. In: Domarus 1965, 643. 
durch des Himmels prächt'gen Plan, laufet, Brüder, eure Bahn,

freudig wie ein Held zum Siegen.“390

Die hier besungene ekstatische „Freude“ beim Betreten des „Elysiums“ und beim Lauf der „Brüder [...] freudig wie ein Held zum Siegen“ erinnern an die emotionspolitische Wirkungsintention der arbeitspsychologischen und während des Kriegs militärstrategisch umgedeuteten NS-Parole „Kraft durch Freude“, welche die Freizeitaktivitäten der gleichnamigen Organisation versprachen. Robert Ley pries 1936 „Kraft durch Freude“ in seiner Rede vor versammelten DAF-Funktionären als ein beispielhaftes Werk der neuen Sozialpolitik im NS-Regime: „Es heißt Mobilisation der Energien in einem Volke, heißt den Gemeinschaftsgedanken pflegen und heißt alles untermauern durch Freude [...] ${ }^{\text {‘391 }}$ Diese historischen Glücksvorstellungen sind abschließende Beispiele für eine Gefühlspolitik eines spezifischen „Glücks“, nämlich eines eng mit dem „Führer“-Kult verknüpften, totalitär gedeuteten Kollektivglücks, welches im Zweiten Weltkrieg beharrlich über den „schönen Schein des Dritten Reiches“392 hinwegzutäuschen versuchte. Diese These konnte mit Blick auf Schriften zur NS-Ideologie und die darin enthaltenen Moralvorstellungen bereits in den Kap. 7.3 und 7.4 aufgezeigt werden. ${ }^{393}$

$\mathrm{Zu}$ Beginn des vierten Kriegsjahrs erhielten diese propagandistischen Täuschungs- und Verschleierungsversuche der Partei angesichts der intensivierten Fliegerbombardements der Alliierten auf deutsche Städte ${ }^{394}$ deutliche Risse. Rhetorisch versiert, deutete Goebbels mit dem „Ernst der Stunde“ in seiner Feierrede nur vage die verheerenden Folgen militärischer Fehleinschätzungen der „Blitzkriegstrategie“ für die 6. Armee vor „Stalingrad“ (Wolograd) an, welche im Winter 1941/42 im angestrebten Vernichtungskrieg gegen die UdSSR unter der Parole des „Endsiegs“ begangen wurden und Ende Januar 1943 in einer Kapitulation enden sollten. Diese Niederlage, welche sich bereits im Dezember 1941 abzeichnete, kennzeichnete eine Zäsur für die bisher als unbezwingbar geltende „Wehrmacht“. .395

390 Beethoven 1978.

391 Wortprotokoll der 5. Tagung der Reicharbeiterkammer am 24. November 1936 in Berlin (Auszüge), vgl. Mason 1975, 191.

392 Reichel 2006.

393 Zur NS-Moral vgl. Bialas 2014, Konitzer und Fritz-Bauer-Institut 2014, Gross 2010, Konitzer, Gross und Fritz-Bauer-Institut 2009, Roth 2005, Haas 1992.

394 Seit dem Kommandowechsel an den britischen Luftmarschall Arthur Harris, vgl. Wildt 2008, $187 \mathrm{f}$.

395 Am 11. Dezember 1941 erklärte NS-Deutschland den USA den Krieg. 
Ein weiteres düsteres Kapitel des Frühjahrs 1942, welches Goebbels in seiner

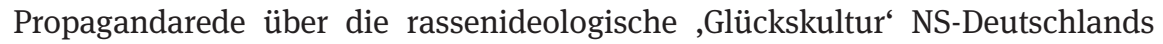
verschweigt, sind die katastrophalen Auswirkungen der Beschlüsse zur „Endlösung der Judenfrage“, zu deren Entwurf Reinhard Heydrich bereits im Januar 1941, in Absprache mit Hermann Göring, aufgefordert und am 31. Juli 1941 ermächtigt worden war. Auf der geheimen „Wannsee-Konferenz“ vom 20. Januar 1942, drei Monate vor Hitlers Geburtstag, wurden nicht - wie in früherer Forschung behauptet - die Deportationen der deutschen und westeuropäischen Jüd^innen in die besetzten Ostgebiete beschlossen. Diese hatten, wie die Beispiele der systematischen Deportationszüge von Wien, Prag und Berlin nach Łódź zeigen, bereits im Oktober 1941 im Zuge politischer und bürokratischer Radikalisierungsprozesse und Einzelaktionen zeitgleich mit dem Angriff auf die Sowjetunion begonnen. ${ }^{396}$ Auf der „Wannsee-Konferenz“, an welcher entscheidungsmächtige SA- und SSFunktionäre aus unterschiedlichen Ministerien und SS-Institutionen teilnahmen, verständigte man sich über die systematische Massenermordung von über 11 Millionen Jüd^innen, aufgrund einer Liste von zum Teil noch nicht zum „Dritten Reich“ zählenden Ländern, u.a. der Schweiz. ${ }^{397}$

Vor dem Hintergrund dieser beispiellosen Verbrechen während des Holocausts, bei denen rund 6 Millionen Jüd^innen, Hunderttausende von Kriegsgefangenen und Zwangsarbeiter*innen in Konzentrationslagern, zivile Kriegsopfer und Hungernde als Folge des Zweiten Weltkriegs ihr Leben verloren, wirken die Gesänge „Seid umschlungen Millionen! Diesen Kuß der ganzen Welt. Brüder überm Sternezelt. Muß ein lieber Vater wohnen“ sowie „Ihr stürzt nieder, Millionen? Ahnest du den Schöpfer, Welt? Such ihn überm Sternenzelt“ wie blanker Hohn. Vielleicht waren es denn auch nicht Freudentränen, die Goebbels in den Augen der Soldaten und Arbeiter`innen sah. Vielleicht waren die Tränen Ausdruck einer schieren Beklommenheit angesichts einer solch dreisten Instrumentalisierung der Künste im Dienst der propagierten Gefühlspolitik eines totalitären „Glücks“.

Abschließend mag man sich fragen, wie Beethovens 9. Sinfonie nach dem Zweiten Weltkrieg rezipiert wurde. Die Rezeptionsgeschichte Beethovens 9. Sinfonie ist so ambivalent wie das ihr inhärente Glückswissen. Einerseits wurde die 9. Sinfonie kontinuierlich mit dem Nationalsozialismus und einer autoritären Gefühlsregung in Verbindung gebracht. Ein Beispiel wäre die musikalische Unter-

396 Vgl. Wildt 2008, 168f. Erste Deportationen polnischer, tschechischer und österreichischer Jüd*innen fanden bereits im Oktober 1939 im Rahmen der „Gestaltung neuer deutscher Siedlungsgebiete“ statt, vgl. Wildt 2008, 149f. Vgl. u.a. Broszat 1977, 739-775. Forschung zu den Deportationen nach Łódź und dem Vernichtungslager in Chelmno, vgl. Kárný, et al. 1995, 38-68. 397 Vgl. Wildt 2008, 174. Zur „Wannsee-Konferenz“ vgl. Pätzold und Schwarz 1992. 
malung der Gewaltexzesse in Stanley Kubricks Verfilmung von „Clockwork Orange“ (1979). ${ }^{398}$ Andererseits erfuhr Beethovens 9. Sinfonie als „Europa-Hymne“, unter Verzicht auf Schillers deutsche Strophen, weltweite Bekanntheit. Die Hymne der Europäischen Union und des Europarats setzt sich seit 1972 aus dem letzten Satz der 9. Sinfonie zusammen und symbolisiert bis heute als „Song of Joy“ oder „Hymne à la joie“ das „Glück“ der seit dem Zweiten Weltkrieg in Frieden wiedervereinten Länder Europas. ${ }^{399}$ Die Europa-Hymne kann als Teil einer transnationalen Politik der europäischen ,Glückskulturen' begriffen werden, welcher ein ambivalentes historisches Glückswissen zugrunde liegt.

\subsection{Fazit}

Die transnationalen Analysebeispiele aus Zürich und Berlin zwischen 1933 und 1945 zeigen, wie Schauplätze eines propagierten „Glücks“ in wissenshistorischer Kontinuität $\mathrm{zu}$ avantgardistischen und sozialistischen Massenspielen, Laienspielen, kultischen Feiern und der vielseitigen Konzert- und Festspieltradition der kulturnationalistischen Emotionalisierung und politischen Mobilisierung dienten. Ein zentrales Merkmal der affirmativen Gefühlspolitik an solchen Schauplätzen war die Dichotomie zwischen einem konstruierten Wir und den Anderen. Gemeinsamkeiten und länderspezifische Unterschiede dieser emotionspolitischen Beschwörung einer massenpsychologischen Exklusivität einer imaginierten Gemeinschaft der Nation konnte der transnationale Vergleich anhand verschiedener Fallbeispielanalyse darlegen.

398 Vgl. Kutschke 2010, 580.

399 Vgl. Linder-Beroud 2009. Mehr zur Entstehungs- und Wirkungsgeschichte der Ode vgl. Meier, Göpfert und Alt 2004. 
